\title{
Developing Spent Fuel Assembly Standards for Advanced NDA Instrument Calibration - NGSI Spent Fuel Project
}

\section{February 2014}

Prepared by:

Jianwei Hu Ian C. Gauld

Oak Ridge National Laboratory

James E. Banfield

GE Hitachi Nuclear Energy

Steven E. Skutnik

University of Tennessee

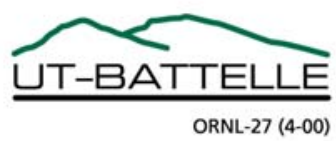




\title{
DOCUMENT AVAILABILITY
}

Reports produced after January 1, 1996, are generally available free via US Department of Energy (DOE) SciTech Connect.

Website http://www.osti.gov/scitech/

Reports produced before January 1, 1996, may be purchased by members of the public from the following source:

\author{
National Technical Information Service \\ 5285 Port Royal Road \\ Springfield, VA 22161 \\ Telephone 703-605-6000 (1-800-553-6847) \\ TDD 703-487-4639 \\ Fax 703-605-6900 \\ E-mail info@ntis.gov \\ Website http://www.ntis.gov/support/ordernowabout.htm
}

Reports are available to DOE employees, DOE contractors, Energy Technology Data Exchange representatives, and International Nuclear Information System representatives from the following source:

Office of Scientific and Technical Information

PO Box 62

Oak Ridge, TN 37831

Telephone 865-576-8401

Fax 865-576-5728

E-mail reports@osti.gov

Website http://www.osti.gov/contact.html

This report was prepared as an account of work sponsored by an agency of the United States Government. Neither the United States Government nor any agency thereof, nor any of their employees, makes any warranty, express or implied, or assumes any legal liability or responsibility for the accuracy, completeness, or usefulness of any information, apparatus, product, or process disclosed, or represents that its use would not infringe privately owned rights. Reference herein to any specific commercial product, process, or service by trade name, trademark, manufacturer, or otherwise, does not necessarily constitute or imply its endorsement, recommendation, or favoring by the United States Government or any agency thereof. The views and opinions of authors expressed herein do not necessarily state or reflect those of the United States Government or any agency thereof. 
Reactor and Nuclear Systems Division

\title{
DEVELOPING SPENT FUEL ASSEMBLY STANDARDS FOR ADVANCED NDA INSTRUMENT CALIBRATION - NGSI SPENT FUEL PROJECT
}

\author{
Jianwei $\mathrm{Hu}$ \\ Ian C. Gauld \\ James E. Banfield* \\ Steven E. Skutnik ${ }^{* *}$
}

*GE Hitachi Nuclear Energy

${ }^{* *}$ University of Tennessee

Date published: February 2014

Prepared by

OAK RIDGE NATIONAL LABORATORY

Oak Ridge, Tennessee 37831-6285

managed by

UT-BATTELLE, LLC

for the

U.S. DEPARTMENT OF ENERGY

under contract DE-AC05-00OR22725 



\section{CONTENTS}

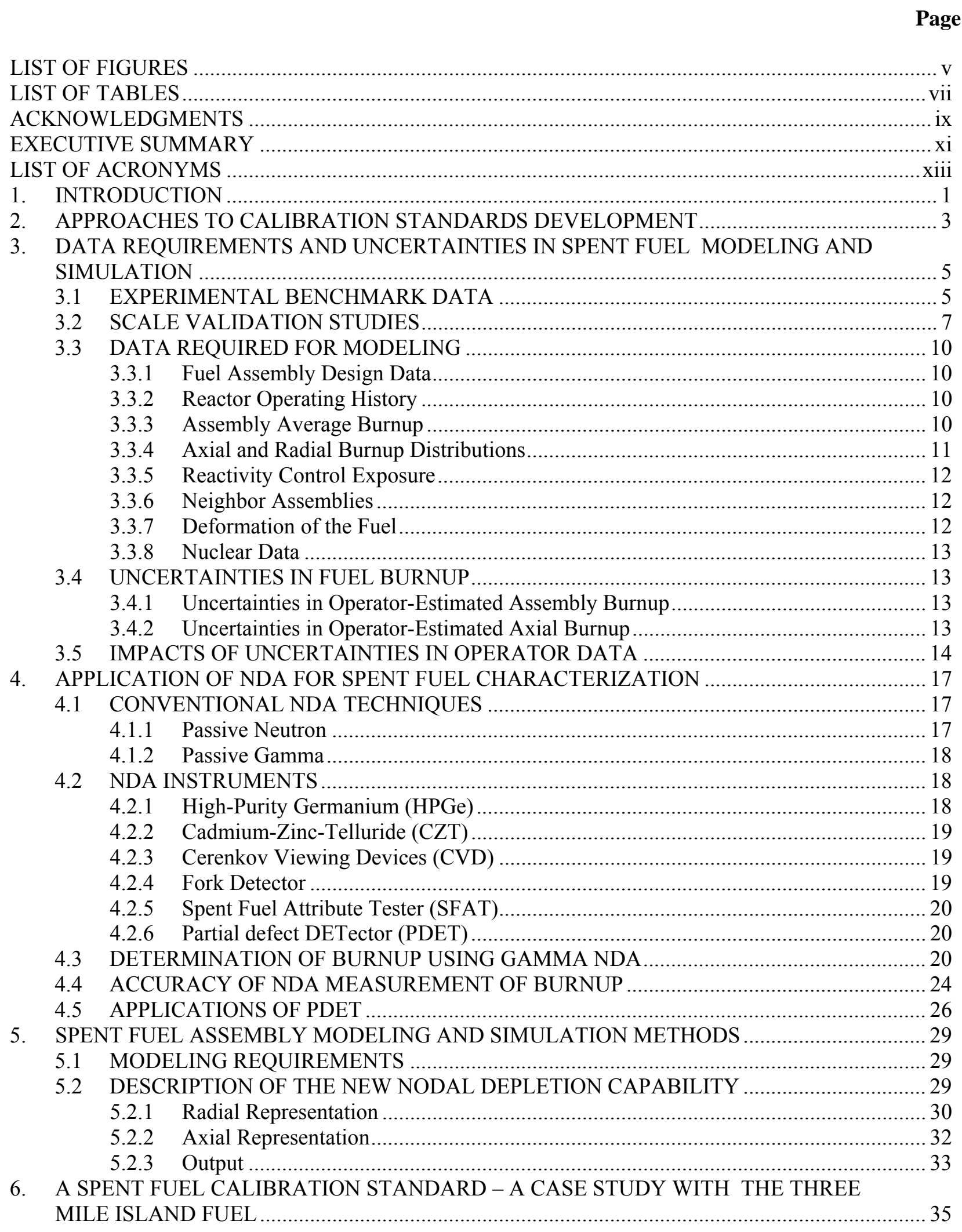




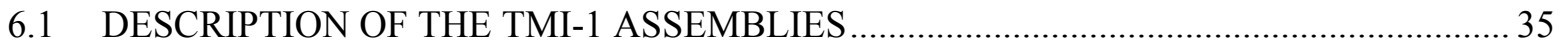

6.2 EVALUATION OF OPERATOR AND NDA DATA FOR TMI-1 FUEL ........................... 38

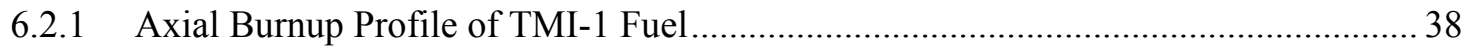

6.2.2 Local Burnups Estimated by Operator, DA, and NDA Data …................................. 40

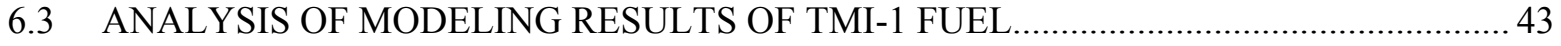

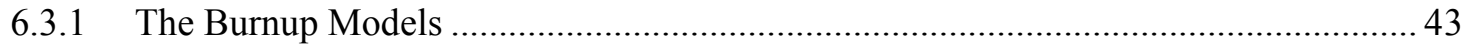

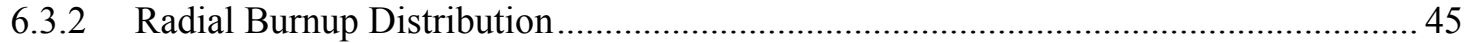

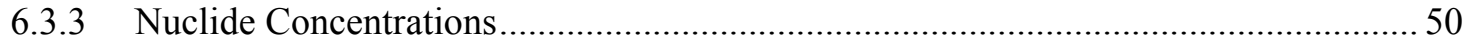

7. IMPACTS OF NUCLEAR DATA UNCERTAINTIES ON CALCULATED NUCLIDE

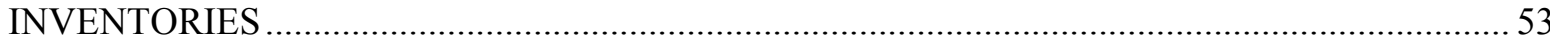

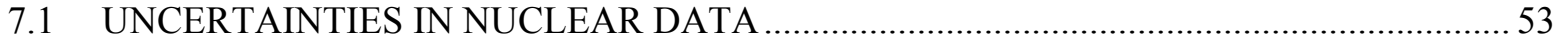

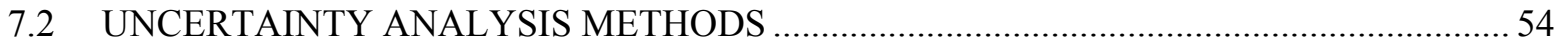

7.3 IMPACT OF NUCLEAR DATA UNCERTAINTIES ON NUCLIDE CONCENTRATIONS

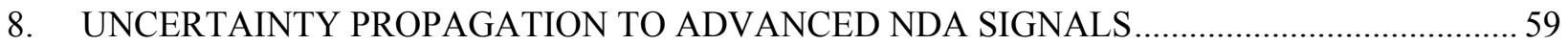

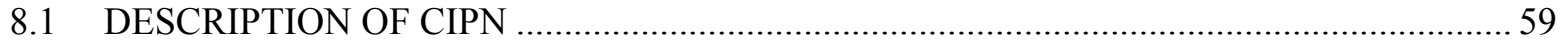

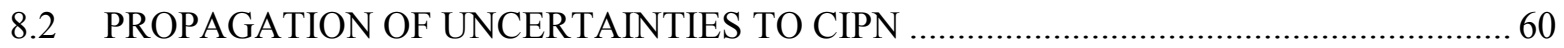

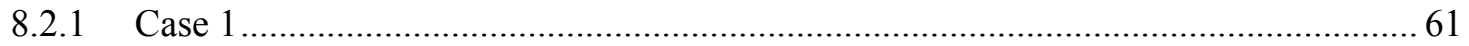

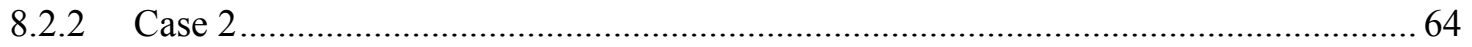

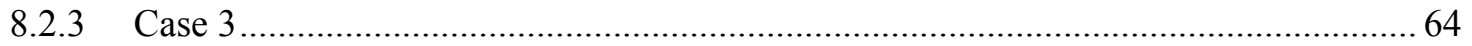

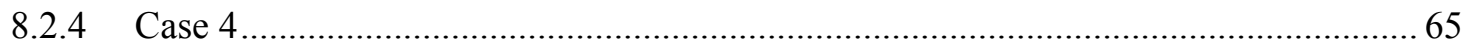

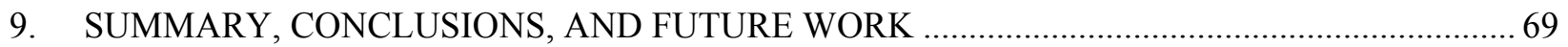

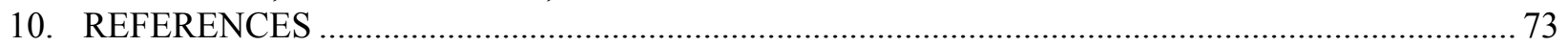




\section{LIST OF FIGURES}

Page

Fig. 1. Comparison of calculated (C) and experimental (E) ${ }^{239} \mathrm{Pu}$ mass in different measured spent fuel samples. The calculations were performed using SCALE 6.1 and ENDF/B-VII libraries [9].

Fig. 2. Comparison of burnup codes in predicting the uranium and plutonium isotopic mass for the OECD/NEA benchmark phase 1-B, Case A [9]. (Note "C" stands for calculation and "E" for experiment.)

Fig. 3. Comparison of operator-estimated and NDA measured burnup on a fuel rod [17]....................... 14

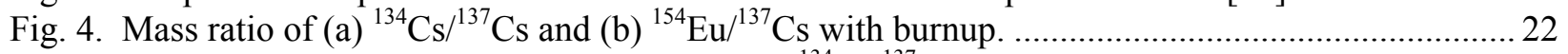

Fig. 5. Gamma ratios vs. Burnup: (a) activity ratio of ${ }^{134} \mathrm{Cs} /{ }^{137} \mathrm{Cs}$ vs. burnup (b) activity ratio of $\left({ }^{134} \mathrm{Cs} /{ }^{137} \mathrm{Cs}\right){ }^{2} /\left({ }^{106} \mathrm{Ru} /{ }^{137} \mathrm{Cs}\right)$ vs. burnup in three different fuel rods [27] (the symbols represent measured data points).

Fig. 6. Burnup vs. activity ratio at two different cooling times: (a) ${ }^{134} \mathrm{Cs} /{ }^{137} \mathrm{Cs}$ (b) $\left({ }^{134} \mathrm{Cs} /{ }^{137} \mathrm{Cs}\right)^{2} /$ $\left({ }^{106} \mathrm{Ru} /{ }^{137} \mathrm{Cs}\right)$

Fig. 7. Mass ratio vs. burnup at two different power levels: (a) ${ }^{134} \mathrm{Cs} /{ }^{137} \mathrm{Cs}$; (b) $\left({ }^{134} \mathrm{Cs} /{ }^{137} \mathrm{Cs}\right){ }^{2} /\left({ }^{106} \mathrm{Ru} /{ }^{137} \mathrm{Cs}\right)$.

Fig. 8. Relative difference (\%) between NDA and DA measured burnup vs. burnup in fuel samples from three different reactors.

Fig. 9. Relative difference (\%) between NDA and DA measured burnup vs. axial locations in spent

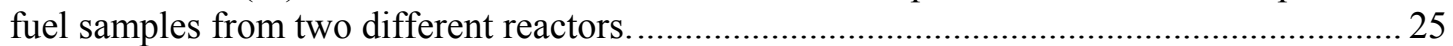

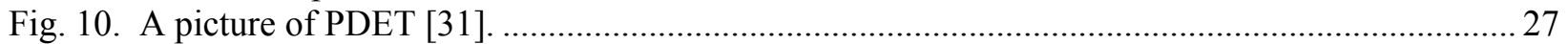

Fig. 11. Relative difference (\%) in burnup for a ROK assembly compared to operator-provided pinby-pin burnups, using pin-by-pin burnup estimates based on (a) PDET gamma measurements in guide tubes and (b) operator data at the corner pins.

Fig. 12. The average pin-by-pin burnup distribution $(\mathrm{GWd} / \mathrm{tU})$ in a $\mathrm{ROK}$ assembly provided by the reactor operator.

Fig. 13. The assembly pin-by-pin burnup distribution represented as the relative distribution in an $\mathrm{X}-\mathrm{Y}$ map used in ORIGAMI input.

Fig. 14. Assembly axial burnup distribution (relative) measured by ${ }^{137} \mathrm{Cs}$ gamma scan............................ 32

Fig. 15. The calculated radial (a) and axial (b) plutonium concentration (g/tU) for the ROK assembly, with burnup gradient shown in Fig. 12, showing the large radial gradient and axial gradient near the ends of the fuel rods.

Fig. 16. Configuration of assembly NJ070G from TMI-1 [38]. Fuel rods O1, O11, O12, and O13 were extracted from the assembly for examinations after Cycle 10.

Fig. 17. Configuration of assembly NJ05YU from TMI-1 [38]. Fuel rods D5 and H6 were extracted from the assembly for examinations after Cycle 10.

Fig. 18. Axial burnup profiles of fuel rod $\mathrm{O} 1$ and $\mathrm{O} 12$ measured by gamma scanning of ${ }^{137} \mathrm{Cs}$; converted to burnup using two different methods: 1) ${ }^{148} \mathrm{Nd}$ measurements, 2) reference rod. Also shown are the destructive measurements of ${ }^{148} \mathrm{Nd}$ at two axial locations......

Fig. 19. Axial burnup profile estimated by operator for assembly NJ070G, rod O1, and rod O12. Also shown is the burnup profile of rod $\mathrm{O} 1$ determined by gamma scan.

Fig. 21. Neighbor assemblies of assembly NJ05YU (centered) in two different cycles: (a) Cycle 9; (b) Cycle 10.

Fig. 22. Assembly NJ070G with its neighbor assemblies in Cycle 10 as modeled in TRITON.......

Fig. 23. (a) Distribution of fast neutron flux in assembly NJ05YU and the neighbors in the energy group of $[2.35,2.48] \mathrm{MeV}$; (b) neighbor configuration of NJ05YU (duplicate of Fig. 21 (a)). 
Fig. 24. (a) Calculated burnup $(\mathrm{GWd} / \mathrm{tU})$ in each fuel rod of assembly NJ05YU after the first cycle (Cycle 9) based on the with-neighbor model. (b) Relative difference (\%) in burnup of each fuel rod of assembly NJ05YU after the first cycle between with- and withoutneighbor models.

Fig. 25. (a) Calculated burnup $(\mathrm{GWd} / \mathrm{tU})$ in each fuel rod of assembly NJ05YU after the second cycle (Cycle 10) based on the with-neighbor model. (b) Relative difference (\%) of burnup in each fuel rod of assembly NJ05YU after the second cycle between the withand without-neighbor models.

Fig. 26. (a) Calculated burnup (GWd/tU) in each fuel rod of assembly NJ070G after Cycle 10 (the first cycle) using the with-neighbor model; (b) Assembly NJ070G with its neighbor assemblies in Cycle 10 (duplicate of Fig. 20).

Fig. 27. Relative difference (\%) in calculated nuclide concentrations of assembly NJ05YU between with- and without- neighbor models: (a) ${ }^{244} \mathrm{Cm}$ after the first cycle; (b) ${ }^{239} \mathrm{Pu}$ after the second cycle.

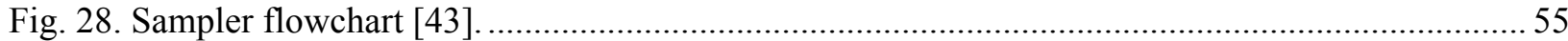

Fig. 29. The simplified $15 \times 15$ PWR spent fuel assembly as modeled in TRITON.................................55

Fig. 30. Uncertainty in calculated ${ }^{239} \mathrm{Pu}$ content as a function of burnup. ..............................................5 56

Fig. 31. Distribution of calculated ${ }^{239} \mathrm{Pu}$ mass results for 120 samples..................................................56

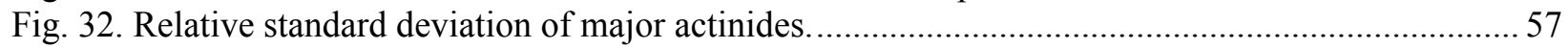

Fig. 33. Relative standard deviation of important fission products. ................................................ 58

Fig. 34. Cross-sectional views of the CIPN instrument at two axial levels: (a) $Z=-3 \mathrm{~cm}$; (b) $Z=3$ $\mathrm{cm}$.

Fig. 35. The relative difference (\%) in CIPN passive neutron count rate due to different nuclide compositions generated by with- and without-neighbor models. Also shown is the relative difference $(\%)$ in ${ }^{244} \mathrm{Cm}$ in each fuel rod between the two models.

Fig. 36. The relative difference (\%) in CIPN photon count rate due to different nuclide compositions generated by with- and without-neighbor models. Also shown is the relative difference (\%) in ${ }^{137} \mathrm{Cs}$ in each fuel rod between the two models.

Fig. 37. Relative difference of the passive gamma count rate of the samples from that of the reference case.

Fig. 38. Relative difference of the passive neutron count rate of the samples from that of the reference case.

Fig. 39. Relative difference (\%) of the net neutron count rate of the samples from that of the reference case. 


\section{LIST OF TABLES}

Page

Table 1. Summary of PWR experimental assay data used for validation [9] ........................................ 6

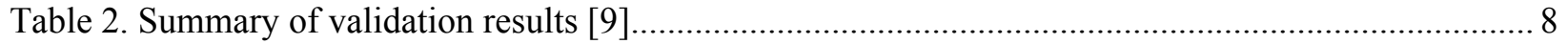

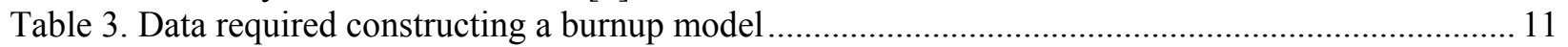

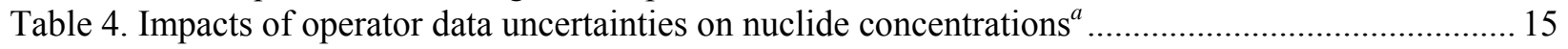

Table 5. List of conventional NDA instruments used to characterize or measure spent nuclear fuel ........ 19

Table 6. Comparison of burnup determined from DA and NDA for Vandellos samples [16] ................. 26

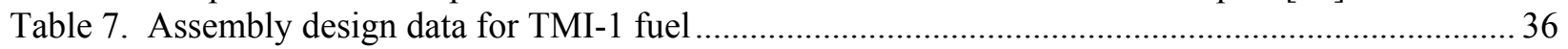

Table 8. Average burnups of rods $\mathrm{O} 1$ and $\mathrm{O} 12$ determined by different methods .................................. 40

Table 9. Burnup $(\mathrm{GWd} / \mathrm{tU})$ of the fuel samples from exterior rods $(\mathrm{O} 1, \mathrm{O} 12$, and $\mathrm{O} 13)$ of assembly

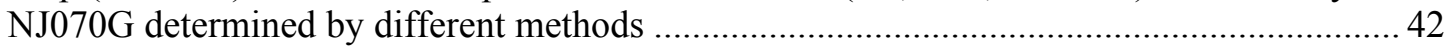

Table 10. Burnup $(\mathrm{GWd} / \mathrm{tU})$ of the fuel samples from interior rods (D5 and H6) of assembly

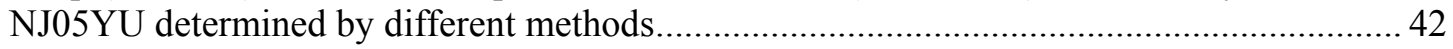

Table 11. Average burnup of rod D5 and H6 in assembly NJ05YU .................................................. 48

Table 12. Average burnup of rods O1 and O12 in assembly NJ070G determined by different methods

Table 13. Relative difference (\%) in predicted nuclide concentrations between the with- and without-neighbor models in the exterior rod $\mathrm{O} 1$ and the interior rod D5 of assembly NJ05YU.

Table 14. Comparison of activity ratios of ${ }^{154} \mathrm{Eu} /{ }^{137} \mathrm{Cs}$ and ${ }^{134} \mathrm{Cs} /{ }^{137} \mathrm{Cs}$ of TMI fuel samples, from assembly NJ05YU NDA vs. calculation

Table 15. Relative differences (\%) in nuclide concentrations calculated by four different models ${ }^{a}$ compared to measurement for the TMI-1 sample O12S5 from assembly NJ070G

Table 16. Relative difference (\%) in neutron count rate of CIPN due to different burnup distributions within the assembly

Table 17. Relative difference (\%) in gamma count rate of CIPN due to different burnup distributions within the assembly

Table 18. Summary of uncertainties in burnup of spent fuel determined using different methods . 70

Table 19. Summary of uncertainties in nuclide concentrations in spent fuel samples ${ }^{a}$ using different methods 



\section{ACKNOWLEDGMENTS}

The authors would like to acknowledge the financial support from the Next Generation Safeguards Initiative, Office of Nonproliferation and International Security, National Nuclear Security Administration. The authors would also like to thank Andrew Worrall, Stephen Croft, and Stephen Bowman for the detailed technical reviews of this report; Germina Ilas and John Scaglione for compiling the information on the TMI-1 fuel; Holly Trellue (LANL) for technical discussions; Matthew Jessee and Brian Ade for assistance with SCALE/TRITON modeling; Young Ham (LLNL) for providing the PDET data; and Tom Burr (LANL) for processing the PDET data. The authors are also grateful to the technical editing of this report performed by Deborah Stevens and Angela Alford. 



\section{EXECUTIVE SUMMARY}

This report summarizes the work by Oak Ridge National Laboratory to investigate the application of modeling and simulation to support the performance assessment and calibration of the advanced nondestructive assay (NDA) instruments developed under the Next Generation Safeguards Initiative Spent Fuel (NGSI-SF) Project. Advanced NDA instrument calibration will likely require reference spent fuel assemblies with well-characterized nuclide compositions that can serve as working standards. Because no reference spent fuel standard currently exists, and the practical ability to obtain direct measurement of nuclide compositions using destructive assay (DA) measurements of an entire fuel assembly is prohibitive in the near term due to the complexity and cost of spent fuel experiments, modeling and simulation will be required to construct such reference fuel assemblies. These calculations will be used to support instrument field tests at the Swedish Interim Storage Facility (Clab) for Spent Nuclear Fuel.

A substantial array of information required for the development of reference spent fuel assemblies has been reviewed in this report. The associated uncertainties in these data have been examined in detail, including the fuel design and operating history data required to model a spent fuel assembly. This report also studied the impacts of these uncertainties on the calculated nuclide compositions and ultimately the advanced NDA instrument signals. Acquisition of detailed assembly design information and reactor operator data are identified as key requirements for the development of reference assemblies. Therefore, instrument calibration will require a spent fuel facility where full cooperation of a trusted operator is assured. An important element of this work is to investigate the application of conventional NDA techniques (e.g., gamma spectroscopy) to better inform and improve the accuracy of spent fuel working standards. Accurately quantifying the uncertainties in the characterizations of these assemblies is critical to the advanced NDA calibration procedure, as this will limit the attainable accuracy of these instruments. The performance of the burnup code in SCALE is established on the basis of direct comparisons to spent fuel DA data from other experimental programs.

Sensitivity studies on the modeling and simulation input parameters identified fuel burnup and reactivity control measures in the reactor (e.g., burnable poison rods or control rods) as two of the most important parameters that affect the nuclide concentrations. Because exposure to reactivity control devices is typically not publicly available, this information can only be obtained from the reactor operator, or their fuel supplier. Assembly burnup and burnup distribution (both radial and axial) can also be obtained from the reactor operator; however, various methods of estimating fuel burnup (and distribution) using independent NDA measurements are described in this work, as these will have to be relied on in the absence of operator-provided data.

To quantify the expected uncertainties associated with a working standard calibration assembly, a case study was conducted using experimental data for spent fuel assemblies from the Three-Mile-Island Unit 1 (TMI-1) power plant. These data include the availability of detailed fuel design and operating history data, NDA measurements, and DA measurements for two assemblies. Using the DA measurements as a reference, representing the best available data, comparisons were performed to evaluate the accuracy of both NDA measurements and operator-provided data to characterize the fuel assemblies. Key findings include the following.

- NDA measurement (gamma spectroscopy) of fuel-rod-average burnup is within 4\% of DA-measured values, and the operator data is within 5\% of DA-measured values.

- For local burnup (fuel pellet level), the uncertainties in NDA measurement and operator data vary widely $(2 \%-19 \%)$, depending on the axial and radial location of the fuel; higher uncertainties are observed on exterior fuel rods of the assembly and also near the axial ends of fuel rods. 
- Neighbor assemblies have significant impacts $(\sim 5 \%)$ on the radial burnup distribution of an assembly with low and intermediate burnups, and the impacts decrease for high burnups $(>40 \mathrm{GWd} / \mathrm{tU})$.

- The ability of the burnup codes, that is, the two-dimensional lattice physics models used in this work, to predict the burnup distribution within an assembly, using neighbor assembly information, is limited. The codes can calculate the burnups of interior fuel rods with relatively low uncertainty $(\sim 3 \%)$, but much larger uncertainties were observed for the exterior fuel rods, especially when the assembly has been exposed to asymmetric boundary/neighbor conditions. Full-core analysis codes can, however, provide a much more accurate radial burnup profile, including the exterior rods, within 3-5\%.

- NDA measurements of the axial burnup profile are valuable and may provide more accurate information than that from the reactor operator. These measurements can also be used to independently confirm operator data when it is available, for example, for working standards.

- NDA measurements of the radial burnup profile, that is, gradients across the assembly, may be obtained using gamma measurements around the assembly and Partial defect DETector (PDET) measurements on the interior of the assembly. PDET may provide information on the profiles in the interior of the assembly that cannot be measured using conventional NDA techniques. The quality of the PDET measurement needs to be further examined using additional tests.

- The impacts of uncertainties in fuel and operator data on the count rates of Californium Interrogation with Prompt Neutron (CIPN) were investigated. The effects from uncertainties in the neighbor assembly information, assembly average burnup, and assembly radial burnup distribution were studied. It is found that the uncertainty in assembly burnup has the greatest impacts on CIPN neutron count rate.

Impacts of nuclear data uncertainties on nuclide concentrations are also studied. It was found that the nuclear cross section data contributes about $1 \%$ to the relative uncertainty of the calculated plutonium isotopes (e.g. ${ }^{239} \mathrm{Pu}$ and ${ }^{240} \mathrm{Pu}$ ). Impacts on NDA instrument responses were further studied using the CIPN model. The CIPN passive neutron count rate has the largest uncertainty because of the large uncertainty in the calculated quantity of ${ }^{244} \mathrm{Cm}$ (the primary neutron source nuclide). Small uncertainties were found in the CIPN count rates due to different burnup distributions because CIPN's detection capability penetrates the entire assembly. Instruments that rely on passive gamma measurement will be affected more by uncertainties in the burnup distribution in the assembly.

To support the generation of reference nuclide compositions for working standard assemblies, a new code named ORIGAMI (ORIGen AsseMbly Isotopics) has been developed that can be used to calculate the nuclide concentrations based on the three-dimensional radial and axial burnup profiles of the assembly. An important attribute of the code is that it can apply input data from either reactor operator estimates or NDA measurements, or a combination of both, depending on the accuracy of the available information.

The findings of this study will be immediately applied to analyze the spent fuels at Clab in Sweden, where field testing of several advanced NDA instruments are scheduled in the near future. 


\section{LIST OF ACRONYMS}

\begin{tabular}{|c|c|}
\hline BOC & Beginning of Cycle \\
\hline BPR & Burnable Poison Rod \\
\hline BPRA & Burnable Poison Rod Assembly \\
\hline BU & Burnup \\
\hline BWR & Boiling Water Reactor \\
\hline CINDER & LANL nuclear inventory code \\
\hline CIPN & Californium Interrogation with Prompt Neutron Detection \\
\hline Clab & Swedish Central Interim Storage Facility for Spent Nuclear Fuel \\
\hline CMS & Core Management System \\
\hline CVD & Cerenkov Viewing Device \\
\hline CZT & Cadmium Zinc Telluride \\
\hline DA & Destructive Assay \\
\hline EPRI & Electric Power Research Institute \\
\hline FDET & Fork DETector \\
\hline GE-VNC & General Electric--Vallecitos Nuclear Center \\
\hline HPGe & High-Purity Germanium \\
\hline IAEA & International Atomic Energy Agency \\
\hline ICPMS & Inductively Coupled Plasma Mass Spectrometry \\
\hline IT & Instrument Tube \\
\hline IFBA & Integral Fuel Burnable Absorber \\
\hline LANL & Los Alamos National Laboratory \\
\hline LLNL & Lawrence Livermore National Laboratory \\
\hline KAERI & Korea Atomic Energy Research Institute \\
\hline MCNP & Monte Carlo N Particle code \\
\hline NGSI-SF & Next Generation Safeguards Initiative-Spent Fuel \\
\hline NDA & Nondestructive Assay \\
\hline NIST & National Institute of Standards and Technology \\
\hline NNSA & National Nuclear Security Administration \\
\hline ORIGAMI & ORIGen AsseMbly Isotopics \\
\hline ORIGEN & Oak Ridge Isotope GENeration code (ORNL nuclear inventory code) \\
\hline ORNL & Oak Ridge National Laboratory \\
\hline PDET & Partial defect DETector \\
\hline PG & Passive Gamma \\
\hline PWR & Pressurized Water Reactor \\
\hline ROK & Republic of Korea \\
\hline SCALE & A comprehensive modeling and simulation suite for nuclear safety analysis and design \\
\hline SFAT & Spent Fuel Attribute Tester \\
\hline SKB & Swedish Nuclear Fuel and Waste Management Company \\
\hline SNF & Spent Nuclear Fuel \\
\hline TIMS & Thermal Ionization Mass Spectrometry \\
\hline TMI-1 & Three-Mile Island Unit 1 \\
\hline $\mathrm{TN}$ & Total Neutron \\
\hline TRITON & Transport Rigor Implemented for Transient depletion with ORIGEN \\
\hline WPNCS & Working Party on Nuclear Criticality Safety \\
\hline
\end{tabular}





\section{INTRODUCTION}

The U.S. Department of Energy Next Generation Safeguards Initiative Spent Fuel (NGSI-SF) Project is nearing the final phase of developing several advanced nondestructive assay (NDA) instruments designed to measure spent nuclear fuel assemblies for the purposes of improved nuclear safeguards [1,2]. The instruments are designed specifically with the objectives of (a) improving the ability to measure partial defects (missing fuel material), (b) autonomous verification of the initial enrichment, burnup, and cooling time of the fuel, and (c) measurement of the plutonium content in the assembly. As the project completes the initial R\&D and instrument development phase, efforts are being focused on the field deployment and experimental measurements for initial detector performance evaluation starting in summer 2013. Initial measurements are planned using spent fuel assemblies located at the Swedish Central Interim Storage Facility for Spent Nuclear Fuel (Clab), operated by the Swedish Nuclear Fuel and Waste Management Company SKB, and at the Post Irradiation Experimental Facility at the Korea Atomic Energy Research Institute (KAERI) in Republic of Korea (ROK).

These advanced NDA instruments must be accurately calibrated to enable inspectors to verify the plutonium mass and other spent fuel properties of interest to safeguards with high reliability. Advanced modeling and simulation codes have been used extensively in detector design and development to predict the relative relationships between the observable detector response and the spent fuel properties and to evaluate the expected system performance with changes in fuel properties and compositions. However, ultimately, the deployed systems will require calibration against actual well-characterized assemblies that can serve as calibration standards in order to establish confidence in the systems, assess instrument bias required for absolute measurements, and determine the total system uncertainties that cannot be quantified on the basis of simulations alone.

The task of instrument calibration is particularly challenging because there are currently no reference standards available for spent nuclear fuel assemblies. Characterization of spent fuel assembly nuclide compositions can be performed by using primarily the following methods:

- destructive radiochemical analysis of fuel samples for direct measurement of a subset of nuclide compositions [3],

- nondestructive measurements, such as gamma spectrometry or neutron counting, to measure a subset of nuclide compositions or infer fuel properties [4], and

- fuel burnup simulations performed using assembly design and reactor operating information acquired from the operator [5],

or a combination of the above techniques. Destructive radiochemical assay (DA) analysis of the spent fuel (usually on the scale of a fuel pellet) represents a high-accuracy method for spent fuel characterization, in which the fuel contents are measured directly, independent of any operator information. These methods are capable of measuring the nuclide content of many nuclides within $2 \%$ [3]. However, given the high cost and time required for DA experiments, and the fact that removal of segments from fuel rods in the assembly for destructive measurement could likely also seriously compromise the quality and integrity of the assembly for future calibration, the development of near-term calibration standards will rely on a combination of simulations using fuel assembly design information and operator data, and indirect assembly measurements including conventional NDA (e.g., gamma spectrometry). The potential future application of DA measurements in the context of a dedicated calibration facility designed with fuel handling and complex radiochemical measurement capability is discussed in a separate report.

Conventional NDA methods generally measure a very limited subset of nuclides: those associated with either gamma or neutron emission in the fuel. Hence, modeling and simulation will play a critical role in instrument calibration by providing the complete set of nuclides required for instrument modeling and calibration. For calibration standards development, full cooperation from the spent fuel facility and access to detailed design and operator data will be a requirement. This is different from routine safeguards 
operations when the system must function autonomously of operator declarations. Collaborations with KAERI and SKB have resulted in access to detailed information for the purposes of modeling and simulation of the spent fuel assemblies to be measured. Without such cooperation, the instruments would have to be calibrated at a secondary facility, and then recalibrated at the facility of interest using an alternate (non-fuel assembly) calibration source that would serve as a working standard.

This report investigates the capabilities of modeling and simulation codes to accurately characterize spent nuclear fuel nuclide contents and radiation emission rates. This work also studied the potential application of conventional NDA techniques to improve the accuracy of the simulations, the success of which involves a detailed understanding of the uncertainties in modeling and simulation, and the uncertainties in conventional NDA techniques. Certainly, conventional NDA may provide measurements that can independently confirm information provided by the operator, and may provide information of higher accuracy than operator data.

It is important to note that the data collected by the advanced NDA instruments developed under the NGSI project was not considered for use in calibration. Because these instruments are initially uncalibrated, the detector signals would not be directly useful for any absolute measurements necessary for calibration.

The uncertainty in a calibration standard is required for the analysis of overall uncertainties associated with the complete instrument calibration process. Any analysis of spent fuel compositions based on simulations for application to instrument calibration will require a detailed assessment to quantify uncertainties in these calculations. The uncertainties in the simulations can derive from inherent approximations in the fuel assembly models, the nuclear data, and moreover the completeness and accuracy of the operating history data provided by the utility. Uncertainties in the calibration assemblies may represent one of the largest sources of calibration uncertainty that will define the attainable accuracy limits for these advanced NDA instruments. This report evaluates the uncertainties associated with design and operator data, and examines the enhanced accuracy that may be attained with the addition of conventional NDA instruments. Uncertainties associated with the nuclear data used in the burnup calculations are examined separately. Nuclear data uncertainties represent an optimistic assessment of the code uncertainties for the ideal case where all other information on the assembly design and operation is well known.

This report is organized into the following sections. Section 2 outlines the approaches to the calibration standards development using advanced modeling and simulation tools along with DA, NDA, and operator data. Section 3 reviews the existing DA data, accuracies in burnup codes, the fuel and operator data needed to construct burnup models and typical uncertainties in these data. Section 4 evaluates the ability of conventional NDA to characterize spent fuel. Section 5 describes a newly developed depletion calculation capability (ORIGAMI) in SCALE and its application to several ROK assemblies. This section also discusses potential application of a new NDA instrument, Partial defect DETector (PDET), being evaluated for use under the NGSI-SF project, for spent fuel characterization. Section 6 uses the ThreeMile Island Unit 1 (TMI-1) fuel as a case study for standard generation including review of operator and NDA data and fuel burnup simulations with the SCALE code system [6]. Section 7 studies the impact of nuclear data uncertainties on nuclide compositions. Section 8 examines how the nuclide composition uncertainties in a calibration assembly can impact advanced NDA responses. Section 9 provides summary and conclusions of this work. 


\section{APPROACHES TO CALIBRATION STANDARDS DEVELOPMENT}

Spent fuel assembly standards are needed to calibrate the advanced NDA instruments being developed and deployed for field testing under the NGSI-SF project. The calibration assemblies must be representative of the range of actual fuel designs and operation parameters (e.g., burnup, initial enrichment, and cooling time) that exist in a designated facility under safeguards. The nuclide compositions of a calibration assembly need to be well characterized, as any uncertainties in the compositions will contribute to the overall accuracy of the NDA instrument calibration and may represent a limiting factor of the system performance. Therefore, these uncertainties need to be quantified to determine the expected impact on the advanced NDA system performance. The main focus of this work is to develop and demonstrate procedures to generate the nuclide compositions for spent fuel assemblies utilizing information of the fuel design and operation of the reactor, quantify the uncertainties in those compositions, and determine the effects of the uncertainties on accurate calibration of advanced NDA instruments.

Destructive assay measurements of the fuel represent the most accurate and direct method of determining the spent fuel assembly compositions. However, material restrictions in most nuclear hot cell facilities typically limit the quantities of spent fuel that can be handled. In addition, laboratory-scale spent fuel radiochemistry typically involves small sections of fuel rods. Therefore, in order to characterize an entire fuel assembly using destructive methods, multiple samples (i.e., typically $1 \mathrm{~mm}$ to several $\mathrm{cm}$ in length) from different fuel rods and different axial positions of the assembly would be needed. In practice, the cost and complexity of performing extensive DA measurements could be prohibitive, and certainly this option is not available in the near term to support the pending field tests to be performed at the spent fuel facilities of ROK and SKB. The option for advanced instrument calibration techniques in a future dedicated facility is discussed in a separate report.

The ability of NDA measurements at this time to support the development of calibration assemblies is viewed by the authors as relatively limited. Conventional NDA instruments can measure several neutronand gamma-emitting nuclides in spent fuel, typically restricted to ${ }^{242} \mathrm{Cm}$ and ${ }^{244} \mathrm{Cm}$ (neutron), and ${ }^{134} \mathrm{Cs}$, ${ }^{137} \mathrm{Cs}$, and ${ }^{154} \mathrm{Eu}$ (gamma) in older fuel, and potentially ${ }^{106} \mathrm{Ru},{ }^{125} \mathrm{Sb}$, and ${ }^{144} \mathrm{Ce}$ for fuel with short cooling times $(<5$ years). The information that can be derived from the concentrations of these nuclides is limited to gross macroscopic quantities such as fuel burnup and cooling time. However, these measurements alone are insufficient to accurately characterize an assembly. Assemblies with the same design, initial enrichment, and burnup can have very different actinide compositions due to unique operating conditions experienced by each assembly. For example, assembly positions in the core lead to varying power levels, and neighbor assemblies impact the neutron spectrum in the assembly and therefore plutonium, higher actinide, and fission product generation. Other conditions, including the exposure to burnable poison or control rods during irradiation, moderator conditions (e.g., variable density and boron concentrations), and fuel temperature can also have a significant impact on the nuclide compositions.

Burnup calculations, or depletion calculations (the two terms are often used interchangeably), are an established and validated approach to generate nuclide compositions in spent fuel. Not only will simulations play an important role in calibration standards development, they currently represent, at least in the near term, the only method available to obtain comprehensive nuclide compositions in calibration assemblies given the present facility limitations on performing DA measurements.

To obtain high-accuracy results by calculation, the burnup models require very detailed information on both the fuel design and the operating conditions of the assembly. In Section 3, the information needed for burnup modeling is discussed. The uncertainties in the calculated nuclide contents depend on the quality and completeness of the input data provided by the operator. In routine safeguards measurement campaigns, such detailed information may be unavailable to the inspector, and would, in any case, not be needed because the advanced NDA instruments are required to operate largely autonomously of 
declarations. However, for the purposes of instrument calibration, not only will this type and level of detailed information be useful, it is essential. Therefore, it is crucial that instrument calibration campaigns be carried out at facilities where there is full cooperation with the reactor operator, as well as the fuel vendor, and that the information provided is trusted and of high pedigree.

Examples of the types of assembly information provided by an operator include the assembly average burnup determined by the operator that is generally estimated to have uncertainties of about 2-3\% [7]. More detailed information such as the neighbor assemblies, and the radial (or pin-by-pin) burnup distribution across the assembly, may or may not be available from the reactor operator. Because of the reliance upon the accuracy and completeness of information for computational accuracy, a flexible approach is required to adapt to different types of information that may be available.

One approach to augment operator data explored in this report is the application of conventional NDA measurements to (a) provide information not available from the operator, (b) independently confirm the operator data, or (c) potentially reduce the uncertainty in the information provided by the utility. For example, the Partial defect DETector (PDET) [8] can potentially map the radial burnup distribution because it inserts neutron and gamma detectors into all guide tubes of the assembly (empty non-fuel rod locations). PDET measurements for ROK assemblies are used in this work to estimate the accuracy of this approach. PDET measurements are also planned at the SKB spent fuel measurement campaign, and they may be used to determine the radial burnup distribution in these assemblies.

The reliance of this approach on modeling and simulation requires that the computational tools and nuclear data used for burnup calculations be extensively validated for the assembly designs under consideration. The SCALE nuclear systems analysis code package, the main modeling tool used in this work, has been validated against a wide range of spent fuel assay data using more than 120 different fuel samples, and involved more than 70 nuclides important to nuclear safety and safeguards [9]. More details on modeling requirements and validation of SCALE are discussed in Section 3.

In summary, modeling and simulation will play an essential role in the development of spent fuel assembly calibration standards, as this represents the only practical method to determine the compositions of large number of nuclides in an assembly, short of destructive analysis of the fuel. NDA data may provide information on the fuel, in addition to operator-provided data, which can be incorporated into the modeling. Detailed fuel design and operator data are needed to develop the computational models, as discussed in the next section. 


\section{DATA REQUIREMENTS AND UNCERTAINTIES IN SPENT FUEL MODELING AND SIMULATION}

Nuclear fuel transmutation is a complex process, and there are numerous parameters that impact the nuclide compositions in a spent fuel assembly. To calculate the nuclide compositions in spent fuel to high accuracy, a detailed model is needed to simulate the evolution of the isotopic concentrations during irradiation and decay of the assembly. The model must not only accurately represent the geometry of the assembly and initial material compositions but also the detailed irradiation history and reactor operating conditions, such as temperature, moderator density, variable boron concentrations, etc. Uncertainties exist in the fuel and operator data, and these uncertainties will propagate to the final nuclide compositions. Sometimes, required information about fuel and operating conditions may be unavailable, resulting in larger uncertainties in the model input parameters and, therefore, larger uncertainties in the calculated nuclide compositions. The important model data and the impact of uncertainties in these data are reviewed in this section.

A critical first step in the application of modeling and simulation tools for fuel isotopic analysis is validation of the computer tools and nuclear data, in order to assess the bias and uncertainty in the calculated results. Validation of burnup codes is widely performed using experimental data from spent fuel measurements that include assay of the nuclide compositions of the irradiated fuel. The measurements generally include destructive radiochemical assay of spent fuel rod segments of the assembly. The majority of available data involves measurements of small sections of fuel rods, typically at the fuel pellet level or smaller. The validation procedure involves developing models of the fuel and assembly, and simulating the burnup evolution and decay, and comparing the calculated nuclide concentrations against the actual measured values. The simulations are usually performed using very detailed information on the fuel and reactor operating conditions as provided by the operator. The operating information includes direct measurements of reactor conditions (e.g., coolant inlet and outlet temperatures, boron concentration, etc.) and calculated information derived from in-core and ex-core monitoring instruments (e.g., power levels, burnup, and fuel temperatures) that are not directly measured quantities. For validation, the operator-provided estimates of the burnup for the measured sample are generally not used. Alternatively, experimentally determined sample burnups, derived from measured

${ }^{148} \mathrm{Nd}$ or other burnup monitor fission products, are used due to the much lower uncertainties compared to operator estimated values.

For the development of assembly calibration standards, the uncertainty in the code calculations represents an uncertainty in the standard and may limit the absolute accuracy that can be achieved with an advanced NDA instrument. The uncertainties in code validation derive from several sources:

- uncertainties in the code solver and nuclear data,

- uncertainties in the model (input data used to represent the design and operating history), and

- uncertainties in the measurements.

\subsection{EXPERIMENTAL BENCHMARK DATA}

The purpose of this subsection is to provide an overview of the existing DA measurement data that can be used for burnup code validation. A large amount of spent fuel DA measurement data has been reported over the years, for both pressurized water reactors (PWRs) and boiling water reactors (BWRs), by different experimental programs, both domestic and international, that were designed to provide data for the purposes of code validation.

Table 1 summarizes many of the widely used experimental datasets for PWR spent fuel measured by various programs and laboratories [9]. As shown, the experimental data includes a broad range of assembly designs, enrichments (from 2.63 to $4.657 \%$ ), burnups (from 7.2 to $54 \mathrm{GWd} / \mathrm{tU}$ ), and cooling 
times that are representative of the commercial fuel inventory. The data include more than 120 fuel samples from $14 \times 14,15 \times 15,17 \times 17$, and $18 \times 18$ assembly lattice designs, and measurements are available for more than 70 different nuclides.

Table 1. Summary of PWR experimental assay data used for validation [9]

\begin{tabular}{|c|c|c|c|c|c|c|}
\hline Reactor & $\begin{array}{l}\text { Measurement } \\
\text { Laboratory }^{a}\end{array}$ & $\begin{array}{c}\text { Experimental } \\
\text { Program }^{b}\end{array}$ & $\begin{array}{l}\text { Assembly } \\
\text { Design }\end{array}$ & $\begin{array}{l}\text { Enrichment } \\
\text { (wt \% }{ }^{235} \mathrm{U} \text { ) }\end{array}$ & $\begin{array}{c}\text { No. of } \\
\text { Samples/ } \\
\text { Fuel Rods }\end{array}$ & $\begin{array}{l}\text { Burnup } \\
\text { (GWd/t) }\end{array}$ \\
\hline \multirow{2}{*}{ Trino Vercellese } & Ispra, Karlsruhe & $\mathrm{JRC}$ & $15 \times 15$ & $\begin{array}{l}2.72,3.13 \\
3.897\end{array}$ & $15 / 5$ & $7.2-17.5$ \\
\hline & Ispra, Karlsruhe & JRC & $15 \times 15$ & 3.13 & $16 / 5$ & $12.8-25.2$ \\
\hline \multirow[b]{2}{*}{ Obrigheim } & Ispra, Karlsruhe & JRC & $14 \times 14$ & $2.83,3.00$ & $22 / 6$ & $15.6-38.1$ \\
\hline & $\begin{array}{l}\text { ITU, IRCh, WAK, } \\
\text { IAEA }\end{array}$ & ICE & $14 \times 14$ & 3.13 & $5 / 5$ & $27.0-29.2$ \\
\hline H. B. Robinson-2 & PNNL & ATM-101 & $15 \times 15$ & 2.561 & $4 / 1$ & $16.0-31.7$ \\
\hline Turkey Point-3 & Battelle-Columbus & NWTS & $15 \times 15$ & 2.556 & $5 / 1$ & $30.5-31.6$ \\
\hline \multirow{3}{*}{ Calvert Cliffs-1 } & PNNL, KRI & ATM-104 & $14 \times 14$ & 3.038 & $3 / 1$ & $27.4-44.3$ \\
\hline & PNNL & ATM-103 & $14 \times 14$ & 2.72 & $3 / 1$ & $18.7-33.2$ \\
\hline & PNNL, KRI & ATM-106 & $14 \times 14$ & 2.453 & $3 / 1$ & $31.4-46.5$ \\
\hline Takahama-3 & JAERI & JAERI & $17 \times 17$ & $2.63,4.11$ & $16 / 3$ & $14.3-47.3$ \\
\hline \multirow{2}{*}{ TMI-1 } & ANL & DOE YMP & $15 \times 15$ & 4.013 & $11 / 1$ & $44.8-55.7$ \\
\hline & GE-VNC & DOE YMP & $15 \times 15$ & 4.657 & $8 / 3$ & $22.8-29.9$ \\
\hline \multirow[b]{2}{*}{ Gösgen } & $\mathrm{SCK} \cdot \mathrm{CEN}, \mathrm{ITU}$ & ARIANE & $15 \times 15$ & $3.5,4.1$ & $3 / 2$ & $29.1-59.7$ \\
\hline & $\begin{array}{c}\mathrm{SCK} \cdot \mathrm{CEN}, \mathrm{PSI}, \\
\mathrm{CEA}\end{array}$ & MALIBU & $15 \times 15$ & 4.3 & $3 / 1$ & $\begin{array}{c}47.2,67.9, \\
70.4 \\
\end{array}$ \\
\hline GKN II & $\mathrm{SCK} \cdot \mathrm{CEN}$ & REBUS & $18 \times 18$ & 3.8 & $1 / 1$ & 54.0 \\
\hline Vandellos & Studsvik Nuclear & ENUSA & $17 \times 17$ & 4.5 & $6 / 1$ & $42.5-78.3$ \\
\hline
\end{tabular}

${ }^{a} \mathrm{ANL}=$ Argonne National Laboratory; GE-VNC = General Electric Vallecitos Nuclear Center; PNNL = Pacific Northwest National Laboratory; KRI = Khlopin Radium Institute; JAERI = Japan Atomic Energy Research Institute; JRC = Joint Research Center, European Commission; ITU = European Institute for Transuranium Elements; IRCh = Institute for Radiochemistry at Karlsruhe; $\mathrm{WAK}=$ Karlsruhe Reprocessing Plant; IAEA = International Atomic Energy Agency; SCK $\bullet$ CEN $=$ Studiecentrum voor Kernenergie Centre d'Etude de l'Energie Nucléaire; PSI = Paul Scherrer Institute; CEA = Commissariat à l'Énergie Atomique.

${ }^{b} \mathrm{JRC}=$ European Joint Nuclear Research Centre; ICE = European Isotopic Correlation Experiment; ATM = Approved Testing Material; NWTS = National Waste Terminal Storage Program; JAERI = Japan Atomic Energy Research Institute (now JAEA); DOE YMP = U.S. Department of Energy Yucca Mountain Project; ARIANE, MALIBU, and REBUS are International Experimental Programs coordinated by Belgonucleaire - currently managed by SCK $\bullet$ CEN, Belgium; ENUSA = Spanish fuel vendor Empresa Nacional del Uranio, S. A.

The list of measured nuclides varies from one experiment to another, depending on the primary interest of the programs, but the list usually includes uranium, plutonium and other higher actinides, major fission products (e.g., ${ }^{137} \mathrm{Cs}$ and ${ }^{154} \mathrm{Eu}$ ), and sometimes the main neutron-absorbing fission products (e.g. ${ }^{149} \mathrm{Sm}$ and ${ }^{155} \mathrm{Gd}$ ). These experiments provide a direct measure of the ability of the codes to predict the isotopes of importance to the response of advanced NDA instruments.

The uncertainties in the nuclide measurements vary widely, depending on the radiochemical analysis technique and the type of mass spectrometer instrument used. For example, measurements performed using Thermal Ionization Mass Spectrometry (TIMS), widely regarded as the most accurate technique for spent fuel measurements, can achieve uncertainties $<1 \%$ (except for the nuclides with low abundances such as ${ }^{151} \mathrm{Eu}$ and $\left.{ }^{155} \mathrm{Gd}\right)$. However, when all uncertainties related to sample handling, dissolution, and radiochemistry are included, the total uncertainties of $1-2 \%$ can be achieved using TIMS for nuclides with high isotopic abundance, a value established by independent laboratory cross-check measurements $[10,11]$. Uncertainties for low abundance nuclides (e.g., $\left.{ }^{238} \mathrm{Pu}\right)$ can be considerably larger $(5-10 \%)$, as 
well as nuclides measured by gamma or alpha spectrometry such as americium and curium $(>10 \%)$. More details can be found in Refs. 10 and 11.

\subsection{SCALE VALIDATION STUDIES}

The SCALE code system is a nuclear systems modeling and simulation package developed at Oak Ridge National Laboratory (ORNL) [6], and it has been used for the assembly calculations described in this report. Burnup calculations have been performed with the SCALE 2-D burnup module TRITON [12], which couples NEWT and ORIGEN. (There is a 3-D burnup module under development in SCALE using KENO.) NEWT is a 2-D $S_{n}$ lattice code that solves the neutron transport problem and calculates the neutron flux and neutron reaction cross sections in each material region of an assembly. These cross sections and fluxes are then used in the ORIGEN code to calculate the time-dependent nuclide concentrations.

Recent validation studies covered a wide range of the existing spent fuel DA data and included measurements for more than 90 different spent fuel samples (a subset of that is shown in Table 1). Figure 1 shows the validation results [9] comparing calculated (C) and experimental (E) values of ${ }^{239} \mathrm{Pu}$ mass in the different spent fuel samples. The calculations were performed using TRITON in SCALE version 6.1 with ENDF/B-VII cross section libraries. As illustrated, SCALE calculates the ${ }^{239} \mathrm{Pu}$ concentration with an average bias of $4.1 \%$ (overestimate) and an uncertainty (standard deviation) of $\pm 3.5 \%$. It is important to note that the comparisons with measurements also include uncertainties associated with the experimental measurements. The typical measurement uncertainty of ${ }^{239} \mathrm{Pu}$ is about $1 \%[3]$.

Table 2 summarizes the SCALE validation results for an extended list of nuclides important to nuclear criticality safety (burnup credit) and radiological safety (i.e., neutron and gamma-ray emitters). These nuclides include many of the nuclides of highest importance to advanced NDA instrument response. These results are obtained using the latest evaluated nuclear cross section data in ENDF/B-VII. The results for some nuclides have been found to be very sensitive to the source of the cross section data [9]. Therefore, the validation results are specific both to the computer code and nuclear data library used in the calculations.

The performance in predicting the mass of the uranium and plutonium isotopes using other advanced burnup codes with similar capabilities as SCALE is shown in Fig. 2 for an Organisation for Economic Co-operation and Development/Nuclear Energy Agency (OECD/NEA) depletion benchmark [13] (phase 1-B, Case A). With the exception of MCNPX2.6, which exhibits unreliable behavior, all the codes perform similarly in predicting isotopic concentrations when using the same nuclear data library. For this case, SCALE predicts the ${ }^{235} \mathrm{U}$ mass within $5 \%$ of measurement and the major plutonium isotopes all within about $2 \%$.

The validation results cited in this section are based on data from experimental programs developed for the purpose of benchmarking burnup code performance. Information on the fuel design and operator data is generally extensive and complete. The results provide a representative measure of the expected code performance when applied to calculating nuclide concentrations for an assembly selected as a calibration standard, provided that the calibration assemblies have a similar level of information as those used in the benchmarks. A notable exception, as discussed previously, is that the benchmarking calculations used burnup values that are experimentally determined using DA data. The burnup of a calibration assembly will likely rely on the operator calculated value that has larger uncertainty than experimentally determined values. 
Table 2. Summary of validation results [9]

\begin{tabular}{|c|c|c|c|c|c|}
\hline \multirow[t]{2}{*}{ Isotope } & \multirow[t]{2}{*}{$\begin{array}{c}\text { Number of } \\
\text { measurements }\end{array}$} & \multicolumn{2}{|c|}{$\begin{array}{c}\text { SCALE 6.1 } \\
\text { ENDF/B-VII }^{a}\end{array}$} & \multirow[t]{2}{*}{ Application $^{b}$} & \multirow[t]{2}{*}{ Comments } \\
\hline & & $(\mathrm{C} / \mathrm{E}-1)_{\mathrm{avg}}(\%)$ & $\sigma(\%)$ & & \\
\hline${ }^{234} \mathrm{U}$ & 55 & 12.4 & 17.6 & $\mathrm{CS}$ & \multirow{9}{*}{$\begin{array}{c}\text { Nuclear Safeguards } \\
\text { subjects }\end{array}$} \\
\hline${ }^{235} \mathrm{U}$ & 92 & 1.2 & 3.5 & $\mathrm{CS}$ & \\
\hline${ }^{236} \mathrm{U}$ & 77 & -1.9 & 3.5 & $\mathrm{CS}$ & \\
\hline${ }^{238} \mathrm{U}$ & 92 & -0.1 & 0.4 & $\mathrm{CS}$ & \\
\hline${ }^{238} \mathrm{Pu}$ & 77 & -11.7 & 5.9 & $\mathrm{C}, \mathrm{RS}$ & \\
\hline${ }^{239} \mathrm{Pu}$ & 92 & 4.1 & 3.5 & $\mathrm{C}, \mathrm{RS}$ & \\
\hline${ }^{240} \mathrm{Pu}$ & 92 & 2.2 & 3.4 & C, RS & \\
\hline${ }^{241} \mathrm{Pu}$ & 92 & -1.4 & 4.5 & $\mathrm{CS}$ & \\
\hline${ }^{242} \mathrm{Pu}$ & 91 & -5.9 & 6.1 & $\mathrm{CS}$ & \\
\hline${ }^{241} \mathrm{Am}$ & 39 & 10.2 & 20.7 & $\mathrm{C}, \mathrm{RS}$ & Neutron absorber \\
\hline${ }^{244} \mathrm{Cm}$ & 57 & -4.4 & 11.1 & $\mathrm{RS}$ & Main neutron emitter \\
\hline${ }^{106} \mathrm{Ru}$ & 31 & 7.9 & 22.7 & $\mathrm{RS}$ & Gamma emitter \\
\hline${ }^{103} \mathrm{Rh}$ & 8 & 9.1 & 10.9 & $\mathrm{CS}$ & Gamma emitter \\
\hline${ }^{134} \mathrm{Cs}$ & 59 & -7 & 7.1 & $\mathrm{RS}$ & \multirow{2}{*}{$\begin{array}{c}\text { Gamma emitter and } \\
\text { burnup indicator used } \\
\text { by NDA }\end{array}$} \\
\hline${ }^{137} \mathrm{Cs}$ & 73 & -0.7 & 3.1 & BU, RS & \\
\hline${ }^{148} \mathrm{Nd}$ & 77 & 0.6 & 1.4 & BU & $\begin{array}{l}\text { burnup indicator used } \\
\text { by DA }\end{array}$ \\
\hline${ }^{144} \mathrm{Ce}$ & 32 & -2.1 & 8.1 & $\mathrm{RS}$ & Gamma emitter \\
\hline${ }^{149} \mathrm{Sm}$ & 20 & 1.9 & 6.2 & $\mathrm{CS}$ & \multirow{2}{*}{ Neutron absorber } \\
\hline${ }^{151} \mathrm{Sm}$ & 24 & -2.1 & 4.4 & $\mathrm{CS}$ & \\
\hline${ }^{154} \mathrm{Eu}$ & 44 & 4.2 & 10.4 & $\mathrm{RS}$ & Gamma emitter \\
\hline${ }^{155} \mathrm{Gd}$ & 19 & -8.4 & 14.4 & $\mathrm{CS}$ & Neutron absorber \\
\hline
\end{tabular}

${ }^{a}$ The mean and standard deviation are calculated as $(C / E)_{\text {avg }}=\frac{1}{N_{s}} \sum_{k=1}^{N_{s}}(C / E)_{k}$ and $\sigma=\left\{\frac{1}{N_{s}-1} \sum_{k=1}^{N_{s}}\left[(C / E)_{k}-(C / E)_{a v g}\right]^{2}\right\}^{1 / 2}$, where $k$ is the sample index and $N_{s}$ is the total number of samples.

${ }^{b} \mathrm{CS}=$ criticality safety; $\mathrm{BU}=$ burnup indicator; $\mathrm{RS}=$ radiological safety. 


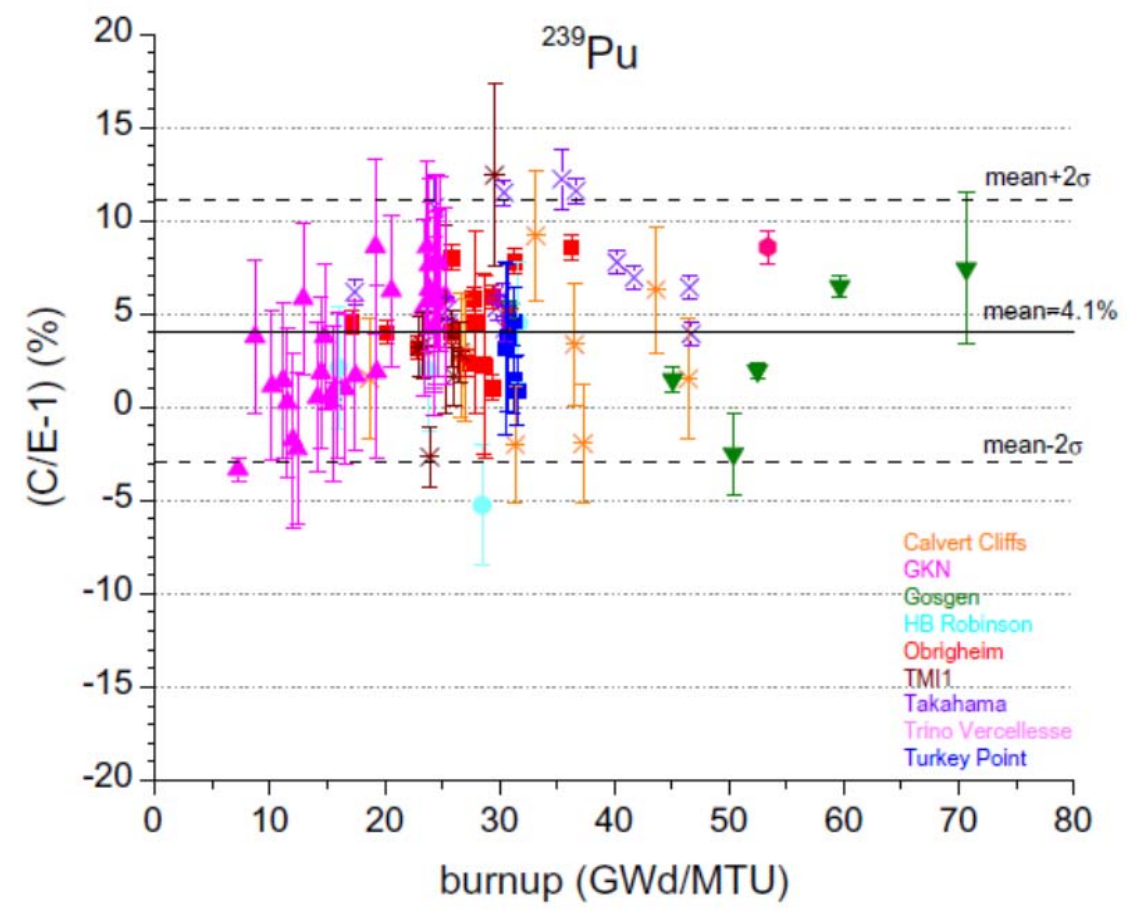

Fig. 1. Comparison of calculated (C) and experimental (E) ${ }^{239} \mathrm{Pu}$ mass in different measured spent fuel samples. The calculations were performed using SCALE 6.1 and ENDF/B-VII libraries [9].

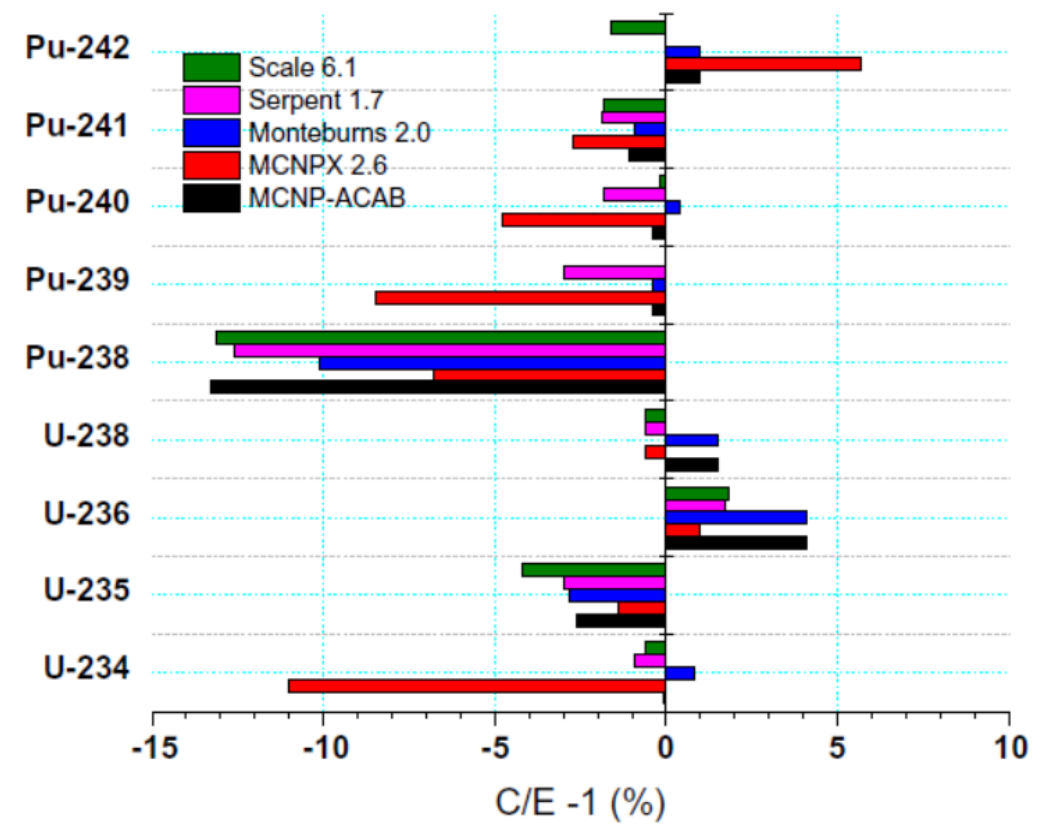

Fig. 2. Comparison of burnup codes in predicting the uranium and plutonium isotopic mass for the OECD/NEA benchmark phase 1-B, Case A [9]. (Note "C" stands for calculation and "E" for experiment.)

The discussions in this section focus mainly on commercial PWR fuel. Validation studies for BWR fuels have also been performed [14]. However, the experimental data available for validation is relatively 
limited with respect to both the number of assay samples and the measured isotopes. More recently, extensive measurements for modern BWR fuels have been reported [15] for GE14 (10×10) and SVEA-96 $(10 \times 10)$ assembly designs. BWR assemblies are significantly more heterogeneous and complex than PWR designs (e.g., greater axial variations, heavy burnable poison loadings), in addition to the added complexity of two-phase flow (void conditions) of the water coolant, and are therefore more challenging to model.

\subsection{DATA REQUIRED FOR MODELING}

The list of data required to construct a burnup model for a PWR assembly is summarized in Table 3. Also included is the accessibility to that information, and general comments. This list is based on the most important modeling parameters based on international experience [10]. These items are discussed in more detail below. The modeling requirements for BWR assembly designs are more complex and are not addressed in this report.

\subsubsection{Fuel Assembly Design Data}

Assembly design data include the configuration and dimensions of the assembly and fuel rods, enrichment of the fuel rods (if it varies within the assembly), burnable poison rod information including gadolinium loading and/or Integral Fuel Burnable Absorber (IFBA) in some rods (if applicable), the number of such rods and their layout in the assembly, and initial material compositions of the fuel and structural material of the assembly. Fuel design information is generally available, although for modern designs detailed information may be deemed proprietary by fuel vendors (e.g., IFBA patterns and dimensions, enrichment variation, etc.) and could be more difficult to obtain. Reference 15 summarizes the types of fuel assemblies used in both PWRs and BWRs in the United States.

\subsubsection{Reactor Operating History}

The reactor operating history information is important because the local power level and duration of irradiation and decay can have significant impacts on many nuclides. This information includes the start and end date of each cycle and the power of the assemblies as provided by the operator. This information is usually easy to obtain. However, detailed day-to-day power variation could be more difficult to obtain unless provided by the operator.

\subsubsection{Assembly Average Burnup}

The assembly average burnup is routinely provided by the operator and included in fuel declarations. During reactor operation, detectors are inserted into the instrument tube (IT) in approximately one-third of the assemblies in the core to measure the reaction rates in the detectors, which can be used to determine power distributions within the core, and then the power (and burnup) share of each assembly can be inferred (the total power of the core at a given time can be accurately measured). Burnup of the fuel is one of the more important factors that affect the nuclide compositions, and the uncertainties in operatorprovided burnup are discussed in subsection 3.4. 
Table 3. Data required constructing a burnup model

\begin{tabular}{|c|c|c|c|}
\hline Category & Items & Accessibility & Comments \\
\hline $\begin{array}{l}\text { Fuel Assembly } \\
\text { Design Data }\end{array}$ & $\begin{array}{l}\text { Assembly dimensions, initial } \\
\text { fuel composition, materials }\end{array}$ & Available & $\begin{array}{l}\text { Some information may be } \\
\text { proprietary. }\end{array}$ \\
\hline $\begin{array}{l}\text { Reactor Operating } \\
\text { History }\end{array}$ & Cycle history, discharge date & Available & Reported by the operator \\
\hline $\begin{array}{l}\text { Reactor Operating } \\
\text { Conditions }\end{array}$ & $\begin{array}{l}\text { Assembly power level, } \\
\text { moderator temperature and } \\
\text { density, fuel temperature, etc. }\end{array}$ & Available & $\begin{array}{l}\text { Day-to-day variations are } \\
\text { difficult to obtain. Data } \\
\text { has to be inferred. }\end{array}$ \\
\hline Assembly Burnup & $\begin{array}{l}\text { The burnup of the assembly } \\
\text { averaged over radial and axial } \\
\text { variations }\end{array}$ & Available & $\begin{array}{l}\text { Not a directly measured } \\
\text { quantity. Calculated by } \\
\text { the operator from in-core } \\
\text { monitoring and computer } \\
\text { codes. }\end{array}$ \\
\hline $\begin{array}{l}\text { Axial and Radial } \\
\text { Burnup Distribution }\end{array}$ & $\begin{array}{l}\text { The spatial distribution of } \\
\text { burnup pin by pin and along } \\
\text { axial length of assembly }\end{array}$ & Difficult to obtain directly & $\begin{array}{l}\text { Values may be available } \\
\text { from the operator. Node } \\
\text { (axial) burnup is routinely } \\
\text { calculated. }\end{array}$ \\
\hline Reactivity Control & $\begin{array}{l}\text { Soluble boron concentration in } \\
\text { moderator, exposure to control } \\
\text { rods, burnable poison rods, and } \\
\text { integral assembly poison rods }\end{array}$ & Difficult to obtain & $\begin{array}{l}\text { Material compositions and } \\
\text { number of burnable } \\
\text { poison rods (BPRs) } \\
\text { sometimes considered } \\
\text { proprietary. }\end{array}$ \\
\hline Neighbor assemblies & $\begin{array}{l}\text { Design and average burnup of } \\
\text { neighbor assemblies at the } \\
\text { beginning and end of cycle. } \\
\text { Exposure to BPR for neighbor } \\
\text { assemblies. }\end{array}$ & Difficult to obtain & $\begin{array}{l}\text { Require core loading } \\
\text { maps provided by the } \\
\text { operator. }\end{array}$ \\
\hline $\begin{array}{l}\text { Deformation of the } \\
\text { Fuel }\end{array}$ & $\begin{array}{l}\text { Dimensional change (e.g., } \\
\text { bowing of fuel rods) of the fuel } \\
\text { assembly due to irradiation, } \\
\text { high temperature and pressure, } \\
\text { etc. }\end{array}$ & Generally unavailable & $\begin{array}{l}\text { Usually not measured. No } \\
\text { data available, thus not } \\
\text { considered in this work. }\end{array}$ \\
\hline Nuclear Data & $\begin{array}{l}\text { Cross section libraries, fission } \\
\text { yield, and decay data }\end{array}$ & Available & Publicly available \\
\hline
\end{tabular}

\subsubsection{Axial and Radial Burnup Distributions}

The burnup varies significantly along the axial length of the assembly due to the power distributions in the reactor core, power depression around spacer grids, axial variation in the moderator density, insertion of control rods, and even operating anomalies (e.g., boron deposition on the fuel rods). The burnup can also vary radially due to design and operating factors, such as guide tube configuration, usage of burnable poison rods (BPRs), insertion of control rods, and asymmetric neighbor assembly conditions. Commercial full-core analysis codes can estimate both the axial and radial burnup distributions, generally within a few percent of measurements [16]. In PWRs, neutron flux is routinely measured in the IT of some of the incore assemblies (one IT per assembly) at different axial elevations, and these measurements can be used to benchmark code calculations. Radial pin-by-pin burnup, although not directly measured, can be 
estimated through full-core code calculations. Similar calculations are also performed by the operator to determine the axial burnup variations for each assembly based on the neutron flux measurements and detailed operating conditions. Both radial pin-by-pin burnup and axial burnup variations are not normally provided to nuclear safeguards inspectors, and they are not included in fuel declarations. Concerns regarding accuracy (not directly measured) and accessibility are the two main issues for this category.

\subsubsection{Reactivity Control Exposure}

Reactor reactivity-control measures can have a very significant impact on assembly nuclide compositions. Soluble boron in the moderator is routinely used to control reactivity in PWRs. The concentrations usually peak at the beginning of each cycle and gradually decrease approximately linearly over the length the cycle. Studies using SCALE have found that using a computed cycle-average boron concentration, instead of the variation in boron concentration vs. burnup, makes only a minor impact on nuclide compositions [17]. The soluble boron concentration is measured by the reactor operator and is usually well known. Information regarding the insertion of control rods is considered more difficult to obtain. For PWRs, the control rods are usually fully withdrawn except during startup and shutdown. Control rods are sometimes partially inserted and therefore affect only axial regions near the top of the assembly. This information is not routinely provided. Exposure to BPRs can have a significant impact on nuclide compositions as they are fully inserted in guide tubes of the assembly when they are used and introduce neutron-absorbing poison in the assembly and displace water. Assemblies often use BPRs in their first cycle, after which the BPRs are usually removed. The total rod number of BPRs and the poison concentration in each poison rod can vary. This information is not routinely reported and can only be provided by the operator or fuel vendor.

\subsubsection{Neighbor Assemblies}

Adjacent assemblies (neighbors) can impact the burnup gradient within an assembly, especially when the burnup of neighbor assemblies vary significantly or the host assembly resides at the edge of the core. The information about neighbor assemblies may be difficult to obtain and requires the core loading patterns showing the assembly locations and properties. Neighbor assemblies can also impact the nuclide concentrations by influencing the neutron spectrum. However, this effect is generally limited to the outer row of fuel rods. Impacts of neighbor assemblies on nuclide compositions studied previously [10] generally had a small $(\sim 1 \%)$ effect on total fissile content for $\mathrm{UO}_{2}$ fuel. In many cases the results obtained by neglecting the neighbor assemblies were comparable to more detailed neighbor models.

However, asymmetric neighbor configuration may introduce significant gradients in burnup and thus on the distribution of nuclide compositions in the assembly (even when the total quantity of certain nuclides is similar in the assembly). To study this effect, an assembly from the TMI-1 reactor was modeled in detail with all its neighbor assemblies for two consecutive irradiation cycles. The impacts on nuclide compositions and radial burnup gradient within this assembly are discussed in Section 6.

\subsubsection{Deformation of the Fuel}

Fuel rods usually experience deformations under the high-temperature, high-pressure environment during irradiation. The fuel swells due to fission gas accumulation and thermal expansion. The fuel rods may also bow in some direction, which may alter the rod pitch and thus impact the local neutron spectrum. Information about the degree of bowing is not usually available, and is therefore not considered in this work. However, changes from the as-built geometry will contribute to the overall uncertainty in the results from computational models. 


\subsubsection{Nuclear Data}

Modeling and simulation requires high-quality nuclear data, and this is particularly true for depletion calculations. Uncertainties in nuclear cross-section data, decay data, and fission yield data contribute to the uncertainties in the calculations. Significant improvements in the accuracy of calculations have been observed for several fission product nuclides using the latest ENDF/B-VII nuclear data [9]. The impacts of nuclear data uncertainties on nuclide compositions are evaluated in Section 7, and the impacts of these uncertainties on advanced NDA responses are summarized in Section 8.

\subsection{UNCERTAINTIES IN FUEL BURNUP}

Fuel burnup represents one of the more important parameters listed in Table 3 in terms of uncertainty analysis and is discussed in more detail. Usually the assembly average burnup can be inferred from the measured reaction rate in the reactor core by the operator, while the detailed burnup (pin-by-pin burnup) within an assembly must be derived from either destructive analysis of the fuel on multiple locations, NDA measurements (usually against a calibrated reference source), or from full-core simulations by the operator assisted by reactor measurement data. For most other items in Table 3, accessibility to the information is a more important issue.

\subsubsection{Uncertainties in Operator-Estimated Assembly Burnup}

There are several publicly available reports that quantify the accuracy of the assembly average burnup provided by a reactor operator. Two such studies were done by EPRI [7] and AREVA [18]. In the AREVA study, a large number of assemblies (over 10,000) from nine different plants were analyzed. The study compared the calculated and measured burnup of these assemblies and found the standard deviation to be about $2 \%$. The EPRI results were similar, with uncertainties of the assembly average burnup of about $2.5 \%$ for first cycle, $1.7 \%$ for the second cycle, and $2.0 \%$ for the third cycle. Note that the results of both studies were based on measured and calculated reaction rates, and the uncertainties stemming from conversion of reaction rates to burnup values were not included. The conversions of reaction rates to burnup (units of $\mathrm{GWd} / \mathrm{tU}$ ) are complex and must include the relative contribution to time-dependent fission from each major nuclide, depending on multiple factors including enrichment, moderator densities, etc. Therefore, after including the uncertainties stemming from the conversions, the estimated uncertainties of the operator-provided assembly average burnup are expected to be larger than the reported values in these two studies, but are usually less than 5\% [17].

\subsubsection{Uncertainties in Operator-Estimated Axial Burnup}

Commercial core simulator codes, such as the Studsvik Scandpower codes CASMO and SIMULATE [20], are used to calculate the burnup distribution of assemblies. The axial (nodal) burnup within individual fuel rods can be calculated using SIMULATE with an integrated pin exposure model. Because these codes have been extensively benchmarked against DA data and include in-core measurement data, they usually predict the axial (nodal) burnup well. Figure 3 shows a comparison of operator-estimated and NDA measured nodal burnup on a single fuel rod [17]. The estimated burnup was calculated using SIMULATE, and the experimental NDA burnup was based on a ${ }^{137} \mathrm{Cs}$ gamma scan. The conversion of

${ }^{137} \mathrm{Cs}$ count rate to burnup was done by comparison to calibration reference fuel rods with the ${ }^{137} \mathrm{Cs}$ content determined by destructive measurement. As shown, the difference is generally within $2 \%$ except at the upper region of the fuel rod where deviations increase to about 3\%. Note that these results represent the most optimistic assessment of the performance of commercial codes and NDA measurements because the analysts had access to detailed fuel and operator data, and the NDA measurements were performed under well-controlled conditions. Much larger discrepancies (up to 9\%) on fuel rod nodal burnup have been reported by other experimental programs [21]. 


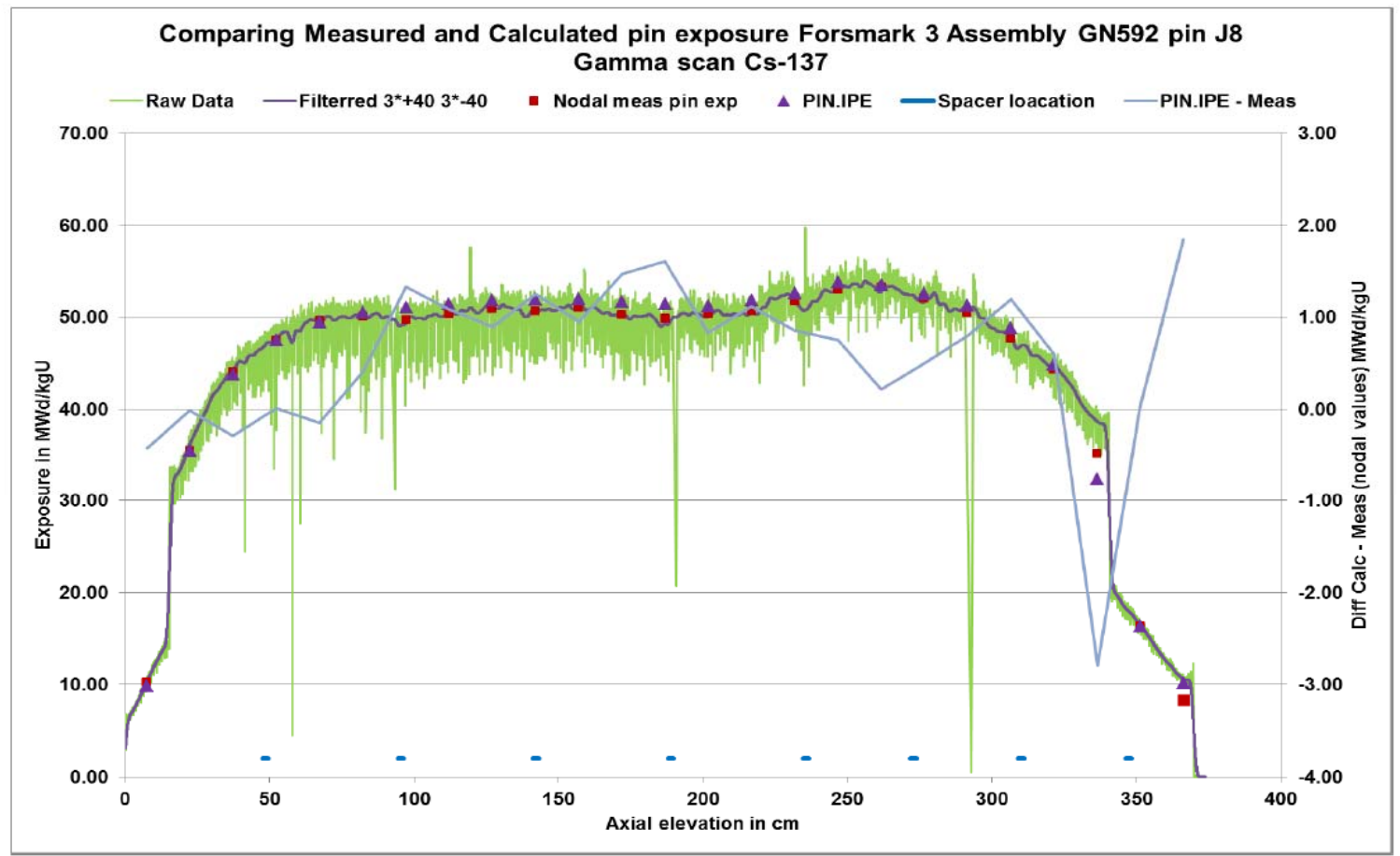

The above calculated results are based on CASMO-4E/Jef-2.2/SIMULATE-3 Vattenfall Nuclear model of Forsmark 3.

Raw Data = Gamma scan data reported by Hans-Urs Zwicky for the GN592 J8 pin, Filtered data correspond to "Raw Data" sliding average of 40 sample "forward and backward" 3 times, Nodal meas pin exp = Nodal average of filtered measured data, PIN.IPE $=$ SIMULATE-3 calculated nodal pin exposure using integrated pin exposure model, PIN.IPE - Meas = SIMULATE-3 calculated nodal pin exposure - Nodal average of filtered measured data

Fig. 3. Comparison of operator-estimated and NDA measured burnup on a fuel rod [16].

\subsection{IMPACTS OF UNCERTAINTIES IN OPERATOR DATA}

The operator data required to construct an assembly depletion model has inherent uncertainties. In some cases, information may be unavailable, requiring approximations or assumptions that can further add to the uncertainties in the calculated nuclide compositions.

Uncertainty analysis in fuel burnup has been studied previously for many of the major modeling parameters, including an international study by the OECD Nuclear Energy Agency [10] and more recently as part of the NGSI project [17]. In these studies, the sensitivities of the nuclide compositions, especially plutonium, to several input parameters were quantified, including burnup, fuel temperature, moderator temperature and density, water gap, boron concentration, IFBA, and BPR exposure. Two factors found to be most influential on plutonium content were moderator densities and reactivity control device exposure. IFBA rods can affect the plutonium up to $\sim 5 \%$, depending on the poison loading and number of rods. Exposure to BPRs had the most significant impact on plutonium of 20\% [17] on a $17 \times 17$ Westinghouse assembly with maximum BPR loadings.

Additional studies have been performed in this work to assess the impacts of uncertainties in fuel and operator data on nuclide compositions due to exposure to BPRs (present vs. not present), soluble boron concentration, number of gadolinia (Gd) rods (four Gd rods vs. none), assembly average burnup, and fuel temperature. The uncertainties in the input data used in the burnup calculations, listed in Table 4, were selected to be realistic of actual operations. The calculations were based on an actual fuel assembly NJ070G from the TMI-1 reactor that had very well-documented operating history data. The uncertainties in the resulting nuclide compositions are evaluated for several important nuclides for advanced NDA 
instruments. As summarized in Table 4, the exposure to BPRs had the largest impacts on ${ }^{239} \mathrm{Pu}$, total plutonium content, and total fissile content (combined mass of ${ }^{235} \mathrm{U},{ }^{239} \mathrm{Pu}$, and ${ }^{241} \mathrm{Pu}$ ). A $5 \%$ uncertainty in burnup had the largest impact on the concentration of ${ }^{235} \mathrm{U}$, the ratio of ${ }^{134} \mathrm{Cs} /{ }^{137} \mathrm{Cs}$, and ${ }^{244} \mathrm{Cm}$ content. (Note the relative difference in ${ }^{239} \mathrm{Pu}$ and total plutonium are both less than $5 \%$ in this case because growth of several plutonium isotopes, especially ${ }^{239} \mathrm{Pu}$, flattens with high burnup.) Burnup has the largest impact on ${ }^{244} \mathrm{Cm}$, because curium typically increases as a function of the fourth power of burnup (i.e., $\mathrm{Cm}$ $\sim \mathrm{BU}^{4}$ ). The impacts from other factors studied are observed to be relatively small, including the four $\mathrm{Gd}$ rods. The Three Mile Island (PWR) fuel used only four Gd rods. Typically in BWR fuel, the number of Gd rods is much larger, and hence the impacts of Gd rods on nuclide concentrations are expected to be greater.

Table 4. Impacts of operator data uncertainties on nuclide concentrations ${ }^{a, b}$

\begin{tabular}{|c|c|c|c|c|c|c|c|}
\hline \multirow[b]{2}{*}{ Parameter } & \multirow[b]{2}{*}{ Uncertainty } & \multicolumn{6}{|c|}{$\begin{array}{l}\text { Relative difference } \\
\text { (\%) in nuclide concentrations due to parameter changes }\end{array}$} \\
\hline & & ${ }^{239} \mathbf{P u}$ & Total Pu & ${ }^{235} \mathbf{U}$ & $\begin{array}{c}\text { Total } \\
\text { fissile }^{c}\end{array}$ & ${ }^{134} \mathrm{Cs} /{ }^{137} \mathrm{Cs}$ & ${ }^{244} \mathrm{Cm}$ \\
\hline BPR exposure & $\begin{array}{l}\text { empty vs. } \\
\text { inserted }\end{array}$ & -7.8 & -6.4 & -5.1 & -6.2 & -2.1 & -7.9 \\
\hline $\begin{array}{l}\text { Boron } \\
\text { concentration }\end{array}$ & $\pm 5 \%$ & 0.6 & 0.4 & 0.3 & 0.4 & 0.2 & 0.7 \\
\hline $\begin{array}{l}\text { Gd rod } \\
\text { exposure }\end{array}$ & $\begin{array}{l}\text { none vs. four } \\
\mathrm{Gd}^{d}\end{array}$ & 1.9 & 1.9 & 1.8 & 1.9 & 0.0 & 1.8 \\
\hline $\begin{array}{l}\text { Assembly } \\
\text { burnup }\end{array}$ & $\pm 2.5 \%$ & 0.3 & 2.1 & -7.4 & -4.1 & 4.5 & 22.6 \\
\hline Fuel Temp & $\pm 50 \mathrm{~K}$ & 1.2 & 0.9 & 0.7 & 0.9 & -0.2 & 0.4 \\
\hline
\end{tabular}

\footnotetext{
${ }^{a}$ The maximum in each category is highlighted in red and bold.

${ }^{b}$ These studies were based on the TMI-1 assembly NJ070G with a burnup of $45 \mathrm{GWd} / \mathrm{tU}$, an initial enrichment of $4.6 \%$, and a cooling time of 5 years.

${ }^{c}$ Combined mass of ${ }^{235} \mathrm{U},{ }^{239} \mathrm{Pu}$, and ${ }^{241} \mathrm{Pu}$.

${ }^{d}$ For the TMI-1 assemblies, there are only four gadolinia $(\mathrm{Gd})$ rods in total in one assembly.
} 



\section{APPLICATION OF NDA FOR SPENT FUEL CHARACTERIZATION}

NDA techniques are widely used for nuclear materials safeguards. These techniques rely on measurement of radiation emissions from nuclear material using neutron or gamma-ray detectors. These emissions can provide important information about the properties and contents of the nuclear material. Application of NDA to spent fuel safeguards has been more challenging due to the complexity of nuclear compositions and radiation emissions in irradiated fuel, and the need to perform assembly measurements in water pools which restricts the types of instruments and detectors that can be used. Although some active NDA methods have been applied at reprocessing facilities, most operational spent fuel measurements currently rely on conventional passive NDA systems to perform verification of the spent fuel burnup and cooling time and to determine other parameters of the fuel.

The development of spent fuel calibration standards described thus far in the report relies extensively on information about the fuel design and operating conditions as provided by the reactor operator. Such information will be essential to develop assembly standards with well-known fuel compositions, and having the full cooperation of the reactor operator is a prerequisite for standards development in the near term. However, operator data, itself derived from both measurements and code calculations, has uncertainties and in some instances may contain errors. Therefore, some degree of independent verification of the reactor data is considered prudent. NDA techniques provide information that may be used to both verify fuel data and potentially reduce the uncertainties in data by supplementing more accurate direct measurements. This would require the NDA data to have smaller uncertainties than data provided by the operator. Therefore, uncertainty analysis is a critical component of this work. In addition, some types of information, including the radial and axial burnup distribution within the assembly, may not always be available, and NDA may provide measurements that can supplement information from the operator.

\subsection{CONVENTIONAL NDA TECHNIQUES}

The focus of the NDA application for spent fuel characterization presented in this section is on the conventional passive NDA techniques currently in use. The advanced detectors developed under the NGSI program are not considered for this purpose, because they have not been calibrated. The reliance on conventional NDA instruments limits the information that can be obtained from spent fuel, because these instruments are limited to gross neutron, gross gamma, and gamma-ray spectroscopy. NDA is used most frequently to obtain estimates of burnup, but has also been used to derive other properties of the fuel including cooling time. This section reviews the conventional NDA techniques and instruments that are most often used to measure spent fuel and the associated uncertainties.

Most of the conventional NDA instruments are based primarily on the following two techniques: total neutron and passive gamma techniques. Passive neutron and gamma stand for the neutron and gamma radiation, respectively, emitted directly from the irradiated fuel without the presence of external radiation sources.

\subsubsection{Passive Neutron}

Spent nuclear fuel emits neutrons primarily through the spontaneous fission of higher actinides, such as curium, that grows with burnup roughly to the fourth power. The accumulation of curium is extremely sensitive to the fuel burnup. Fission chambers are commonly used to measure neutrons from spent fuel. The measured neutron signal may be used to infer the fuel burnup. However, there are several significant complications to neutron measurements: 1) passive neutrons (e.g., ${ }^{242} \mathrm{Cm}$ and ${ }^{244} \mathrm{Cm}$ ) induce fissions from fissile nuclides in the fuel (e.g., ${ }^{235} \mathrm{U}$ and ${ }^{239} \mathrm{Pu}$ ) that generate secondary fission neutrons and contribute to the measured signal, 2) neutron-absorbing nuclides (e.g., ${ }^{149} \mathrm{Sm}$ and ${ }^{155} \mathrm{Gd}$ ) can reduce the neutron signal, and 3) neutrons from $(\alpha, n)$ reactions can contribute significantly to the neutron signal, especially when 
the fuel burnup is relatively low. The multiplication of the neutron signal from secondary fission depends not only on the concentration of fissile and absorbing nuclides in the fuel but also on the configuration (dimensions and spacing of the fuel rods) of the assemblies and on the pool conditions (e.g., boron concentration, as boron also absorbs neutrons).

Although neutron measurement can be used to verify operator data with the assistance of advanced modeling and simulation, it cannot be readily used for the purpose of spent fuel characterization, given the previously discussed complications.

\subsubsection{Passive Gamma}

Spent fuel emits gamma-ray radiation, primarily through the decay of fission products. The fission products that are most frequently observed in gamma spectra from spent fuel include ${ }^{134} \mathrm{Cs},{ }^{137} \mathrm{Cs},{ }^{144} \mathrm{Ce}$,

${ }^{154} \mathrm{Eu},{ }^{106} \mathrm{Ru},{ }^{125} \mathrm{Sb}$, and others. The passive gamma technique usually examines two aspects of the gamma radiation: the total gamma emission rate (gross gamma) and the gamma energy spectrum. The gamma spectrum can be used to identify specific gamma lines (energies) that are characteristic of specific nuclides. The intensity of these lines can then be used to infer the amount of the source nuclides in the fuel. Gamma spectra are of special interest to spent fuel nuclear safeguards because the inferred fission products (from measured gamma spectra) provide information on how the fuel has been irradiated and, in particular, the burnup. However, attenuation of gamma rays is substantial within a fuel assembly; it is therefore challenging to infer the amount of the source nuclides from gamma measurements performed at the periphery of an assembly. Signal corrections are needed to account for gamma-ray self-attenuation. As a consequence, count rate ratios (instead of absolute counts) are frequently used to infer the mass ratio of the source nuclides. In addition to the attenuation problem, gross gamma has other complications for the purpose of spent fuel characterization; for spent fuel with relatively short cooling time, gross gamma is very sensitive to the power level at which the fuel was last irradiated. For fuels with long cooling time, gross gamma is normally considered as proportional to burnup. Gross gamma is often measured by ion chambers, while the gamma energy spectrum is usually measured with High-Purity Germanium (HPGe), and cadmium-zinc-telluride (CZT) detectors.

\subsection{NDA INSTRUMENTS}

Table 5 summarizes the conventional NDA instruments used to characterize or measure spent nuclear fuel. Also included are the measured signals, the advantages, and the disadvantages (in the context of spent fuel measurement or characterization) of each NDA technique. The details of each NDA instrument are further discussed below.

\subsubsection{High-Purity Germanium (HPGe)}

HPGe detectors are a type of semiconductor diode with a high-energy resolution, which allows excellent gamma energy peak distinction in measured gamma spectra (from either solid fuel or solution). Major contributors to the gamma spectrum in spent fuel include ${ }^{134} \mathrm{Cs},{ }^{137} \mathrm{Cs}$, and ${ }^{154} \mathrm{Eu}$, with ${ }^{134} \mathrm{Cs}$ and ${ }^{154} \mathrm{Eu}$ having multiple major peaks. While different configurations are available, all HPGe detectors basically consist of a detector crystal with a preamplifier which is mounted under vacuum typically in an aluminum cap. The difficulty in using the detector is the necessity to cool it to around $-196{ }^{\circ} \mathrm{C}$ with either liquid nitrogen or an electrically powered cryogenic refrigerator $[10,22]$, which generally prohibits the usage of HPGe for in-pool measurements frequently required for spent fuel assemblies. 
Table 5. List of conventional NDA instruments used to characterize or measure spent nuclear fuel

\begin{tabular}{|c|c|c|c|}
\hline Instrument & Measured signals & Advantages & Disadvantages \\
\hline $\begin{array}{c}\text { High-Purity } \\
\text { Germanium (HPGe) }\end{array}$ & Gamma spectrum & High resolution & $\begin{array}{c}\text { Cooling requirements restrict } \\
\text { use in water pools. }\end{array}$ \\
\hline $\begin{array}{c}\text { Cadmium-Zinc- } \\
\text { Telluride (CZT) }\end{array}$ & Gamma spectrum & $\begin{array}{c}\text { Moderate energy resolution. } \\
\text { No cooling requirement, more } \\
\text { flexible than HPGe. }\end{array}$ & $\begin{array}{c}\text { Lower energy resolution than } \\
\text { HPGe }\end{array}$ \\
\hline $\begin{array}{c}\text { Cerenkov Viewing } \\
\text { Device (CVD) }\end{array}$ & Cerenkov light & $\begin{array}{c}\text { Portable, easy to use and } \\
\text { maintain. }\end{array}$ & $\begin{array}{c}\text { Offers a qualitative but not } \\
\text { quantitative measurement. }\end{array}$ \\
\hline Fork Detector & $\begin{array}{c}\text { Total neutron (fission } \\
\text { chamber) and gross } \\
\text { gamma (ion chamber) }\end{array}$ & $\begin{array}{c}\text { Neutron signal has good } \\
\text { penetration. Widely used by } \\
\text { safeguards authorities. }\end{array}$ & $\begin{array}{c}\text { No energy information. } \\
\text { Measurements made at outer } \\
\text { surface of assembly are } \\
\text { subject to attenuation. }\end{array}$ \\
\hline $\begin{array}{c}\text { Spent Fuel Attribute } \\
\text { Testor (SFAT) }\end{array}$ & $\begin{array}{c}\text { Gamma lines of a few } \\
\text { fission products }\end{array}$ & $\begin{array}{c}\text { Portable, easy to use and } \\
\text { maintain. }\end{array}$ & $\begin{array}{c}\text { Measures only fission } \\
\text { products. }\end{array}$ \\
\hline $\begin{array}{c}\text { Partial defect } \\
\text { DETector (PDET) }\end{array}$ & $\begin{array}{c}\text { Total neutron and } \\
\text { gross gamma }\end{array}$ & $\begin{array}{c}\text { Detectors provide } \\
\text { measurements at locations } \\
\text { throughout (inside) the } \\
\text { assembly. }\end{array}$ & $\begin{array}{c}\text { Difficult to correlate neutron } \\
\text { signal to local burnup. }\end{array}$ \\
\hline
\end{tabular}

\subsubsection{Cadmium-Zinc-Telluride (CZT)}

The CZT detector is a room-temperature semiconductor detector that can measure the gamma spectrum of spent fuel with moderate energy resolution. Because it does not require active cooling, CZT can be used for in-pool measurement. For example, a CZT detector has been used in combination with the fission and ionization chambers in a Fork detector [22] for spent fuel measurements, enabling simultaneous measurements of passive neutron, gross gamma, and gamma energy spectra. The ability to measure gamma spectrum, rather than just gross gamma, is a significant improvement over the conventional Fork detector. The CZT detector has more flexibility than HPGe for spent fuel measurement because it does not have strict cooling requirements.

\subsubsection{Cerenkov Viewing Devices (CVD)}

Cerenkov viewing devices typically measure the light produced in the water from gamma-ray excitations. This device is used to detect partial defects of a spent fuel assembly by judging if the Cerenkov glow is present at fuel rod locations. Although the CVD is widely used for spent fuel verification at nuclear facilities, it does not provide a quantitative measure of the fuel. It can also be challenged by low-burnup and poor water clarity. Therefore, it is not considered as useful for the current study.

\subsubsection{Fork Detector}

The Fork detector is widely used in operational measurements of spent fuel safeguards to verify operator declaration and to detect partial defects (e.g., missing nuclear material). This device is usually equipped with an ionization chamber and two fission chambers on each arm to measure gross gamma and total neutron respectively. Past experience with the Fork detector suggests that it can only detect partial defect when $50 \%$ or greater amounts of fuel rods are removed or replaced [23]. In some cases, the Fork detector 
is also equipped with a CZT detector, adding the capability of measuring the gamma spectrum. Recent work has shown that by coupling with advanced modeling and simulation, the Fork detector can be used to verify operator declarations of burnup with relatively low uncertainties (e.g., $~ 5 \%$ ) [24]. Based on these recent new findings, a Fork detector can potentially be used to independently verify operatorprovided assembly burnup and operating history data.

\subsubsection{Spent Fuel Attribute Tester (SFAT)}

A SFAT detection system makes use of a CZT detector to detect the presence/absence of ${ }^{137} \mathrm{Cs}$ in spent fuel [25]. It typically measures the upper fraction of the assembly. Given the significant attenuation in the system, it is difficult to quantitatively relate the measured signal to source nuclide concentrations in the fuel assembly. This device is intended to provide qualitative measurement of one of the dominant fission products.

\subsubsection{Partial defect DETector (PDET)}

PDET was developed with the goal to detect missing fuel rods in spent fuel assemblies [26]. Although this device is currently still under development and not used operationally, it is included in the discussion because PDET test measurements are planned at the ROK and SKB spent fuel facilities together with other NGSI-SF measurement campaigns. Consequently, there is an opportunity to explore the application of PDET results for developing calibration assemblies. PDET is equipped with ion chambers to measure gross gamma and fission chambers to measure total neutrons, similar to the Fork detectors. It resembles the PWR control rod cluster that can be inserted into empty guide tube locations within the assembly to measure the local (spatial) neutron and gamma intensities within the assembly. PDET is unique because it is the only NDA instrument that measures the interior of an assembly, thereby providing information on the spatial distribution of radionuclide in different fuel rods of the assembly. In this work it is found that the gamma measurement of PDET may be used to infer the burnup distribution of the assembly when distributions are not available from the operator. More details on the application of PDET to spent fuel characterization are presented in the next section.

\subsection{DETERMINATION OF BURNUP USING GAMMA NDA}

Fuel burnup, both the assembly average and the distribution within the assembly, is an important factor that influences the fuel compositions and detector response. The uncertainties associated with gamma NDA measurements of fuel burnup are discussed in the following subsections, and are also demonstrated through examples.

Several gamma emitters are widely used in safeguards to estimate burnup in spent fuel. Many techniques rely on ratios of gamma-emitting isotopes instead of absolute measurements. Ratios are advantageous because uncertainties in detection efficiency and fuel attenuation can be largely eliminated when gamma lines with similar energies are used. Three widely used fission products gamma ratios in spent fuel are

$$
\begin{aligned}
& \text { - }{ }^{134} \mathrm{Cs} /{ }^{137} \mathrm{Cs}, \\
& \text { - }{ }^{154} \mathrm{Eu} /{ }^{137} \mathrm{Cs}, \text { and } \\
& \text { - }\left({ }^{134} \mathrm{Cs} /{ }^{137} \mathrm{Cs}\right) /\left({ }^{2}{ }^{106} \mathrm{Ru} /{ }^{137} \mathrm{Cs}\right) \text {. }
\end{aligned}
$$


The fission product ${ }^{137} \mathrm{Cs}$ is the most widely used NDA measure of spent fuel due to its large fission yield and long half-life, high-intensity gamma line $(662 \mathrm{keV})$, and very linear correlation with fuel burnup, which is a derived quantity related to the total number of fissions that occurred in the fuel. The fission products ${ }^{134} \mathrm{Cs}$ and ${ }^{154} \mathrm{Eu}$, which also have large activities and emit high-intensity gamma lines in spent fuel, are actually not produced directly by fission. Unlike ${ }^{137} \mathrm{Cs}$, these two isotopes are produced indirectly via neutron capture of other direct yield fission products (e.g. ${ }^{133} \mathrm{Cs} \rightarrow{ }^{134} \mathrm{Cs} ;{ }^{153} \mathrm{Eu} \rightarrow{ }^{154} \mathrm{Eu}$ ). The production of ${ }^{134} \mathrm{Cs}$ and ${ }^{154} \mathrm{Eu}$ therefore involves two processes - fission followed by neutron capture resulting in quadratic trend with burnup (i.e., $\sim \mathrm{BU}^{2}$ ). Hence, the ratios of ${ }^{134} \mathrm{Cs} /{ }^{137} \mathrm{Cs}$ and ${ }^{154} \mathrm{Eu} /{ }^{137} \mathrm{Cs}$ trend quasi-linearly with burnup. Gamma lines from ${ }^{134} \mathrm{Cs},{ }^{137} \mathrm{Cs}$, and ${ }^{154} \mathrm{Eu}$ can be easily identified in spent fuel. The mass ratios of ${ }^{134} \mathrm{Cs} /{ }^{137} \mathrm{Cs}$ and ${ }^{154} \mathrm{Eu} /{ }^{137} \mathrm{Cs}$ can thus be inferred using the characteristic gamma lines from each nuclide. Figure 4 shows the calculated ratios of (a) ${ }^{134} \mathrm{Cs} /{ }^{137} \mathrm{Cs}$ and (b) ${ }^{154} \mathrm{Eu} /{ }^{137} \mathrm{Cs}$ with burnup for a typical PWR fuel assembly.

There are several limitations and complications with the use of these ratios as discussed below.

1) Neutron spectrum. Because ${ }^{134} \mathrm{Cs}$ and ${ }^{154} \mathrm{Eu}$ are produced through neutron capture reaction of ${ }^{133} \mathrm{Cs}$ and ${ }^{153} \mathrm{Eu}$, respectively, their production rates are dependent on the neutron spectrum in the fuel. Because the neutron spectrum is dependent on the fuel design, composition, and operating conditions of the reactor, the relationship between ${ }^{134} \mathrm{Cs}$ and ${ }^{154} \mathrm{Eu}$ and burnup is assembly dependent. Figure 5(a) shows the correlation between the ${ }^{134} \mathrm{Cs} /{ }^{137} \mathrm{Cs}$ ratio and burnup as measured using DA nuclide data from Takahama-3 spent fuel samples [27]. As shown, the ${ }^{134} \mathrm{Cs} /{ }^{137} \mathrm{Cs}$ ratio in the $\mathrm{UO}_{2}$-Gd rod has a different slope from the standard $\mathrm{UO}_{2}$ fuel rods caused primarily by the different enrichments of these rods and the presence of gadolinium. Smaller differences between the two $\mathrm{UO}_{2}$ fuel rods are also observed due to different fuel rod locations and power histories (discussed further in the next item).

2) Decay time. Both ${ }^{134} \mathrm{Cs}$ and ${ }^{154} \mathrm{Eu}$ have relatively short half-lives, around 2 years and 8.6 years, respectively, compared to ${ }^{137} \mathrm{Cs}$, which has a relatively long half-life of about 30 years. For fuels with very long decay times, the ${ }^{134} \mathrm{Cs}$ and ${ }^{154} \mathrm{Eu}$ can decay to undetectable levels. As shown in Fig. 6 (a), the ${ }^{134} \mathrm{Cs} /{ }^{137} \mathrm{Cs}$ ratio has distinctly different slopes in fuels with different cooling times. Because ${ }^{134} \mathrm{Cs}$ has a relatively short half-life, decay is occurring even during irradiation. Therefore the irradiation time and power history can have a significant effect on the concentration at the time of measurement. As shown in Fig. 7(a), fuel with a higher power level has higher ${ }^{134} \mathrm{Cs} /{ }^{137} \mathrm{Cs}$ ratio compared to lower power fuel for the same burnup. This difference is driven primarily by the larger in-reactor decay during irradiation in the lower power fuel, because a longer irradiation time is required to achieve the same burnup level.

3) Nonlinearity. Both ${ }^{134} \mathrm{Cs}$ and ${ }^{154} \mathrm{Eu}$ exhibit non-linear trends with burnup (Fig. 4). The non-linear behavior of ${ }^{134} \mathrm{Cs} /{ }^{137} \mathrm{Cs}$ is caused primarily by the decay of ${ }^{134} \mathrm{Cs}$ during irradiation. The ${ }^{154} \mathrm{Eu}$ has a longer half-life than ${ }^{134} \mathrm{Cs}$. However, the ${ }^{239} \mathrm{Pu}$ fission yield for ${ }^{153} \mathrm{Eu}$ (precursor of ${ }^{154} \mathrm{Eu}$ ) is about twice the value for ${ }^{235} \mathrm{U}$ fission, causing increased ${ }^{154} \mathrm{Eu}$ production with increasing burnup until ${ }^{239} \mathrm{Pu}$ saturates in higher burnup. Also, more ${ }^{154} \mathrm{Eu}$ is lost to neutron absorption because it has relatively large neutron capture cross sections. The combined effect of these two factors leads to the saturation of ${ }^{154} \mathrm{Eu}$ in higher burnup fuel, which limits the use of ${ }^{154} \mathrm{Eu} /{ }^{137} \mathrm{Cs}$ as a burnup indicator for high-burnup fuel. 


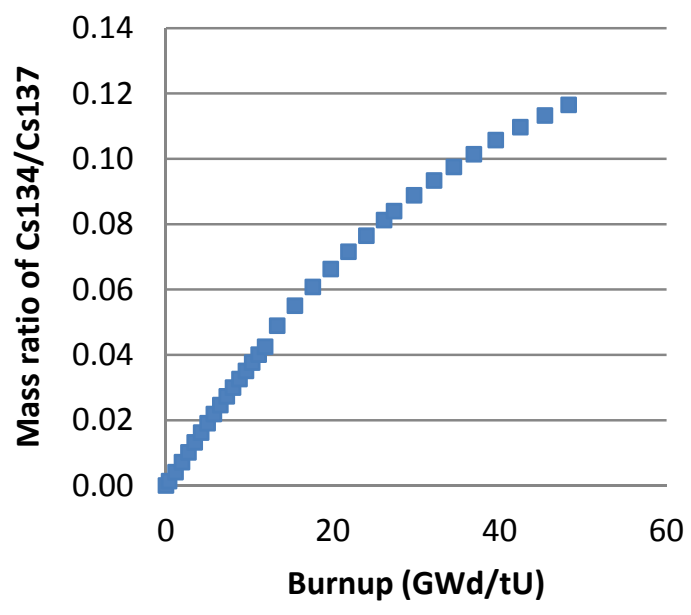

(a) the ${ }^{134} \mathrm{Cs} /{ }^{137} \mathrm{Cs}$ ratio

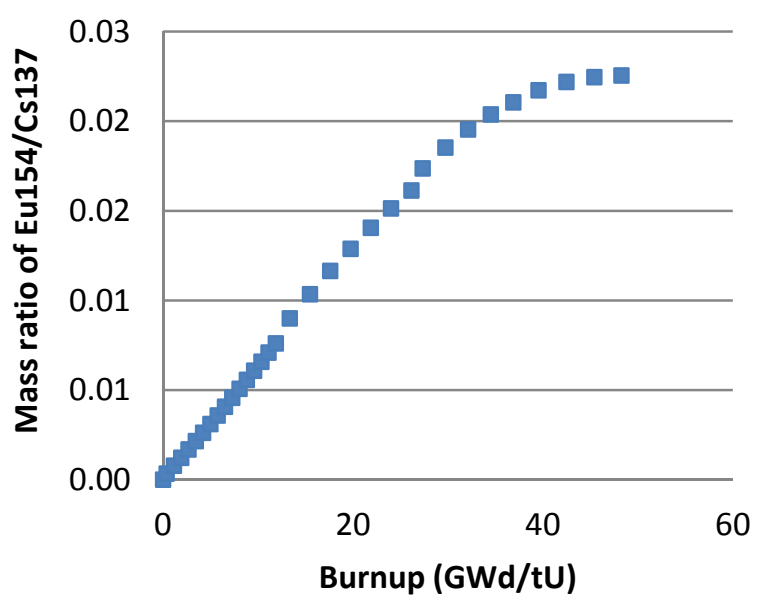

(b) the ${ }^{154} \mathrm{Eu} /{ }^{137} \mathrm{Cs}$ ratio

Fig. 4. Mass ratio of (a) ${ }^{134} \mathrm{Cs} /{ }^{137} \mathrm{Cs}$ and (b) ${ }^{154} \mathrm{Eu} /{ }^{137} \mathrm{Cs}$ with burnup.

Given these factors, detailed fuel and operating data are often required to properly interpret the gamma measurements and to correlate the gamma ratios to fuel burnup. However, the ratio of $\left({ }^{134} \mathrm{Cs} /{ }^{137} \mathrm{Cs}\right) /\left({ }^{2} \mathrm{Ru} /{ }^{137} \mathrm{Cs}\right)$, a less widely used measure, has shown some advantages over the ratios of ${ }^{134} \mathrm{Cs} /{ }^{137} \mathrm{Cs}$ and ${ }^{154} \mathrm{Eu} /{ }^{137} \mathrm{Cs}$ because it is less susceptible to the variation of initial enrichment and power history [27, 28]. As shown in Fig. 5(b), the ratio of $\left({ }^{134} \mathrm{Cs} /{ }^{137} \mathrm{Cs}\right){ }^{2} /\left({ }^{106} \mathrm{Ru} /{ }^{137} \mathrm{Cs}\right)$ trends well with burnup for the same set of data points as presented in Fig. 5(a). This ratio is less sensitive to cooling time than the ratio of ${ }^{134} \mathrm{Cs} /{ }^{137} \mathrm{Cs}$ as shown in Fig. 6(b). Fig. 7(b) shows that this ratio is also less sensitive to power history than ${ }^{134} \mathrm{Cs} /{ }^{137} \mathrm{Cs}$. One major drawback of this ratio is that ${ }^{106} \mathrm{Ru}$ has a short half-life (about 1 year). For assemblies with short cooling times ( $<5$ years), this ratio may be more accurate than the ${ }^{134} \mathrm{Cs} /{ }^{137} \mathrm{Cs}$ ratio in determining burnup, although more studies are needed to to assess the accuracies.

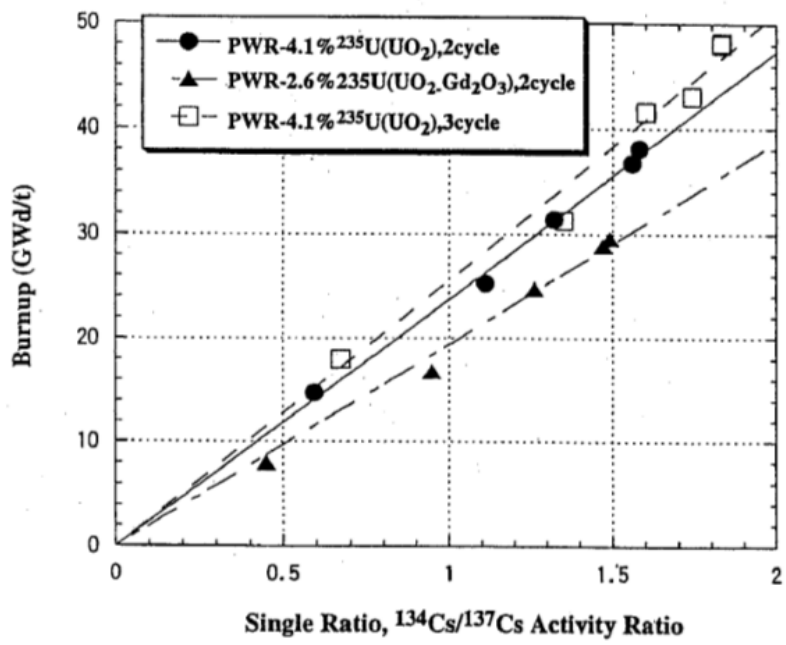

(a)

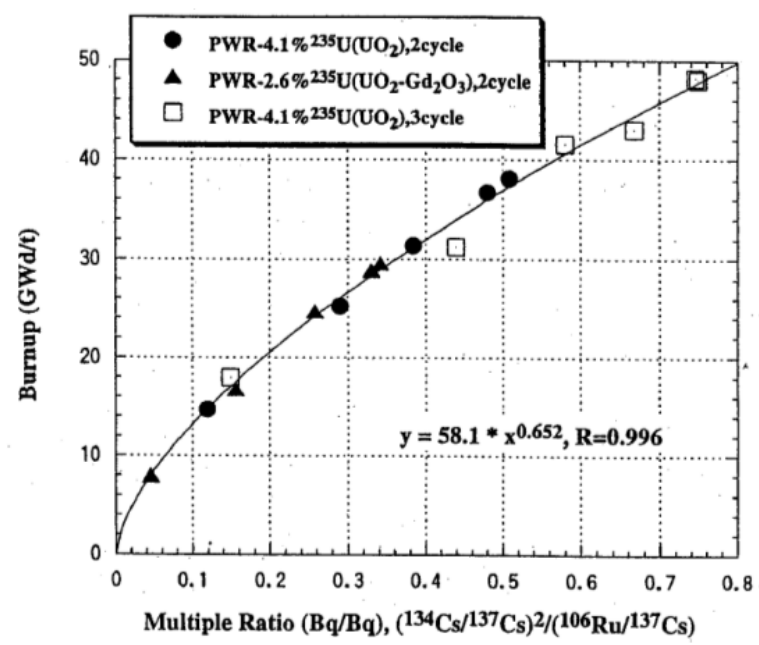

(b)

Fig. 5. Gamma ratios vs. Burnup: (a) activity ratio of ${ }^{134} \mathrm{Cs} /{ }^{137} \mathrm{Cs}$ vs. burnup (b) activity ratio of $\left({ }^{134} \mathrm{Cs} /{ }^{137} \mathrm{Cs}\right){ }^{2} /$ $\left({ }^{106} \mathrm{Ru} /{ }^{137} \mathrm{Cs}\right)$ vs. burnup in three different fuel rods [27] (the symbols represent measured data points). 


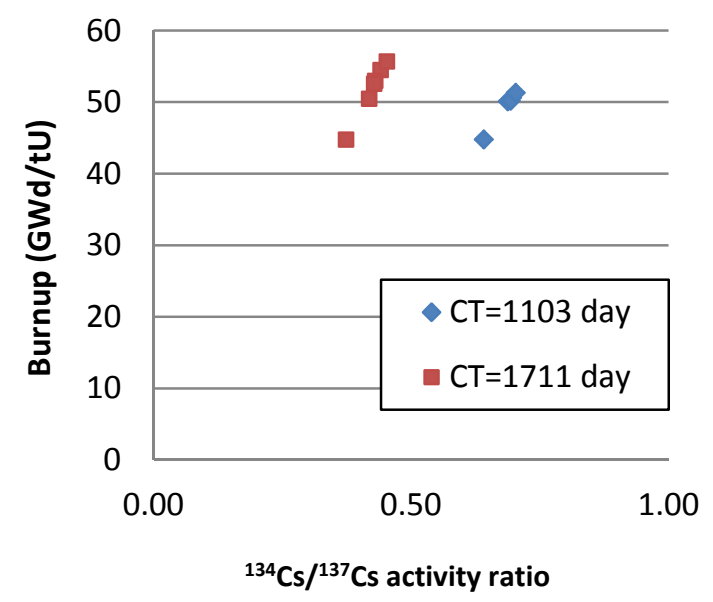

(a)

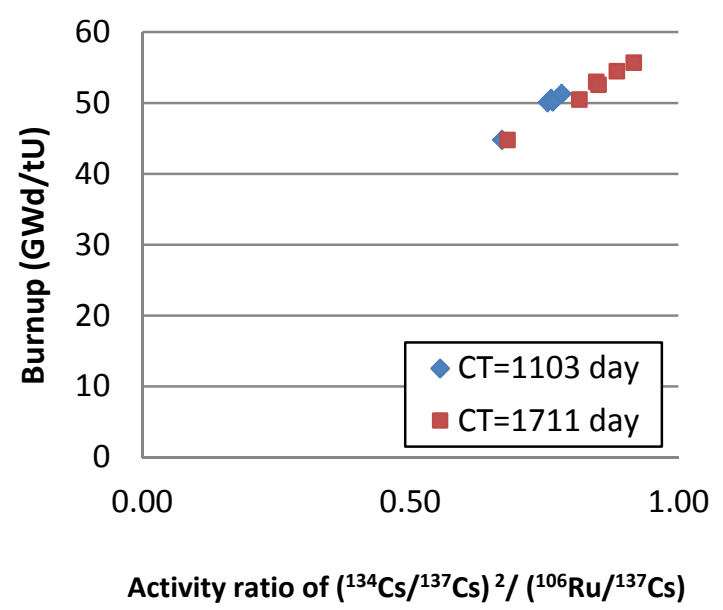

(b)

Fig. 6. Burnup vs. activity ratio at two different cooling times: (a) ${ }^{134} \mathrm{Cs} /{ }^{137} \mathrm{Cs}(\mathrm{b})$ $\left.\left({ }^{134} \mathrm{Cs} /{ }^{137} \mathrm{Cs}\right)\right)^{2} /\left({ }^{106} \mathrm{Ru} /{ }^{137} \mathrm{Cs}\right)$.

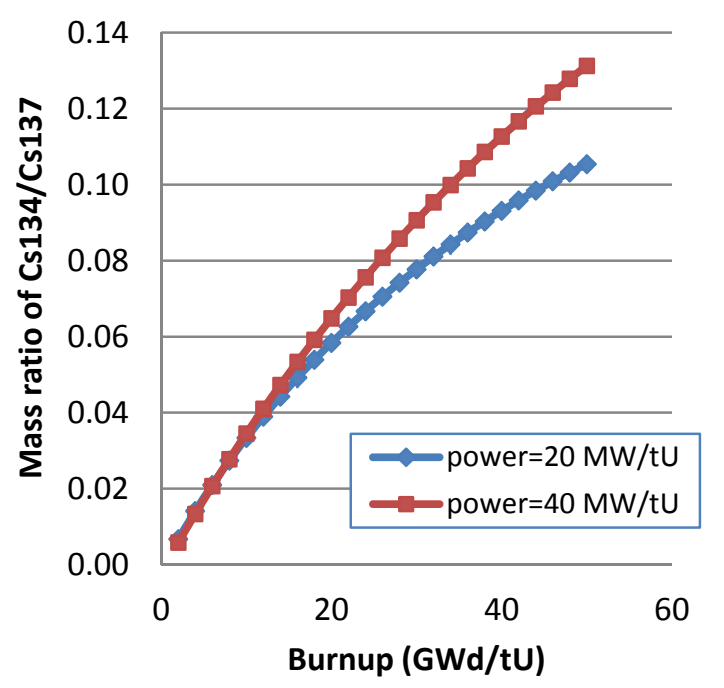

(a)

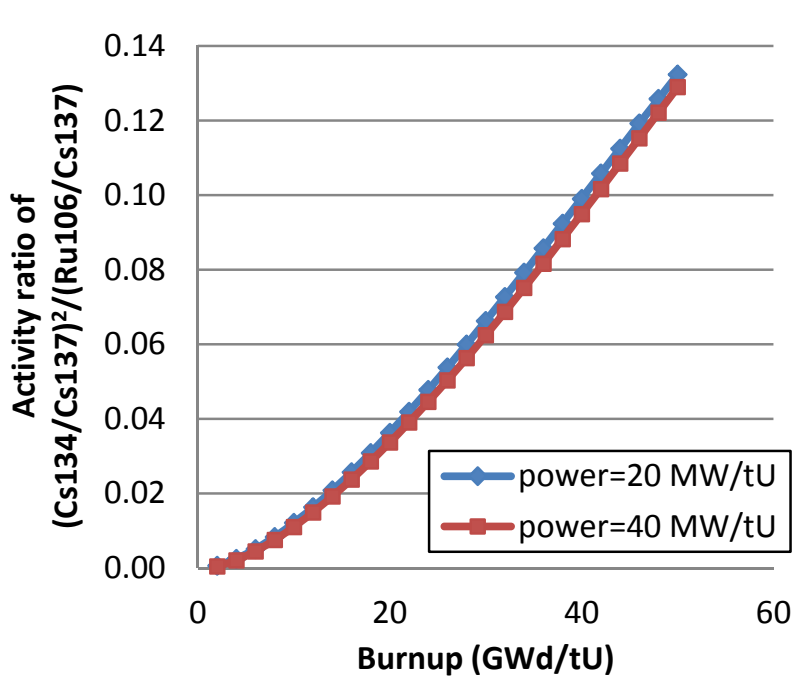

(b)

Fig. 7. Mass ratio vs. burnup at two different power levels: (a) ${ }^{134} \mathrm{Cs} /{ }^{137} \mathrm{Cs}$; (b) $\left({ }^{134} \mathrm{Cs} /{ }^{137} \mathrm{Cs}\right){ }^{2} /\left({ }^{106} \mathrm{Ru} /{ }^{137} \mathrm{Cs}\right)$.

One caveat of using ratios to determine burnup is that this method has mainly been demonstrated and applied to individual fuel rods. It is difficult to apply the technique to an entire spent fuel assembly because the gamma rays from interior rods are attenuated, and thus the measured gamma signals are dominated by the outer rods of the assembly. Therefore the burnup determined using gamma ratios may not be representative of the assembly average when there is a burnup gradient across the assembly. This effect may potentially be mitigated by performing NDA measurements on different sides of an assembly. (The gamma ratios can also be used as a relative tool on similar types of fuel assemblies.) In order to assess the distribution of burnup within an assembly, without first dismantling the assembly and measuring individual fuel rods, one or more of the following are needed to reduce uncertainties: operator-provided data; full-core reactor calculations that assess the impact of neighbor assemblies; and other operational factors (e.g., use of BPRs), or more intrusive NDA instruments such as a PDET that inserts detectors inside the assemblies. 


\subsection{ACCURACY OF NDA MEASUREMENT OF BURNUP}

Usage of NDA methods to estimate spent fuel burnup has been studied in the past, and the reported accuracies (compared to DA results) vary widely from $4 \%$ to $20 \%[22,29]$. As described earlier, multiple experimental programs (Table 1) have examined spent fuel for the purpose of providing benchmarks for computer models and codes. These programs included detailed operator data (e.g., estimates of assembly and fuel rod burnup, operating conditions, etc.); NDA measurements of the fuel (e.g., gamma scans); and also destructive measurements of the fuel concentrations. Three experimental programs were reviewed to estimate the typical accuracy that can be achieved by comparing burnup determinations made using both NDA (gamma spectroscopy) and destructive analysis (DA). The selected experiments include measurements for more than 50 different fuel samples from the Trino Vercellese (Italy) [5], Obrigheim (Germany) [5], and Vandellós (Spain) [16] reactors. The Trino Vercellese and Obrigheim measurements were conducted circa 1985 under a European experimental program, and the Vandellós measurements were performed in 2009 at Studsvik Nuclear Laboratory.

Figure 8 shows the relative difference (\%) between NDA and DA measured burnup in different spent fuel samples from the three aforementioned reactors. The NDA measured burnup was determined based on the ${ }^{137} \mathrm{Cs}$ content, measured using gamma spectrometry on individual fuel rods. The correlation between ${ }^{137} \mathrm{Cs}$ and burnup was established through a reference fuel rod calibrated using destructive measurements. The DA measured burnups were based on the amount of ${ }^{148} \mathrm{Nd}$ present in the samples, which was measured using mass spectrometry in the dissolved fuel sample solution. The correlation between ${ }^{148} \mathrm{Nd}$ and burnup has been well established through the standards of ASTM E 321 [30]. The uncertainties were 3-4\% in the NDA measurements [16] and 1-2\% for the DA measurements [5]. As shown, the NDA estimated burnup is within $6 \%$ of the destructive analysis values for the majority of the samples (i.e., the standard deviation is 6\%). It is also observed that the newer measurement data (Vandellós) have much smaller discrepancies, suggesting significant improvements have been made in reducing uncertainties in both NDA and DA measurements.

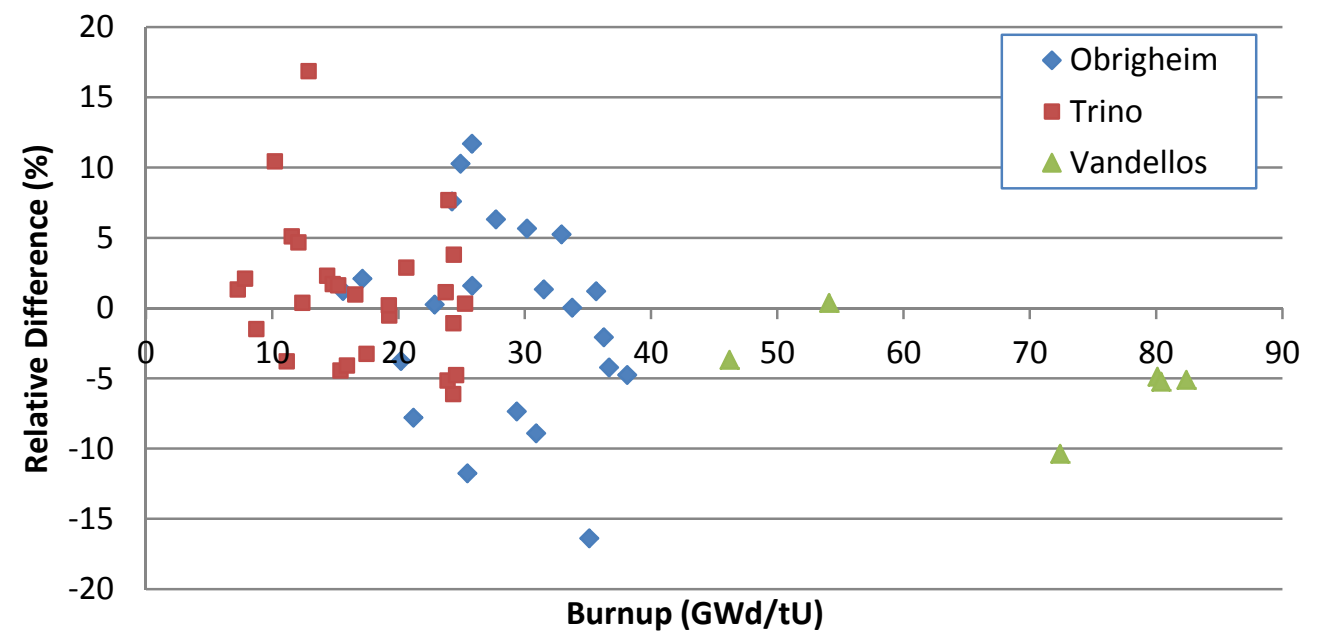

Fig. 8. Relative difference (\%) between NDA and DA measured burnup vs. burnup in fuel samples from three different reactors. 


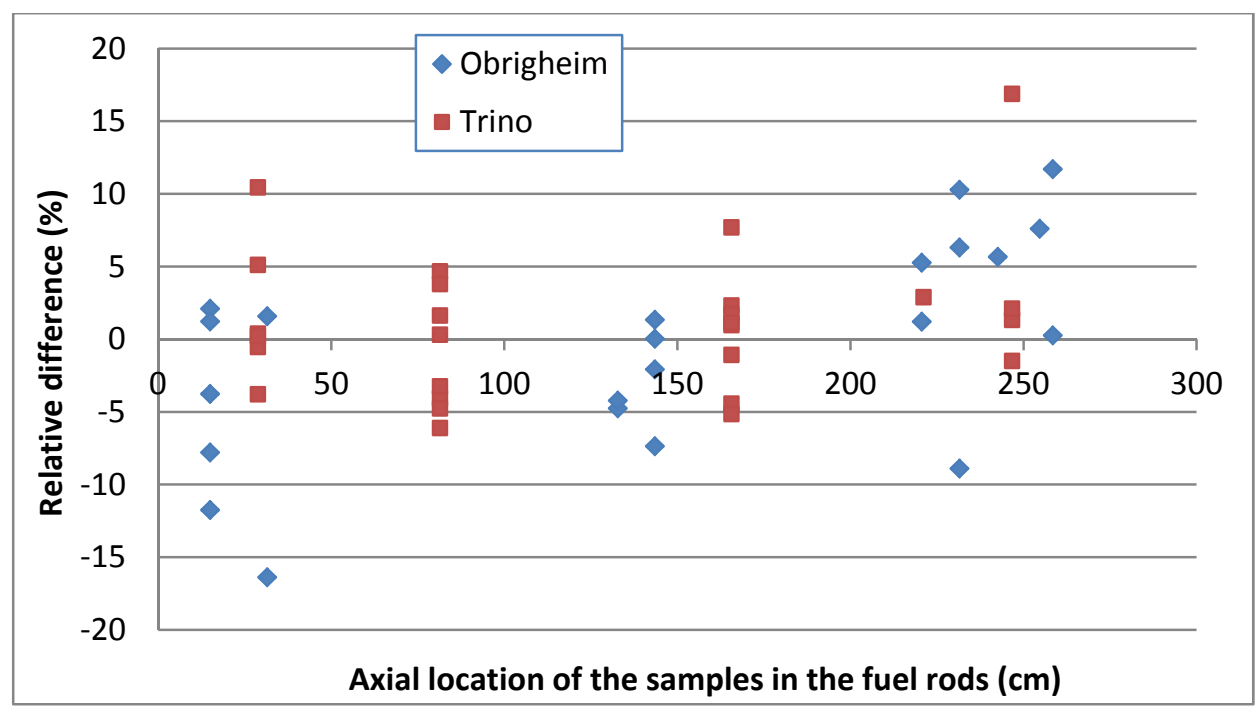

Fig. 9. Relative difference (\%) between NDA and DA measured burnup vs. axial locations in spent fuel samples from two different reactors.

Figure 9 presents the same two sets of data from Obrigheim and Trino but along the axial locations of the spent fuel samples in the fuel rods. The differences are greater on both ends of the fuel rods, especially for Obrigheim. This is expected because the burnup varies much more dynamically on both ends of fuel rods than in the middle. The uncertainties existing in the conversions from measured ${ }^{137} \mathrm{Cs}$ (using NDA) and measured ${ }^{148} \mathrm{Nd}$ (using DA) to burnup also contribute to the observed differences in these burnup results. Although both ${ }^{137} \mathrm{Cs}$ and ${ }^{148} \mathrm{Nd}$ are excellent burnup indicators, there still exist small differences in fission yields of these two nuclides among the fissioning nuclides (and the fraction of fission caused by each of these fissioning nuclides varies from one fuel to another), thus resulting in uncertainties in the correlated burnup.

Table 6 compares fuel burnups determined using these same two techniques for the more recently measured Vandellós fuel [16]. The burnup values determined by these two methods are in good agreement, with a standard deviation of $1.7 \%$. These results provide an optimistic assessment of NDA performance, because these measurements are performed under the controlled conditions within a hot cell, and the burnup of the samples was similar.

With the examples described above and the recent improvement in NDA techniques, the NDA measurements (gamma spectroscopy with HPGe) usually have low uncertainties on the fuel rod level (2-5\%). Through integration of experimental data, detailed operator data, and modeling and simulation tools, NDA measurements can be used to infer burnup relatively accurately for a measured fuel rod. However, as previously discussed, it is much more challenging and there will be additional uncertainties when applying this method to the fuel assembly level given the burnup variations within an assembly. The requirement of in-pool measurement under many safeguards situations presents additional challenges to NDA measurements. 
Table 6. Comparison of burnup determined from DA and NDA for Vandellos samples [16]

\begin{tabular}{|l|c|c|c|}
\hline $\begin{array}{l}\text { Sample ID } \\
\text { Uncertainty }\end{array}$ & $\begin{array}{c}\text { DA measured burnup } \\
\text { (GWd/tU) (inferred } \\
\left.\text { from }{ }^{\mathbf{4 1 8}} \mathbf{N d}\right)\end{array}$ & $\begin{array}{c}\text { NDA measured burnup } \\
\text { (GWd/tU) (inferred from } \\
\text { gamma scan of }{ }^{\mathbf{1 3 7}} \mathbf{C s )}\end{array}$ & $\begin{array}{c}\text { Difference } \\
\mathbf{( \% )}\end{array}$ \\
\hline ENUSA-1 & $50.7+/-0.7$ & 50.6 & -0.20 \\
\hline ENUSA-2 & $51.0+/-0.9$ & 50.6 & -0.78 \\
\hline ENUSA-3 & $49.8+/-0.5$ & 50.4 & 1.20 \\
\hline ENUSA-4 & $53.6+/-1.6$ & 53.9 & 0.56 \\
\hline ENUSA-5 & $44.3+/-0.9$ & 43.9 & -0.90 \\
\hline ENUSA-6 & $44.3+/-0.9$ & 44.3 & 0.00 \\
\hline ENUSA-7 & $48.5+/-0.6$ & 50.4 & 3.92 \\
\hline ENUSA-8 & $38.4+/-0.9$ & 39.6 & 3.13 \\
\hline
\end{tabular}

\subsection{APPLICATIONS OF PDET}

Although PDET is under development and has not been used in operational measurements, it could potentially be used to measure radial burnup distribution within an assembly in situations where such information is not available from the reactor operator. This instrument is being tested with the ROK and SKB assemblies (also selected for the field tests of the NGSI advanced NDA instruments).

Figure 10 shows a PDET instrument [31] customized for PWR fuel assemblies. This device can be inserted into the guide tubes of the assembly to measure the total gamma and neutron counts using small ion chambers and fission chambers, respectively, at each guide tube location at the same axial level. For a typical $17 \times 17$ assembly design, up to 24 different guide tube locations are available to perform measurements. The gamma counts are proportional to the burnup of the fuel rods surrounding each guide tube because cooling time is the same within an assembly. Measurements have been performed on a few spent fuel assemblies at a ROK spent fuel facility [8], and the gamma results were used to reconstruct the pin-by-pin burnup map of the assembly. The pin-by-pin burnup map was also available from the operator for these assemblies.

For these $14 \times 14$ PWR assemblies, PDET measurements were taken in 16 guide tube channels. Because the PDET does not measure all 179 fuel rods in the assembly, interpolation and extrapolation are needed to reconstruct the pin-by-pin burnup. The gamma counts collected by PDET in the 16 guide tubes provide the burnup profile among all the guide tube locations, from which the burnup distribution of all fuel rods can be inferred using interpolation/extrapolation. This distribution is then multiplied by the assembly average burnup (usually provided by operator) to yield the absolute burnup in each fuel rod.

Figure 11(a) compares the pin-by-pin burnup map inferred from PDET data against the map provided by operator. Interpolation based only on the burnup of corner pins was also compared to operator data as shown in Fig. 11(b) in order to assess the ability of estimating burnup profiles based on NDA measurements (e.g., gamma scan) on corner rods. Large uncertainties are observed in both sets of data. PDET data are in better agreement with the operator data than the corner data, especially on the interior fuel pins. This study is based on old PDET measurements in 2005; note that PDET has been improved 
significantly since that time [8]. These different distributions are all tested for detector responses, and will be discussed in Section 7.

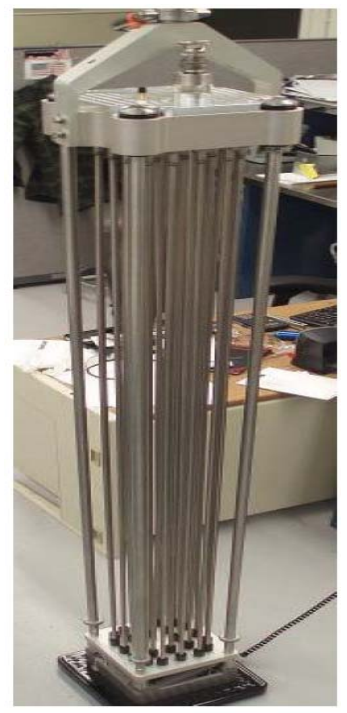

Fig. 10. A picture of PDET [31].

\begin{tabular}{|c|c|c|c|c|c|c|c|c|c|c|c|c|c|}
\hline 3.0 & -0.1 & -1.8 & -0.9 & 2.3 & 2.9 & 3.2 & 3.7 & 3.4 & 2.8 & 0.3 & -0.4 & 1.3 & 4.3 \\
\hline 0.1 & -3.7 & -7.1 & -5.5 & 0.0 & -1.3 & -0.6 & 0.4 & -0.9 & 0.3 & -4.0 & -5.6 & -2.3 & 1.5 \\
\hline-1.3 & -5.8 & & -10.8 & -3.7 & & -4.1 & -3.1 & & -3.4 & -9.6 & & -4.9 & -0.3 \\
\hline-1.8 & -7.8 & -10.5 & -1.4 & -3.7 & -2.1 & -4.9 & -1.3 & -4.4 & -3.0 & -3.3 & -8.1 & -7.0 & -1.1 \\
\hline 2.6 & 0.5 & -4.2 & -4.9 & & -4.0 & -2.4 & -0.9 & -2.0 & & -5.2 & -3.7 & 0.3 & 2.5 \\
\hline 4.1 & 0.4 & & -4.6 & -2.4 & -1.9 & -2.3 & 0.2 & 1.3 & -1.8 & -5.2 & & -1.6 & 3.2 \\
\hline 4.4 & 0.6 & -2.3 & -3.3 & -1.7 & -2.1 & & -0.9 & 1.4 & -0.8 & -3.1 & -2.3 & 1.0 & 4.4 \\
\hline 4.9 & 1.5 & -3.5 & -4.7 & -1.3 & 0.0 & -1.1 & 0.5 & 1.3 & -0.1 & -2.4 & -3.0 & 1.5 & 4.7 \\
\hline 4.2 & -0.6 & & -0.7 & -1.1 & 0.9 & 1.2 & 1.3 & 1.0 & -0.7 & -0.6 & & -1.1 & 3.7 \\
\hline 4.0 & 2.2 & -2.4 & -0.7 & & -0.2 & -0.7 & -1.2 & -0.5 & & -2.4 & -2.9 & 1.5 & 3.6 \\
\hline-0.1 & -6.1 & -9.4 & -9.0 & -6.4 & -5.2 & -2.5 & -5.0 & -5.9 & -7.4 & -9.9 & -9.2 & -4.4 & 0.6 \\
\hline 0.5 & -4.7 & & -7.7 & -3.6 & & -4.8 & -4.3 & & -3.7 & -9.4 & & -4.6 & 0.6 \\
\hline 3.0 & -0.7 & -4.4 & -4.3 & 1.2 & 1.1 & 1.7 & 0.6 & -1.9 & 0.7 & -6.3 & -3.4 & -0.4 & 3.1 \\
\hline 6.4 & 3.3 & 1.3 & 1.2 & 4.2 & 5.2 & 5.4 & 4.3 & 3.1 & 2.9 & -0.3 & 1.2 & 3.4 & 6.2 \\
\hline
\end{tabular}

(a) PDET data

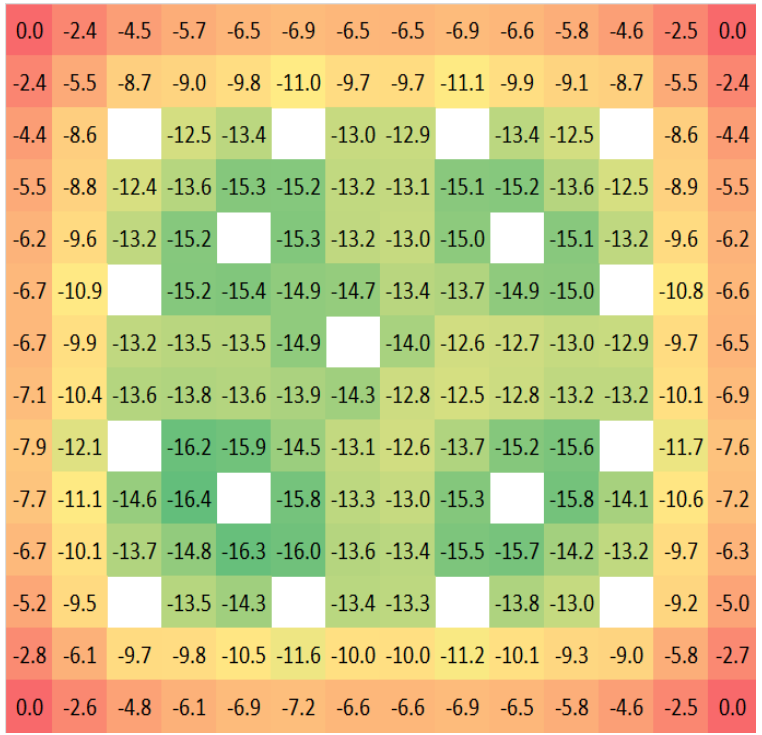

(b) Corner data

Fig. 11. Relative difference (\%) in burnup for a ROK assembly compared to operator-provided pin-by-pin burnups, using pin-by-pin burnup estimates based on (a) PDET gamma measurements in guide tubes and (b) operator data at the corner pins. 



\section{SPENT FUEL ASSEMBLY MODELING AND SIMULATION METHODS}

As previously discussed, spent fuel assembly nuclide compositions are needed for advanced NDA instrument calibration and to support detector performance simulations. The accuracy of the nuclide compositions will play an important role in defining the accuracy that can be achieved using advanced NDA instruments. Computational analysis of the spent fuel assembly compositions is necessary to determine the assembly compositions and will be an important component of the calibration procedure.

Two software packages that are widely used internationally for spent fuel composition calculations are SCALE and MCNP [32]. SCALE includes several modules to perform the neutron transport calculations necessary to simulate the assembly during irradiation in the reactor and uses the ORIGEN code [33] to calculate the isotopic evolution and decay. MCNPX [34] internally couples MCNP with CINDER [35] (an inventory code), while Monteburns [36] externally couples MCNP with CINDER or ORIGEN, to perform burnup calculations. Commercial core simulator codes, such as CASMO and SIMULATE, are generally not applicable for comprehensive characterization of spent fuel because they track a limited set of isotopes required for reactor physics modeling. However, CMS does include a spent fuel analysis capability in the SNF code which provides a more complete set of approximately 350 nuclides. However, this is much smaller than the more than 2000 nuclides tracked by ORIGEN or CINDER. Both SCALE and MCNP transport and depletion capabilities are applied in this work.

\subsection{MODELING REQUIREMENTS}

An important requirement of the modeling and simulation codes for this project is the need to accurately represent the three-dimensional (3-D) variation of the nuclide compositions of the assembly, radially (pinby-pin) and axially. Variations in the compositions within an assembly will directly impact the measured signals of advanced NDA instruments. These variations can be caused by many factors including asymmetric power gradients from neighbor assemblies, leakage at the core boundaries, control rod exposure, layout of guide tubes, BPRs, and other operating conditions. Key requirements include the ability to model the following:

- the complete set of nuclide compositions (approximately 90 nuclides are currently considered in the MCNP detector modeling simulations);

- pin-by-pin variation of compositions using pin burnup values defined by operator simulation or NDA measurements;

- axial variation of compositions using axial burnup distribution from the operator or NDA measurements;

- $\quad$ specific assembly design details, for example, rod layout, dimensions, burnable poison rod configuration, etc.;

- actual operating conditions (defined in Sect. 3), for example, exposure to control rods, moderator temperature and density, etc.;

- detailed operating power history of each assembly; and

- neighbor assemblies or other boundary conditions, as available (spectral effects only, because the burnup distribution is accounted for separately using pin burnup values).

\subsection{DESCRIPTION OF THE NEW NODAL DEPLETION CAPABILITY}

Under this task of the NGSI project, a new 3-D assembly depletion capability, named ORIGAMI (ORIgen AsseMbly Isotopics), has been developed at ORNL to generate nuclide compositions for an entire fuel assembly using a user-defined pin-by-pin (radial) burnup map and axial burnup profile. The axial distribution is represented using any number of discrete axial zones as required. For a typical $14 \times 14$ PWR assembly (179 fuel rods), represented axially using 25 zones (typical of data provided by the reactor 
operator), there are approximately 4,300 separate fuel regions of the assembly to be calculated. The number of axial zones needed for modeling of advanced NDA instruments may be substantially smaller because sometimes the instruments measure only a single axial level. However, for full assembly characterization (e.g., determining the total plutonium content), all regions must be calculated. Therefore, these calculations must be relatively fast.

ORIGAMI serves as a custom interface for ORIGEN, translating an assembly average power history and axial and radial power distributions into individual ORIGEN depletion cases for each pin depletion zone. Outputs from ORIGAMI include zone-by-zone material compositions and radiation source terms in a variety of formats suitable for analysis, including MCNP materials cards (which can be used with a predefined MCNP geometry for modeling detector response).

ORIGEN is part of the SCALE code package and is used internationally and widely within the DOE complex, the Nuclear Regulatory Commission (NRC), and by industry for design, safety, and licensing analysis. As described in Sect. 3, ORIGEN has been extensively validated against measured spent fuel destructive assay data [37]. High spatial fidelity is achieved by pre-generating the cross section libraries for the ORIGEN burnup calculations, using the design and operating conditions for the assembly being characterized. This function is performed using the depletion analysis sequence TRITON in SCALE, which performs a neutron transport analysis of the assembly (using either 2-D or 3-D models), to generate spatially (pin-by-pin) and time (burnup) dependent cross-section libraries for ORIGEN. These crosssection libraries contain all of the information related to the assembly design and operating conditions and are specific to each unique assembly. Variations in cross sections with moderator temperature and density (axial variations) or other operating conditions can be calculated in advance using additional transport calculations that include the range of conditions. These cross sections can then be interpolated rapidly to the specific conditions at any axial or radial location within the assembly.

ORIGEN can perform the burnup analysis for a fuel region using the specific fuel library in a small fraction of the time required by TRITON or MCNP. This efficiency is achieved because the majority of the calculation time is typically used in the neutron transport analysis of the assembly. Because the transport calculations used to generate cross sections are performed in advance, a typical single fuel region calculation using ORIGEN alone requires only seconds on a typical computer. Therefore, a full assembly with 4,300 discrete fuel regions may require up to 2 days on a single processor (serial). Recent parallel implementation (multiple processors) of ORIGAMI on multiple processors has enabled full assembly calculations to be completed within hours.

\subsubsection{Radial Representation}

The nuclide compositions for each fuel pin of the assembly are calculated explicitly using ORIGEN with the burnup distribution provided for each rod. These distributions may be provided by the reactor operator or measured using NDA instruments (e.g., passive gamma). This information is described in Section 4.

As an example, the fuel rod burnup distribution of a $14 \times 14$ ROK assembly as provided by the reactor operator is shown in Fig. 12. This particular assembly had a very large burnup gradient from corner to corner, although not typical for most assemblies. Another observable trend is that the peripheral rods have a slightly lower burnup than the inner rods, attributed to the presence of inner water rods (moderation). The pin-by-pin burnup distribution is represented in the ORIGAMI input, shown in Fig. 12, as an X-Y burnup map, where each matrix value represents the relative burnup of the particular rod. Each ORIGEN calculation is performed by adjusting the assembly power (therefore also burnup) by the relative power of the particular fuel rod to obtain the desired final burnup of the rod as estimated by the operator or by measurement. The X-Y burnup map is normalized to unity such that the burnup averaged over all fuel rods is consistent with the given assembly average value. 


\begin{tabular}{|l|l|l|l|l|l|l|l|l|l|l|l|l|l|}
\hline 28.2 & 27.8 & 27.5 & 27.3 & 27.1 & 27.0 & 26.9 & 25.4 & 25.3 & 25.0 & 24.6 & 24.0 & 23.2 & 22.3 \\
\hline 29.6 & 29.5 & 29.7 & 29.1 & 28.8 & 29.2 & 28.7 & 27.1 & 27.4 & 26.8 & 28.3 & 26.0 & 24.8 & 23.6 \\
\hline 31.0 & 31.4 & & 31.3 & 31.1 & & 30.7 & 29.0 & & 28.8 & 28.3 & & 26.5 & 24.8 \\
\hline 32.1 & 32.2 & 32.8 & 32.5 & 32.8 & 32.5 & 31.5 & 29.6 & 30.3 & 30.2 & 29.3 & 28.7 & 27.2 & 25.8 \\
\hline 33.2 & 33.4 & 34.0 & 34.2 & & 33.4 & 32.4 & 30.1 & 30.9 & & 30.7 & 29.7 & 28.1 & 26.7 \\
\hline 34.3 & 34.9 & & 35.0 & 34.5 & 34.0 & 34.0 & 30.9 & 30.9 & 31.3 & 31.2 & & 28.2 & 27.4 \\
\hline 35.1 & 35.2 & 35.7 & 34.9 & 34.4 & 34.9 & & 31.8 & 31.0 & 30.9 & 30.9 & 30.7 & 29.3 & 27.9 \\
\hline 36.2 & 36.3 & 36.8 & 35.9 & 35.2 & 34.9 & 35.0 & 34.4 & 33.8 & 33.6 & 33.5 & 33.3 & 31.7 & 30.3 \\
\hline 37.0 & 37.7 & & 37.8 & 37.0 & 35.8 & 35.0 & 34.7 & 34.8 & 35.2 & 35.1 & & 32.8 & 30.9 \\
\hline 37.7 & 38.0 & 38.7 & 38.8 & & 37.3 & 35.9 & 35.5 & 38.3 & & 36.0 & 34.8 & 32.9 & 31.4 \\
\hline 38.5 & 38.7 & 39.4 & 39.0 & 39.2 & 38.6 & 37.2 & 36.8 & 37.6 & 37.3 & 36.2 & 35.4 & 33.6 & 32.1 \\
\hline 39.2 & 39.9 & & 39.8 & 39.5 & & 38.6 & 38.2 & & 37.7 & 37.0 & & 34.8 & 32.9 \\
\hline 39.7 & 39.8 & 40.2 & 39.4 & 39.1 & 39.3 & 38.4 & 38.2 & 38.5 & 37.5 & 36.9 & 36.6 & 35.0 & 33.6 \\
\hline 40.3 & 40.0 & 39.7 & 39.4 & 39.1 & 38.8 & 38.5 & 38.6 & 38.3 & 37.8 & 37.2 & 36.5 & 35.5 & 34.6 \\
\hline
\end{tabular}

Fig. 12. The average pin-by-pin burnup distribution (GWd/tU) in a ROK assembly provided by the reactor operator.

$\begin{array}{llllllllllllll}0.85 & 0.84 & 0.83 & 0.82 & 0.81 & 0.81 & 0.81 & 0.76 & 0.76 & 0.75 & 0.74 & 0.72 & 0.70 & 0.67 \\ 0.89 & 0.89 & 0.89 & 0.87 & 0.87 & 0.88 & 0.86 & 0.81 & 0.82 & 0.80 & 0.85 & 0.78 & 0.74 & 0.71 \\ 0.93 & 0.94 & & 0.94 & 0.94 & & 0.92 & 0.87 & & 0.86 & 0.85 & & 0.79 & 0.75 \\ 0.97 & 0.97 & 0.99 & 0.98 & 0.99 & 0.98 & 0.95 & 0.89 & 0.91 & 0.91 & 0.88 & 0.86 & 0.82 & 0.77 \\ 1.00 & 1.00 & 1.02 & 1.03 & & 1.00 & 0.97 & 0.90 & 0.93 & & 0.92 & 0.89 & 0.84 & 0.80 \\ 1.03 & 1.05 & & 1.05 & 1.04 & 1.02 & 1.02 & 0.93 & 0.93 & 0.94 & 0.94 & & 0.85 & 0.82 \\ 1.05 & 1.06 & 1.07 & 1.05 & 1.03 & 1.05 & & 0.96 & 0.93 & 0.93 & 0.93 & 0.92 & 0.88 & 0.84 \\ 1.09 & 1.09 & 1.11 & 1.08 & 1.06 & 1.05 & 1.05 & 1.03 & 1.02 & 1.01 & 1.01 & 1.00 & 0.95 & 0.91 \\ 1.11 & 1.13 & & 1.13 & 1.11 & 1.08 & 1.05 & 1.04 & 1.05 & 1.06 & 1.05 & & 0.98 & 0.93 \\ 1.13 & 1.14 & 1.16 & 1.16 & & 1.12 & 1.08 & 1.07 & 1.15 & & 1.08 & 1.04 & 0.99 & 0.94 \\ 1.15 & 1.16 & 1.18 & 1.17 & 1.18 & 1.16 & 1.12 & 1.11 & 1.13 & 1.12 & 1.09 & 1.06 & 1.01 & 0.96 \\ 1.18 & 1.20 & & 1.19 & 1.19 & & 1.16 & 1.15 & & 1.13 & 1.11 & & 1.05 & 0.99 \\ 1.19 & 1.19 & 1.21 & 1.18 & 1.17 & 1.18 & 1.15 & 1.15 & 1.16 & 1.13 & 1.11 & 1.10 & 1.05 & 1.01 \\ 1.21 & 1.20 & 1.19 & 1.18 & 1.17 & 1.17 & 1.15 & 1.16 & 1.15 & 1.14 & 1.12 & 1.10 & 1.07 & 1.04\end{array}$

Fig. 13. The assembly pin-by-pin burnup distribution represented as the relative distribution in an X-Y map used in ORIGAMI input.

This methodology is fundamentally different from most transport-depletion approaches such as TRITON, MCNPX, or Monteburns and is more accurate because it matches the known pin-by-pin burnups. These burnup codes do not allow the user to define the actual burnup distribution of the fuel rods, but rather this distribution is calculated automatically by the transport code. Introducing large burnup gradients in an 
assembly, such as that shown in Fig. 12, would require that the model be adjusted to reduce the power on one side (or sides) of the assembly by either introducing an absorbing material or otherwise changing the boundary conditions of the problem. However, it would not be possible to match the burnup profile across the entire assembly, for example, adjustments to match the burnup in one region of the assembly frequently results in large deviations in other regions. Moreover, the cause of the burnup gradient may not be known, and therefore changing the boundary conditions to adjust the burnup may introduce other undesired effects that impact the nuclide compositions in a non-physical way.

Another attribute of the code system is the ability to apply different cross-section libraries for the analysis of different fuel rods. For instance, the cross sections for a fuel rod located adjacent to a guide tube (usually filled with water) are different from those for a fuel rod at the edge of the assembly. Cross sections for different fuel rods are pre-generated using TRITON with the actual assembly configuration and saved for later application to the ORIGEN assembly analysis. For this study, separate libraries were generated for groups of similar fuel rods: (1) corner rods, (2) periphery (edge) rods, (3) rods adjacent to guide tubes, and (4) other interior fuel rods. Also, separate libraries are required for $\mathrm{UO}_{2}$ fuel rods and $\mathrm{Gd}_{2} \mathrm{O}_{3}-\mathrm{UO}_{2}$ fuel rods. For more complex and heterogeneous assembly designs, a more detailed representation may be warranted and can be modeled.

\subsubsection{Axial Representation}

The axial burnup distribution is represented in the model in the same way as the radial (X-Y) distribution. The axial distribution is discretized, and the relative burnup value is assigned to each axial zone. These axial values are normalized to unity and become multipliers of the $\mathrm{X}-\mathrm{Y}$ map burnup values to obtain the power for each axial and radial fuel region of the assembly.

Axial burnup information is calculated by the reactor operator and may be available for assembly modeling. Typically 24 to 28 nodes with uniform or varying heights of each node are used in calculations by the operator. Axial burnups may also be measured by NDA, most frequently using an axial gamma scan of the fuel rod or assembly using ${ }^{137} \mathrm{Cs}$ as the burnup indicator. An example of a ${ }^{137} \mathrm{Cs}$ gamma scan of an assembly is shown in Fig. 14. The slight increase in burnup near both ends of the fuel rod is caused by increased moderation (water) in this region, and the depressions (five) are caused by the fuel rod grid spacers (displacement of moderator and neutron absorption by the grid).

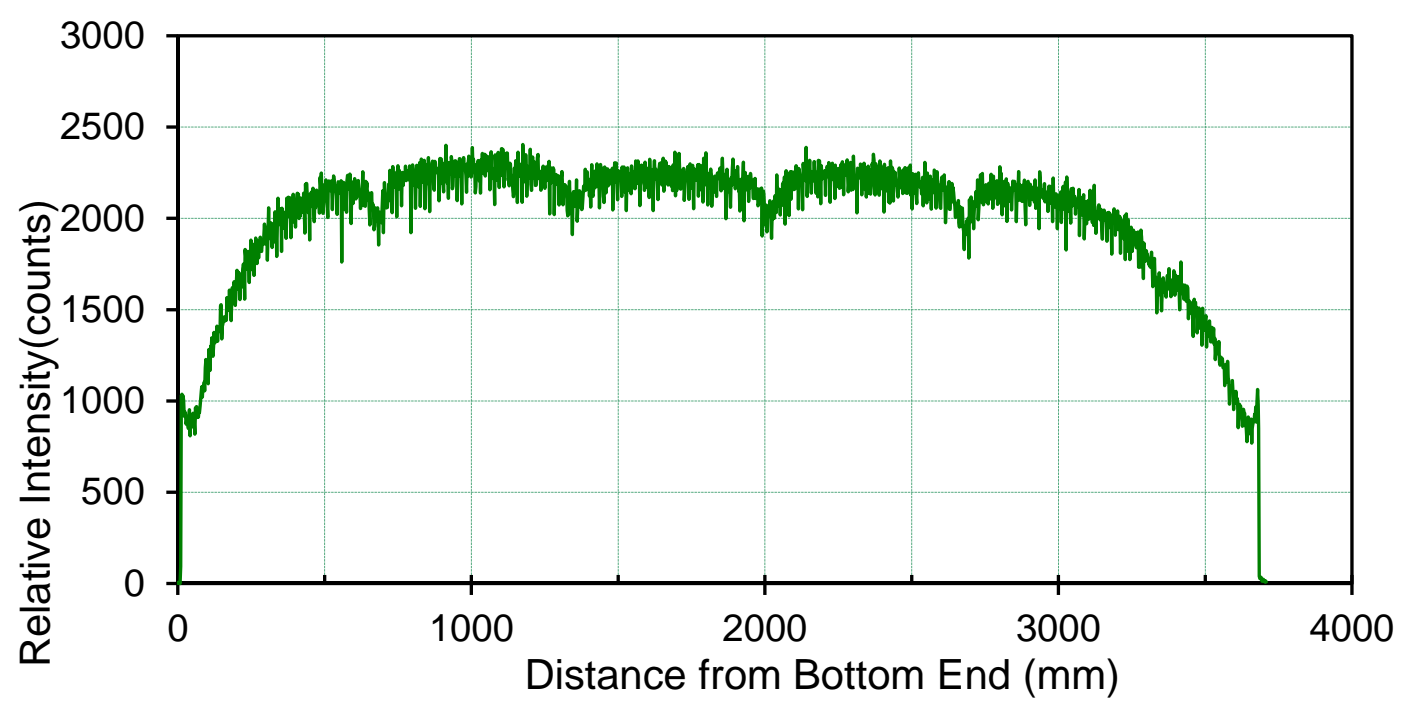

Fig. 14. Assembly axial burnup distribution (relative) measured by ${ }^{137}$ Cs gamma scan. 


\subsubsection{Output}

ORIGAMI has been used to generate the detailed isotopic results in each axial and radial fuel region in each ROK assembly destined to be tested with the NGSI advanced NDAs. Currently, the code automatically processes concentrations for 90 nuclides and then formats the concentrations into MCNP material cards, which can be used directly in MCNP detector modeling. In addition, ORIGEN will generate the passive gamma emission rates and energy spectra in each fuel region and the passive neutron source that includes spontaneous fission and $(\alpha, n)$ sources. The calculation procedure also generates plots of the distributions for key nuclides of the assembly. As an example, the plutonium concentrations (in the unit of "gram/tU") for the ROK assembly described earlier in this section are illustrated in Fig. 15(a) for the X-Y view (rod by rod) and in Fig. 15(b) for an X-Z view (vertical cutaway). (The two blank channels in Fig. 15(b) are two guide tubes at that cut plane.) As shown in Fig. 15(a), the plutonium content correlates well to the radial burnup gradient as depicted in Fig. 12. Similar observations can be made on the axial distribution.

This powerful 3-D depletion capability developed at ORNL to support the assembly modeling requirements for the NGSI-SF project, and specifically for the development of assembly calibration standards, addresses a key requirement for calibration: the need to directly and accurately apply measured assembly data and operator data to improve the simulation models with reasonable run times. This methodology has been used to generate calibration standards for the ROK assemblies where pin-by-pin burnup maps are available from the operator.

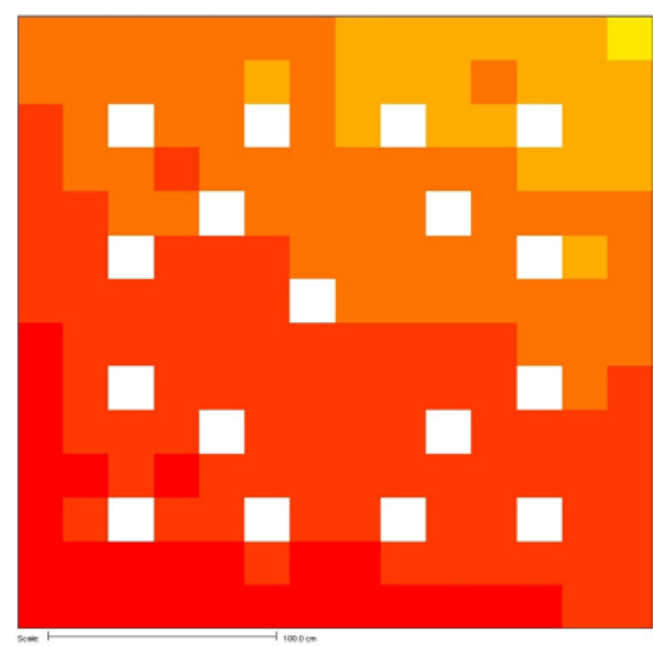

(a)
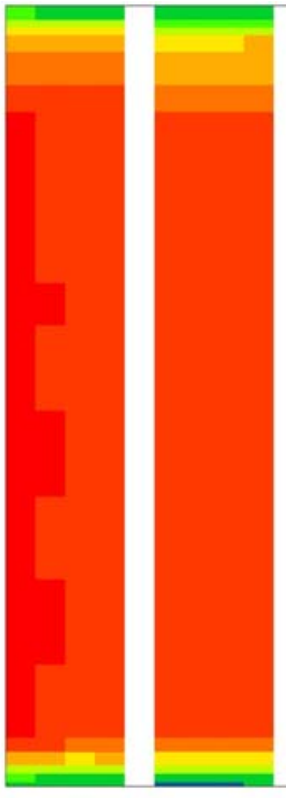

(b)

Fig. 15. The calculated radial (a) and axial (b) plutonium concentration (g/tU) for the ROK assembly, with burnup gradient shown in Fig. 12, showing the large radial gradient and axial gradient near the ends of the fuel rods. 



\section{A SPENT FUEL CALIBRATION STANDARD - A CASE STUDY WITH THE THREE MILE ISLAND FUEL}

This report has discussed the application of fuel design information, operator data, and NDA measurements to predict the compositions for a spent fuel assembly used for instrument calibration. This section applies the proposed methods to develop a working standard calibration assembly based on two spent fuel assemblies from the Three Mile Island unit 1 (TMI-1) reactor. These assemblies were the subject of extensive post-irradiation examinations under an experimental program of the Electric Power Research Institute (EPRI) investigating fuel rod failure and operating anomalies that occurred during Cycle 10 of the reactor operation [4]. Detailed fuel design information (e.g., enrichment, gadolinium loading), core loading records, cycle history, operating conditions (e.g., BPR insertion, boron loading) $[5,38,39]$ were documented as part of the EPRI study. In addition, destructive radiochemical analysis of spent fuel samples (on fuel-pellet scale) from two TMI-1 assemblies was performed under the Yucca Mountain Project $[3,40]$ to measure the isotopic content in the fuel samples. The availability of detailed design and operation data for the TMI assemblies makes them candidates for testing the proposed approach to generating working standards using advanced computer codes. The uncertainties in the operator data and NDA data, and how these uncertainties affect the accuracies in the calculated nuclide compositions, are also an important component in this study.

The specific goals of this case study are to

1) assess the accuracies of operator data and NDA data on axial burnup profile;

2) assess the accuracies of operator data and NDA data on local fuel burnup values;

3) assess the ability of SCALE to predict radial burnup distribution and nuclide concentrations; and

4) assess impacts of neighbor assemblies on both radial burnup distributions and nuclide concentrations across the assembly.

\subsection{DESCRIPTION OF THE TMI-1 ASSEMBLIES}

Several fuel rods from two assemblies, NJ070G and NJ05YU, were removed from the reactor after Cycle 10 for examinations. By then, assembly NJ070G had been irradiated for one cycle and achieved an average burnup of $27.31 \mathrm{GWd} / \mathrm{tU}(2)$, and assembly NJ05YU was irradiation for two cycles (Cycle 9 and 10) and was discharged with an average burnup of $48.64 \mathrm{GWd} / \mathrm{tU}$ [41]. Both assemblies were Babcock and Wilcox (B\&W) 15×15 Mark B-type designs. Assembly NJ05YU achieved a final burnup that is similar to typical discharged fuel. Table 7 lists the basic design data for the two TMI-1 assemblies. For fuel temperature and soluble boron, though only average values are cited here, time-varying values are available in Ref. 38, and those detailed values are used in the models in this work. Similarly, axially varying moderator densities, instead of average values, are also used in the models.

Figure 16 illustrates the configuration of assembly NJ070G [38]. Fuel rods in location O1, O11, O12, and O13 were extracted from the assembly for destructive and nondestructive examinations after Cycle 10. (Among these four rods, $\mathrm{O} 11$ was the only one that failed under irradiation.) The locations of the four gadolinia $(\mathrm{Gd})$ rods are also marked in the figure. Figure 17 depicts the configuration of assembly NJ05YU [38]. Fuel rods D5 and H6 were extracted from the assembly for examinations after Cycle 10 (the second irradiation cycle of the assembly). The orientation of each assembly is also marked in the figures and is used to identify the neighbor assemblies. BPRs were inserted in all guide tube locations during the first cycle of both assemblies, and were removed in the second cycles. Details about the nondestructive and destructive examinations of the removed rods are discussed later in this section. 
Table 7. Assembly design data for TMI-1 fuel

\begin{tabular}{|c|c|c|}
\hline Parameter & $\begin{array}{c}\text { Data for assembly } \\
\text { NJ05YU }\end{array}$ & $\begin{array}{c}\text { Data for assembly } \\
\text { NJ070G }\end{array}$ \\
\hline \multicolumn{3}{|l|}{ Assembly and reactor data $^{a}$} \\
\hline Reactor & TMI-1 & TMI-1 \\
\hline Lattice geometry & $15 \times 15$ & $15 \times 15$ \\
\hline Rod pitch $(\mathrm{cm})$ & 1.44272 & 1.44272 \\
\hline Number of fuel rods & 208 & 208 \\
\hline Number of guide tubes & 16 & 16 \\
\hline Number of instrument tubes & 1 & 1 \\
\hline Assembly pitch $(\mathrm{cm})$ & 21.81098 & 21.81098 \\
\hline \multicolumn{3}{|l|}{ Fuel rod data ${ }^{a}$} \\
\hline Fuel material type & $\mathrm{UO}_{2}$ & $\mathrm{UO}_{2}$ \\
\hline Fuel pellet density $\left(\mathrm{g} / \mathrm{cm}^{3}\right)$ & 10.196 & 10.217 \\
\hline Fuel pellet diameter $(\mathrm{cm})$ & 0.9362 & 0.9398 \\
\hline Average fuel temperature $(\mathrm{K})^{b}$ & 820 & 820 \\
\hline Enrichment (wt $\left.\%{ }^{235} \mathrm{U}\right)$ & 4.013 & 4.657 \\
\hline Clad material & Zircaloy-4 & Zircaloy-4 \\
\hline Clad inner diameter $(\mathrm{cm})$ & 0.95758 & 0.95758 \\
\hline Clad outer diameter $(\mathrm{cm})$ & 1.0922 & 1.0922 \\
\hline Average clad temperature $(\mathrm{K})$ & 640 & 640 \\
\hline Number of rods with $\mathrm{Gd}_{2} \mathrm{O}_{3}$ & 0 & 4 \\
\hline $\mathrm{Gd}_{2} \mathrm{O}_{3}$ content $(\mathrm{wt} \%)$ & NA & 2.0 \\
\hline \multicolumn{3}{|l|}{ Initial fuel composition (wt \%) } \\
\hline${ }^{234} U$ & 0.040 & $0.045(0.0)^{c}$ \\
\hline${ }^{253} \mathrm{U}$ & 4.013 & $4.657(4.019)^{c}$ \\
\hline${ }^{238} \mathrm{U}$ & 95.947 & $95.298(95.981)^{c}$ \\
\hline \multicolumn{3}{|l|}{ Moderator data } \\
\hline Average moderator density $\left(\mathrm{g} / \mathrm{cm}^{3}\right)^{d}$ & 0.713 & 0.713 \\
\hline Average soluble boron in moderator $(\mathrm{ppm})^{e}$ & 846,1012 & 1012 \\
\hline \multicolumn{3}{|l|}{ Burnable poison rod (BPR) data ${ }^{a}$} \\
\hline Absorber diameter $(\mathrm{cm})$ & 0.8636 & 0.8636 \\
\hline Clad inner diameter $(\mathrm{cm})$ & 0.9144 & 0.9144 \\
\hline Clad outer diameter $(\mathrm{cm})$ & 1.0922 & 1.0922 \\
\hline Absorber material & $\mathrm{Al}_{2} \mathrm{O}_{3}-\mathrm{B}_{4} \mathrm{C}$ & $\mathrm{Al}_{2} \mathrm{O}_{3}-\mathrm{B}_{4} \mathrm{C}$ \\
\hline Absorber material density $\left(\mathrm{g} / \mathrm{cm}^{3}\right)$ & 3.7 & 3.7 \\
\hline $\mathrm{B}_{4} \mathrm{C}$ content $(\mathrm{wt} \%)$ & 1.7 & 2.1 \\
\hline Cladding material & Zircaloy-4 & Zircaloy-4 \\
\hline \multicolumn{3}{|l|}{ Guide/instrument tube data ${ }^{l}$} \\
\hline Guide/instrument tube material & Zircaloy-4 & Zircaloy-4 \\
\hline Guide tube inner diameter $(\mathrm{cm})$ & 1.26492 & 1.26492 \\
\hline Guide tube outer diameter $(\mathrm{cm})$ & 1.3462 & 1.3462 \\
\hline Instrument tube inner diameter $(\mathrm{cm})$ & 1.12014 & 1.12014 \\
\hline Instrument tube outer diameter $(\mathrm{cm})$ & 1.25222 & 1.25222 \\
\hline
\end{tabular}

\footnotetext{
${ }^{a}$ As provided in Ref. 39.

${ }^{b}$ Derived from axial temperature values as provided in Ref. 38.

${ }^{c}$ Values in parentheses correspond to gadolinia-bearing fuel rods.

${ }^{d}$ Derived from axial moderator values as provided in Ref. 39.

${ }^{e}$ Average for Cycle 9 is 846 ppm; 1012 ppm for Cycle 10. Derived from time-varying values as provided in Ref. 38.

${ }^{f}$ As provided in Ref. 38.
} 
4 NORTH

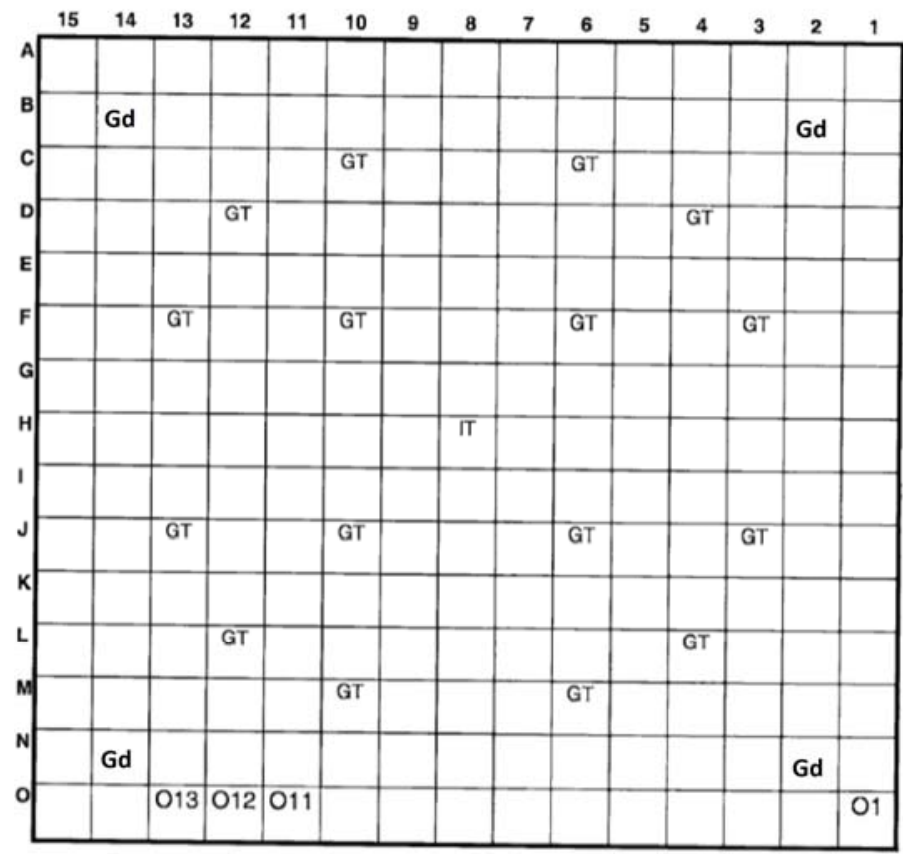

Fig. 16. Configuration of assembly NJ070G from TMI-1 [38]. Fuel rods O1, 011, O12, and 013 were extracted from the assembly for examinations after Cycle 10.

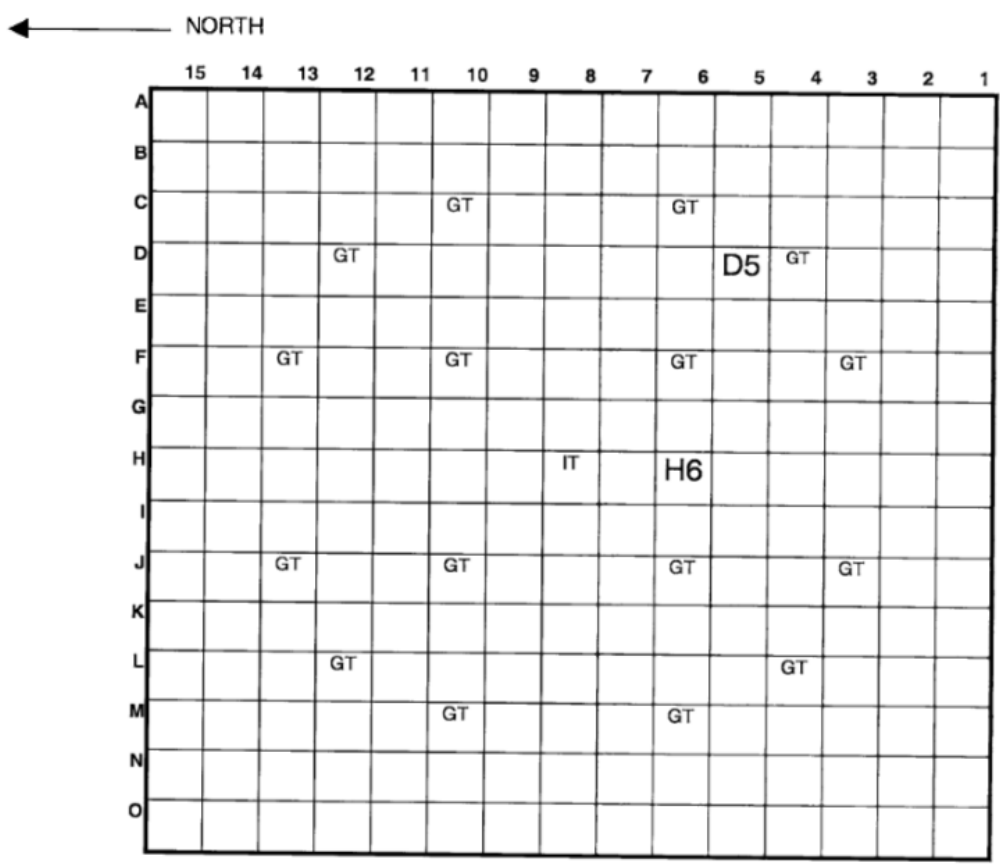

Fig. 17. Configuration of assembly NJ05YU from TMI-1 [38]. Fuel rods D5 and H6 were extracted from the assembly for examinations after Cycle 10. 


\subsection{EVALUATION OF OPERATOR AND NDA DATA FOR TMI-1 FUEL}

Under the EPRI investigation of the root cause of fuel failure in TMI-1, extensive examinations have been performed on the fuel rods from these two assemblies (NJ070G and NJ05YU), including gamma scanning, neutron radiography, and destructive radiochemical assay [4]. Of most interest to this work are the gamma scanning and radiochemical measurements, because (a) the axial gamma scanning provides the axial burnup profile of the fuel rods, and (b) the radiochemical measurements provide the nuclide compositions of the fuel samples. Significant amounts of operator data on the TMI-1 fuel were also collected by the EPRI and other studies [4, 38, 39]. Before using the operator and NDA data for burnup calculations, it is prudent to evaluate the quality of these data.

\subsubsection{Axial Burnup Profile of TMI-1 Fuel}

The axial burnup profile of TMI-1 fuel was measured using NDA methods (gamma scanning) and can also be derived from operator data. Details are discussed in the following subsections.

\subsubsection{Axial Burnup Profile Measured by Gamma Scanning}

Cesium-137 gamma scanning was performed for fuel rods O1, O12, and O13 in assembly NJ070G [4]. Cesium-137 is an excellent burnup indicator because of the similar fission yields among the main fissioning nuclides. The count rates of ${ }^{137} \mathrm{Cs}$ gamma scanning were then converted to burnup using two different methods: 1) by benchmarking to DA burnup data; 2) by benchmarking to a reference fuel rod, for which the ${ }^{137} \mathrm{Cs}$ content was both destructively and nondestructively measured (the burnup was also destructively measured). For the DA measurements of burnup for this fuel, two "microsamples" were taken at two axial locations (79.2 in. and 119.2 in.) from rods O1 and O12 [4]. These microsamples were only fractions of the cross section of fuel pellets, rather than the entire cross section as in a typical DA sample. Inference was then conducted by EPRI to make the measurements representative of the entire cross section, and minor errors were expected to be introduced in the procedure. In this work, we refer to the first method as "scan+Nd148" and the second as "scan+Ref. rod."

Figure 18 shows the axial burnup profiles of fuel rods $\mathrm{O} 1$ and $\mathrm{O} 12$ measured by gamma scanning of ${ }^{137} \mathrm{Cs}$ [4], each with conversion to burnup using these two methods. Also shown are the ${ }^{148} \mathrm{Nd}$ measurements at two axial locations. As shown, the "scan+Nd148" method leads to slightly higher $(\sim 3 \%)$ predictions of burnup than the "scan+Ref. rod" method (more discussions on these differences are provided in the following subsections). Burnup depressions around spacer grids (every 20 in.) are clearly visible. For each set of data, it is also observed that the burnup values fluctuate around a similar average for the nodes between 20 to $90 \mathrm{in}$. The burnup for the fuel at the bottom of the rod is slightly higher than at the top primarily because the higher moderator densities near the bottom lead to higher neutron moderation and thus higher power there. Rod $\mathrm{O} 1$ was determined to have significantly higher burnup than rod O12, because rod $\mathrm{O} 1$ was at the corner, while $\mathrm{O} 12$ was at the edge of the assembly, and corner rods are usually more moderated than edge rods due to small gaps $(\sim 0.4 \mathrm{~mm})$ between adjacent assemblies. 


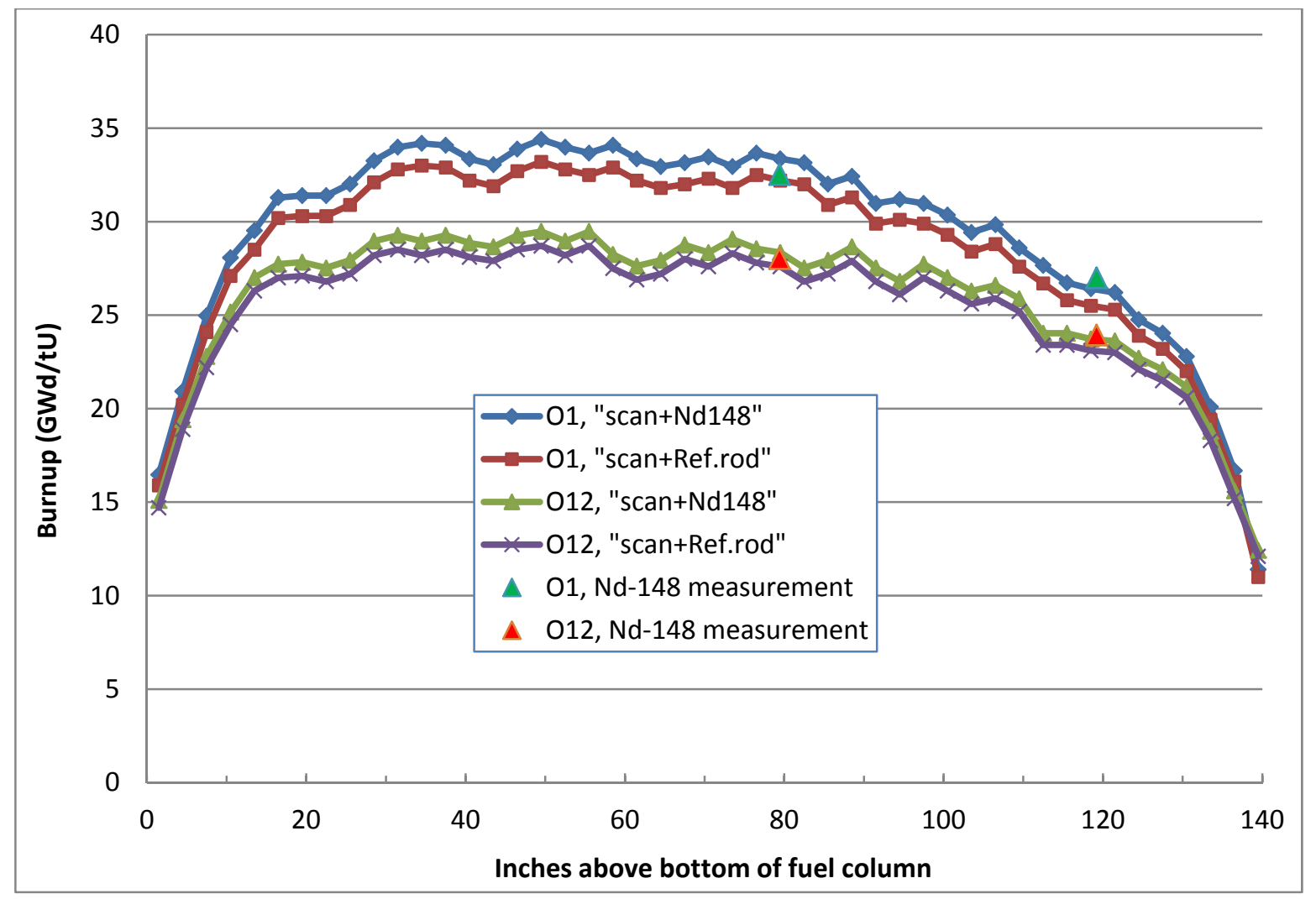

Fig. 18. Axial burnup profiles of fuel rod 01 and 012 measured by gamma scanning of ${ }^{137}$ Cs; converted to burnup using two different methods: 1) ${ }^{148} \mathrm{Nd}$ measurements, 2) reference rod. Also shown are the destructive measurements of ${ }^{148} \mathrm{Nd}$ at two axial locations.

\subsubsection{Axial Burnup Profile Provided by Operator}

Axial burnup profiles can also be derived from operator data. Operator-estimated burnups of each axial node (18 nodes in total) of several fuel rods can be found in Ref. 38. This reference listed the calculated nodal burnup for all TMI-1 assemblies (including assembly NJ070G and NJ05YU), and also for selected fuel rods (including O1, O12, O13, D5, and H6). The axial burnup profiles for assembly NJ070G, rods $\mathrm{O} 1$ and $\mathrm{O} 12$, were derived from these nodal values and presented in Fig. 19. For comparison, this figure also includes the profile of rod $\mathrm{O} 1$ measured by gamma scan. Note that in this plot the axial average burnup for each set of data is normalized to unity to facilitate comparison.

Significant differences between operator estimates and gamma measurements can be observed in Fig. 19, especially near the top end of fuel rods, and greater structures (around spacer grids) can be observed in the gamma measurements. It can also be observed that the operator-estimated axial profiles are almost identical for rods $\mathrm{O} 1$ and $\mathrm{O} 12$ and for the assembly average, which is not realistic. These results demonstrate that it is important to review and cross-check operator data before using it.

Usually the operator measures the axial burnups through in-core instruments on a fraction of assemblies. There is only one (at most) set of axial measurement data for each assembly, and the axial burnup for each fuel rod has to be derived using calculations. Better operator data for the axial burnup profile was obtained in the Studsvik Scandpower [16] study, as shown in Subsection 3.4.2.

Table 8 shows the average burnup of rod $\mathrm{O} 1$ and $\mathrm{O} 12$ determined by different methods. As shown, all three methods yield comparable results ( $<5 \%$ different). The average burnups predicted by "scan+Ref. rod" and operator estimate were both compared to those by "scan+Nd148". For rod O1, 
operator data are in better agreement to "scan + Nd148", whereas for rod O12, the "scan + Ref. rod" method agrees better.

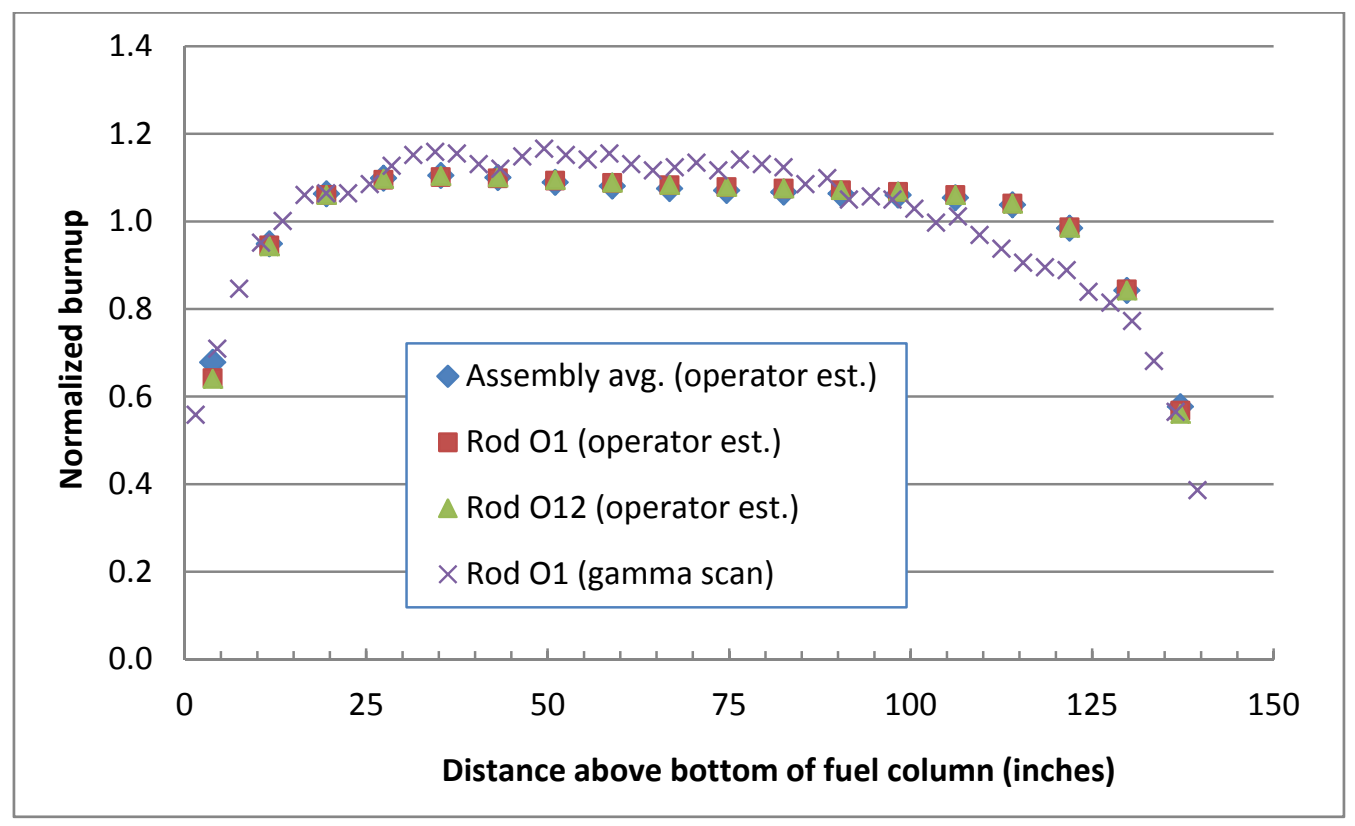

Fig. 19. Axial burnup profile estimated by operator for assembly NJ070G, rod O1, and rod 012. Also shown is the burnup profile of rod 01 determined by gamma scan.

Table 8. Average burnups of rods $\mathrm{O} 1$ and 012 determined by different methods

\begin{tabular}{|c|c|c|c|c|c|}
\hline & \multicolumn{2}{|c|}{ Average burnup of the fuel rod (GWd/tU) } & \multicolumn{2}{|c|}{$\begin{array}{c}\text { Relative difference (\%) compared to } \\
\text { "scan+Nd148” }\end{array}$} \\
\hline Rod ID & scan + Nd148 & OP.-est. $^{b}$ & scan + Ref. rod & OP.-est. & scan + Ref. rod \\
\hline O1 & 29.50 & 29.1 & 28.48 & -1.39 & -3.47 \\
\hline O12 & 25.93 & 27.1 & 25.25 & 4.60 & -2.63 \\
\hline
\end{tabular}

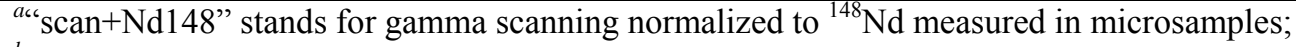

b،"OP.- est." stands for operator estimate;

c"scan+Ref. rod" stands for gamma scanning normalized to a reference rod.

\subsubsection{Local Burnups Estimated by Operator, DA, and NDA Data}

The purpose of this subsection is to evaluate the quality of operator and NDA data in terms of determining local burnups (on fuel pellet levels). The TMI-1 fuel samples (selected for DA measurements) were taken as examples for this study. (Pin-by-pin burnups for TMI-1 fuel were not provided by the operator or measured by NDA.) 


\subsubsection{DA Measurements of TMI-1 Fuel Samples}

DA measurements were performed on 19 TMI-1 fuel samples under the DOE Yucca Mountain program [5]. Neodymium-148 was measured in all these samples, from which the corresponding burnups were determined using the ASTM standard method [30]. Eight of the samples were cut from rods O1, O12, and O13 of assembly NJ070G (Table 9), and analyzed at General Electric Vallecitos Nuclear Center (GE-VNC). High-precision thermal ionization mass spectrometry (TIMS) was used, and quality results have been obtained in the measurements of these samples [5]. The measurements were used to benchmark calculated nuclide concentration results in this work.

The remaining 11 were cut from rod H6 of assembly NJ05YU (Table 10) and were analyzed at Argonne National Laboratory (ANL). These ANL measurements used inductively coupled plasma mass spectrometry (ICPMS) for most nuclides, rather than TIMS, resulting in much larger uncertainties than the GE-VNC results. Earlier studies have determined the ANL measurements had significant errors [5]. In this work it was decided not to use the ANL measurements to benchmark the calculated nuclide concentration results, but the DA measured burnups of the samples are cited in this section for reference. New DA measurements on rod H6 and D5 from assembly NJ05YU are being performed at ORNL, but the results are not available at the time of writing.

\subsubsection{Comparison of Local Burnups Determined Using Different Methods}

In addition to DA measurements, the burnups of the fuel samples can be inferred based on their axial elevations from the axial burnup profiles determined by the three aforementioned methods: operator data, "scan+Nd148," and "scan+Ref. rod." The inferred burnup values of the samples from rods O1, O12, and O13 are presented in Table 9 along with the DA measurements. In general, it is very challenging to predict the local burnups (on fuel pellet level), especially on exterior fuel rods such as these three rods, given the radial and axial power variations within the assemblies and the reactor core as a whole. The disagreements with DA data are significant in most cases, ranging from $4.8 \%$ to $20.6 \%$. Similar results have been reported in literature [21]. These discrepancies are also similar in magnitude as the results shown in Fig. 9. The differences for the three samples at the axial elevation of 15.5 in., near the bottom of the assembly, are significantly greater than the others, because the axial burnup profile has a large gradient around that elevation (as shown in previous figures). Among the three methods, the "scan+Ref. rod" method resulted in the best agreements with DA, and the other two methods provided comparable results to each other. The results are not satisfactory, which is not surprising given the fact that the ${ }^{148} \mathrm{Nd}$ measured used in the "scan+Nd148" method was based on microsamples (instead of full samples) and the operator data (for the TMI-1 fuel) did not have rod-specific axial burnup profiles. The burnup fluctuations around grid spacers introduce additional challenges to the determination of local burnups.

For the fuel samples from assembly NJ05YU, only two sets of data are available: DA and operator estimates. All the samples were taken from the two interior fuel rods: D5 and H6. The comparison of the burnup values determined by these two methods is presented in Table 10. As shown, the differences for most samples are within 5\%, indicating these limited operator data are satisfactory for interior fuel rods.

These results demonstrate that the "scan+Ref. rod" method (gamma scan normalized to a reference rod) can measure the overall axial burnup profile relatively well, but it is challenging to measure the local burnups due to the limitation of measurement techniques and burnup fluctuations around grid spacers. The "scan+Ref. rod" is a nondestructive method and is also more economical and faster than the "scan+Nd148" method. The "scan+Ref. rod" provides more detailed and reliable results than the operator data. The results also suggest that careful examinations of operator data are warranted to ensure quality. These data provide excellent examples of passive gamma measurements, and more tests like these are needed, especially on off-normal fuel and non-PWR fuels. 
Table 9. Burnup (GWd/tU) of the fuel samples from exterior rods $(01,012$, and 013$)$ of assembly NJ070G determined by different methods

\begin{tabular}{|c|c|c|c|c|c|c|c|c|c|}
\hline \multirow[b]{2}{*}{$\begin{array}{l}\text { Rod } \\
\text { ID }\end{array}$} & \multirow[b]{2}{*}{$\begin{array}{l}\text { Sample } \\
\text { ID }\end{array}$} & \multirow{2}{*}{$\begin{array}{c}\begin{array}{c}\text { Axial } \\
\text { elev. }\end{array} \\
\text { inch }\end{array}$} & \multicolumn{4}{|c|}{$\begin{array}{l}\text { Burnup (GWd/tU) determined by different } \\
\text { methods }\end{array}$} & \multicolumn{3}{|c|}{ Difference (\%) compared to DA } \\
\hline & & & DA & $\begin{array}{l}\text { OP.- } \\
\text { est. }^{a}\end{array}$ & $\operatorname{scan}+\mathrm{Nd} 148^{b}$ & $\begin{array}{l}\text { scan+Ref. } \\
\text { rod }^{c}\end{array}$ & $\begin{array}{l}\text { OP.- } \\
\text { est. }\end{array}$ & scan+Nd148 & $\begin{array}{l}\text { scan+Ref. } \\
\text { rod }\end{array}$ \\
\hline $\mathrm{O} 13$ & O13S7 & \multirow{3}{*}{15.5} & 22.8 & 26.9 & 27.5 & $d$ & 17.9 & 20.6 & -- \\
\hline $\mathrm{O} 12$ & $\mathrm{O} 12 \mathrm{~S} 4$ & & 23.7 & 27.2 & 27.5 & 26.8 & 14.5 & 16.0 & 13.1 \\
\hline $\mathrm{O} 1$ & O1S1 & & 25.8 & 29.1 & 30.7 & 29.6 & 12.9 & 19.0 & 14.7 \\
\hline $\mathrm{O} 13$ & O13S8 & \multirow{3}{*}{77.6} & 26.3 & 29.0 & 28.5 & $d$ & 10.2 & 8.3 & -- \\
\hline $\mathrm{O} 12$ & O12S5 & & 26.5 & 29.2 & 28.5 & 27.7 & 10.3 & 7.5 & 4.5 \\
\hline $\mathrm{O} 1$ & O1S2 & & 29.9 & 31.3 & 33.6 & 32.4 & 4.8 & 12.2 & 8.4 \\
\hline $\mathrm{O} 12$ & O12S6 & \multirow{2}{*}{109.5} & 24.0 & 28.5 & 25.9 & 25.2 & 18.9 & 7.8 & 5.0 \\
\hline \multirow[t]{2}{*}{$\mathrm{O} 1$} & $\mathrm{O} 1 \mathrm{~S} 3$ & & 26.7 & 30.6 & 28.6 & 27.6 & 14.6 & 7.1 & 3.4 \\
\hline & Avg. & \multicolumn{5}{|c|}{--- } & 13.0 & 12.3 & 8.2 \\
\hline
\end{tabular}

ac'OP.-est." stands for operator estimate;

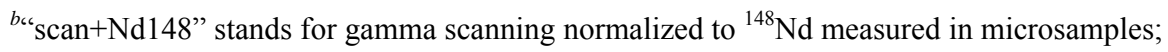

c"scan+Ref. rod" stands for gamma scanning normalized to a reference rod.

$d$ "scan+Ref.rod" results are not available for rod $\mathrm{O} 13$.

Table 10. Burnup (GWd/tU) of the fuel samples from interior rods (D5 and H6) of assembly NJ05YU determined by different methods

\begin{tabular}{|c|l|c|c|c|c|}
\hline \multirow{2}{*}{ Rod ID } & $\begin{array}{c}\text { Sample } \\
\text { ID }\end{array}$ & $\begin{array}{c}\text { Axial } \\
\text { elevation }\end{array}$ & \multicolumn{2}{|c|}{$\begin{array}{c}\text { Burnup (GWd/tU) } \\
\text { determined by different } \\
\text { methods }\end{array}$} & $\begin{array}{c}\text { Relative } \\
\text { Difference }\end{array}$ \\
\hline \multirow{7}{*}{} & & inch & DA & OP-est. $^{a}$ & $\%$ \\
\cline { 2 - 6 } & A1B & 15 & 44.8 & 45.7 & 2.0 \\
\cline { 2 - 6 } & A2 & 29 & 50.6 & 51.9 & 2.5 \\
\cline { 2 - 6 } & B3J & 30 & 53.0 & 51.9 & -2.1 \\
\cline { 2 - 6 } & B2 & 45 & 50.1 & 52.1 & 4.0 \\
\cline { 2 - 6 } & B1B & 61 & 54.5 & 51.7 & -5.1 \\
\cline { 2 - 6 } & C3 & 62 & 51.3 & 51.7 & 0.8 \\
\cline { 2 - 6 } & C2B & 77 & 52.6 & 51.6 & -2.0 \\
\cline { 2 - 6 } & C1 & 93 & 50.2 & 51.5 & 2.7 \\
\cline { 2 - 6 } & D1A2 & 103 & 55.7 & 51.5 & -7.5 \\
\cline { 2 - 6 } & D1A4 & 115 & 50.5 & 50.8 & 0.6 \\
\cline { 2 - 6 } & D2 & 127 & 44.8 & 48.6 & 8.4 \\
\hline
\end{tabular}

a“'OP.-est.” stands for operator estimate. 


\subsection{ANALYSIS OF MODELING RESULTS OF TMI-1 FUEL}

The performance of the burnup codes and models to predict radial burnup distributions and nuclide concentrations has been evaluated based on the TMI-1 fuel.

\subsubsection{The Burnup Models}

Both assemblies NJ070G and NJ05YU were modeled using SCALE/TRITON in the burnup calculations in this study, and the models are described later in this subsection. The neighbor assemblies are an important element to include in the burnup models because they might significantly impact the burnup results. The neighbor configurations of the two assemblies are described first.

Figure 20 shows assembly NJ070G and its eight neighbor assemblies in Cycle 10. As shown, the previously irradiated assemblies were colored in yellow, for which the batch ID and the BOC (beginning of cycle) burnup ( $\mathrm{GWd} / \mathrm{tU})$ are listed. The fresh assemblies were colored in white, for which the batch ID, the $\mathrm{wt} \%$ of $\mathrm{B}_{4} \mathrm{C}$ of the BPRs, and the initial enrichment of ${ }^{235} \mathrm{U}$ are listed. The neighbor configuration is not symmetric in the east-west direction because the east neighbor is a fresh assembly and the west neighbor was previously irradiated. Column $\mathrm{O}$ is on the west edge of the assembly (as shown in Fig. 16) with rod $\mathrm{O} 1$ at the southwest corner.

Figure 21 (a) and (b) show assembly NJ05YU and its neighbor assemblies for Cycles 9 and 10, respectively. Unlike NJ070G, assembly NJ05YU was irradiated in the reactor for two cycles (to $\sim 50 \mathrm{GWd} / \mathrm{tU}$ ) before fuel rods were removed for examination. As shown, the neighbor configuration is not symmetric in Cycle 9 (notice the difference between the southwest and northeast corner), but is symmetric in Cycle 10.

\begin{tabular}{|c|c|c|}
\hline \multicolumn{3}{|c|}{ North } \\
\hline $\begin{array}{c}\text { batch 12D, } \\
4.75 \% \text { IE }\end{array}$ & $\begin{array}{c}\text { batch } 11 C, \\
B U=25.6\end{array}$ & $\begin{array}{c}\text { batch 12B, } 2.0 \% \\
\text { bpra, } 4.65 \% \text { IE }\end{array}$ \\
\hline $\begin{array}{c}\text { batch } 12 \mathrm{~A}, \\
4.00 \% \mathrm{IE}\end{array}$ & $\begin{array}{c}70 \mathrm{G}, \text { batch } 12 \mathrm{C}, \\
2.1 \% \text { bpra, } \\
4.65 \% \mathrm{IE}, 4 \text { gad } \\
\text { rods }\end{array}$ & $\begin{array}{c}\text { batch } 11 \mathrm{~A}, \\
\mathrm{BU}=21.1\end{array}$ \\
\hline $\begin{array}{c}\text { batch } 12 \mathrm{E}, 0.2 \% \\
\text { bpra, } 4.75 \% \mathrm{IE}, 4 \\
\text { gad rods }\end{array}$ & $\begin{array}{c}\text { batch } 11 C \text {, } \\
B U=20.9\end{array}$ & $\begin{array}{c}\text { batch } 12 \mathrm{C}, 2.1 \% \\
\text { bpra, } 4.65 \% \text { IE, } 4 \\
\text { gad rods }\end{array}$ \\
\hline
\end{tabular}

Fig. 20. Neighbor assemblies of assembly NJ070G (centered) in Cycle 10. Previously irradiated assemblies are colored in yellow, while fresh ones are colored in white. 


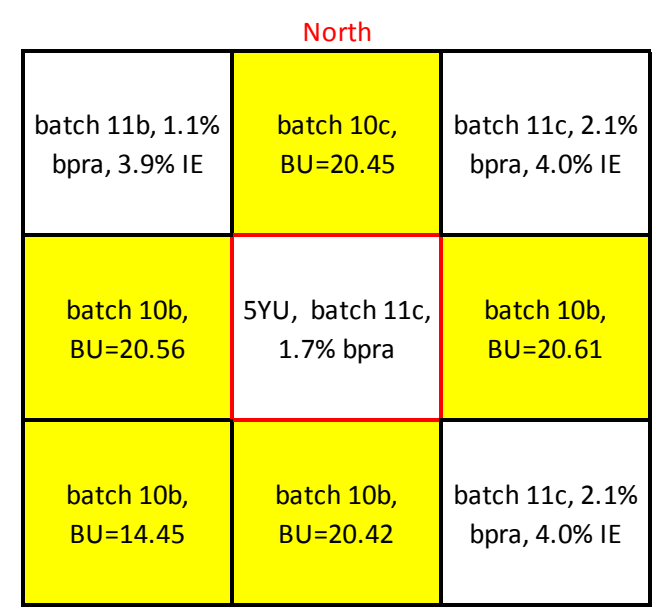

(a) Cycle 9

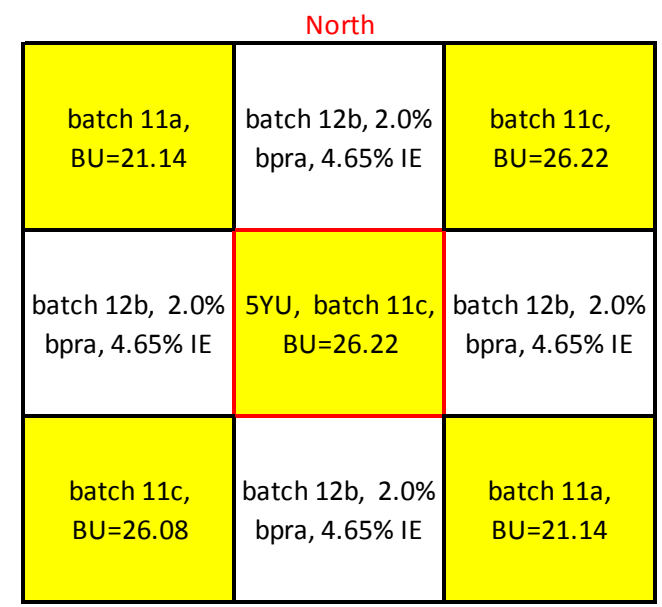

(b) Cycle 10

Fig. 21. Neighbor assemblies of assembly NJ05YU (centered) in two different cycles: (a) Cycle 9; (b) Cycle 10.

Figure 22 shows the TRITON model for assembly NJ070G and its eight neighbors. As shown, the neighbors on four sides were modeled in half symmetry, while the ones in corners were modeled in quarter symmetry. Reflective boundary conditions were applied on the outer surfaces of this model. The fuel rods in assembly NJ070G were modeled discretely, while the fuel rods in the neighbor assemblies were modeled uniformly in each assembly. The BPRs were modeled as inserted in assembly NJ070G and in the northeast, southeast, and southwest neighbors, with the appropriate $\mathrm{B}_{4} \mathrm{C}$ loading as shown in Fig. 20. The gadolinia rods are also modeled in the assemblies where they are used. The nuclide compositions for the previously irradiated assemblies were generated beforehand using ORIGEN with customized cross-section libraries based on TMI-1 fuel designs and operating conditions. These compositions were then loaded into the TRITON model. In the burnup calculation, the irradiation power was determined to be a certain level so that assembly NJ070G achieved the specific average burnup as estimated by the operator at the end of Cycle 10 (cycle length is known). The power of each fuel rod is allowed to "float" (relative to the assembly average), as determined by the burnup code based on the transport and depletion calculations with the specific local conditions.

The TRITON models for assembly NJ05YU (not shown here for brevity) are similar to that for assembly NJ070G, with the same level of details included. Two models were developed for assembly NJ05YU model for each cycle separately.

To study the impacts of neighbor assemblies, both assembly NJ070G and NJ05YU were also modeled as stand-alone (i.e., no neighbor assemblies included) assemblies with reflective boundary conditions and these models are referred to as "without-neighbor" model. The models that include the neighbor assemblies as described earlier are referred to as "with-neighbor" models. 
North

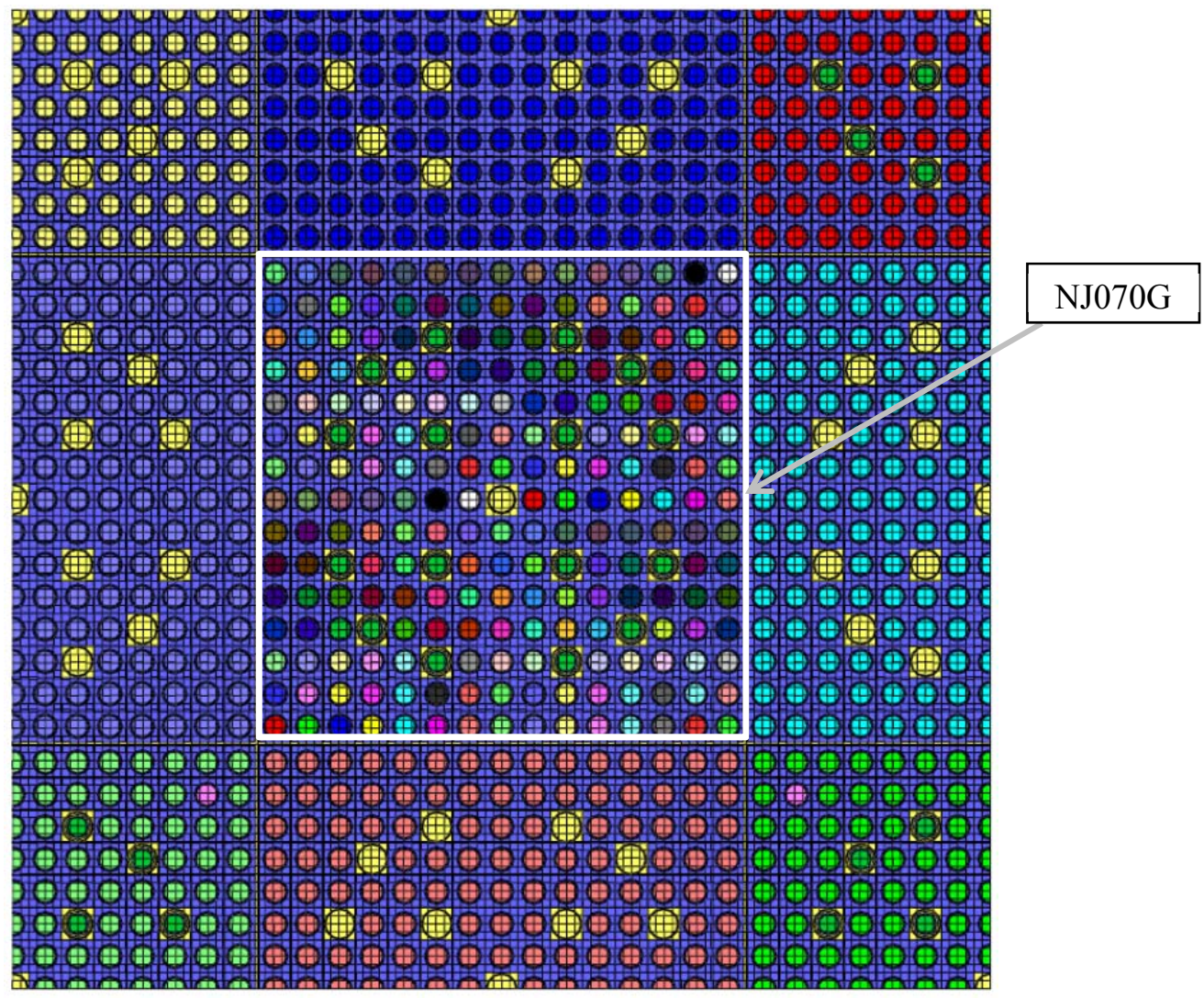

Fig. 22. Assembly NJ070G with its neighbor assemblies in Cycle 10 as modeled in TRITON.

\subsubsection{Radial Burnup Distribution}

\subsubsection{Assembly NJ05YU}

To study the radial burnup distribution, the neutron flux distribution is first examined, because the fast neutron flux is indicative of the power (and burnup) distribution. Figure 23(a) shows the fast flux distribution for the energy group of $[2.35,2.48] \mathrm{MeV}$ in Cycle 9. For comparison, the neighbor configuration of assembly NJ05YU is shown on the side (Fig. 23(b)). Because fast neutrons are created in fission and the average fission neutron has an energy of about $2.45 \mathrm{MeV}$, the fast neutron flux in this energy group is proportional to the fission rate in the fuel. Normally the fresh fuel is more reactive than the irradiated fuel, and thus there are higher fission rates and higher fast neutron fluxes in the fresh fuel, which corresponds well to what is observed in this figure. For example, the fast neutron flux is higher in the northeast neighbor assembly than that in southwest. The differences among neighbor assemblies also cause a gradient in flux distribution within assembly NJ05YU, as observed in this figure. 


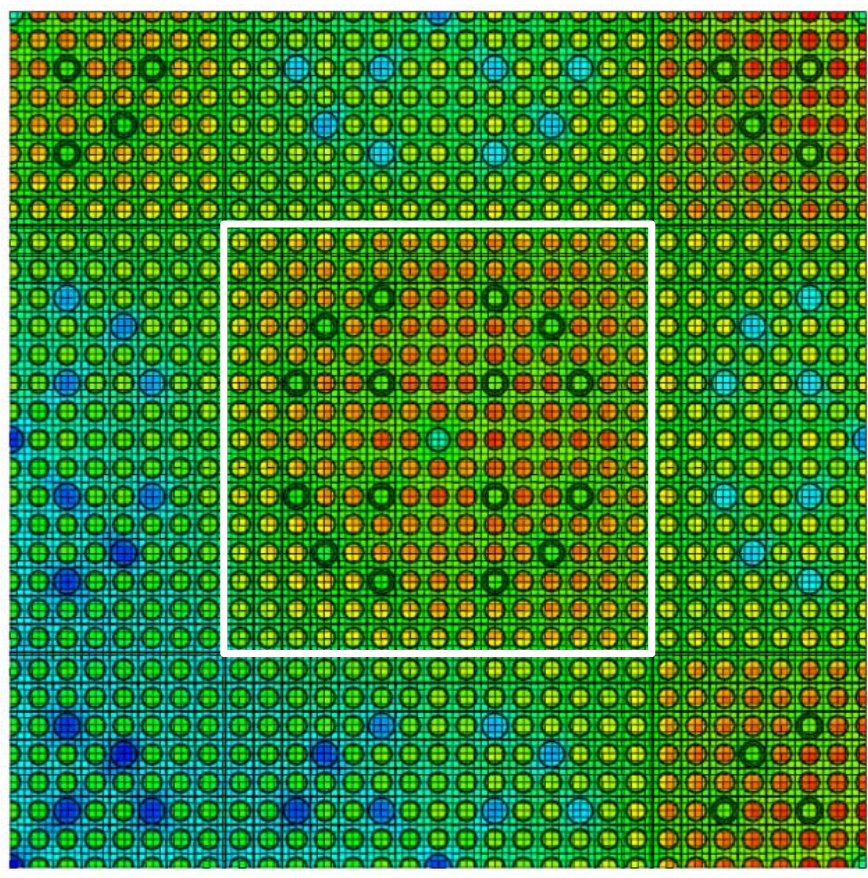

(a) Fast neutron flux

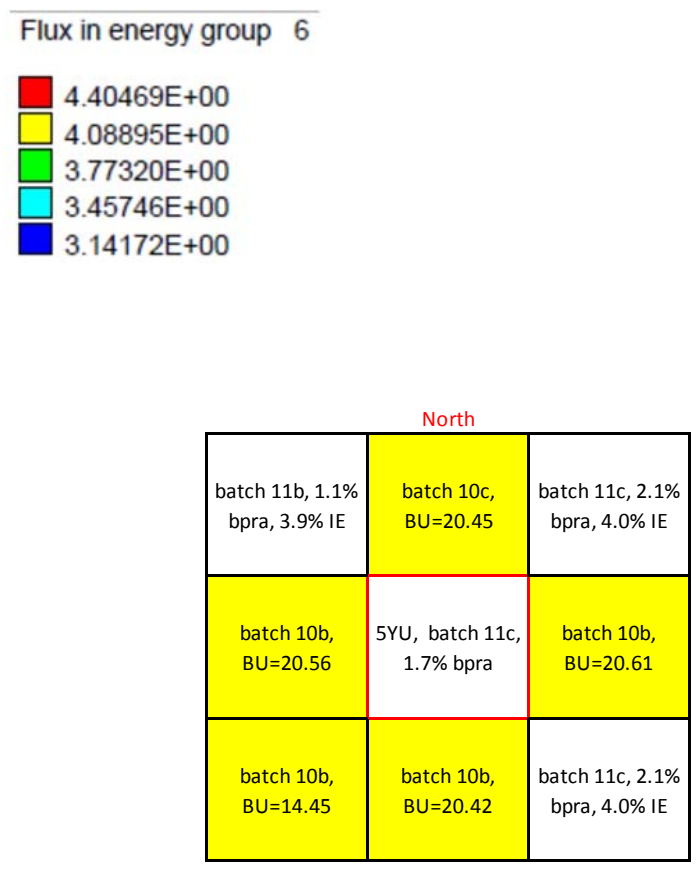

(b) Neighbor configuration

Fig. 23. (a) Distribution of fast neutron flux in assembly NJ05YU and the neighbors in the energy group of [2.35, 2.48] MeV; (b) neighbor configuration of NJ05YU (duplicate of Fig. 21 (a)).

Figure 24 (a) shows the pin-by-pin (radial) burnup distributions within assembly NJ05YU after the first cycle, and the distribution correlates well to the fast-neutron flux distribution as shown in Fig. 23 (a) - the burnup is lower in the southwest corner than the assembly average due to the asymmetric neighbor configuration. Fuel rods around the central instrument tube have the highest burnup because of the extra moderation provided by the water inside this tube. BPRs were inserted in the 16 guide tubes (represented by white blanks) for this cycle; thus, no power peaking is observed around these tubes.

Figure 24 (b) shows the relative difference (\%) in burnup of each fuel rod of assembly NJ05YU after the first cycle (Cycle 9) between with- and without-neighbor models. These results illustrate that if the information about neighbor assemblies is not available, one could miscalculate the pin-by-pin burnup to a maximum of $3.8 \%$, given the particular neighbor configuration for this cycle.

Figure 25 (a) shows the pin-by-pin burnup in assembly NJ05YU after the second cycle (Cycle 10) based on the with-neighbor model. Because the neighbor configuration in the second cycle is symmetric, the radial burnup distribution becomes almost symmetric after the second cycle. The fuel rods around guide tubes have higher burnups than others because of the extra moderation in these tubes. (BPRs were removed from guide tubes and replaced by water in the second cycle.)

Fig. 25Figure 25 (b) shows the relative difference (\%) of burnup in each fuel rod of assembly NJ05YU between with- and without-neighbor models. Compared to the first cycle, the differences between the two models are smaller (with the maximum of $1.5 \%$ ), due to the fact that the second cycle had a symmetric neighbor configuration. As indicated in other studies reported in literature [10], the radial burnup distribution tends to become more evenly distributed in high-burnup fuel. 


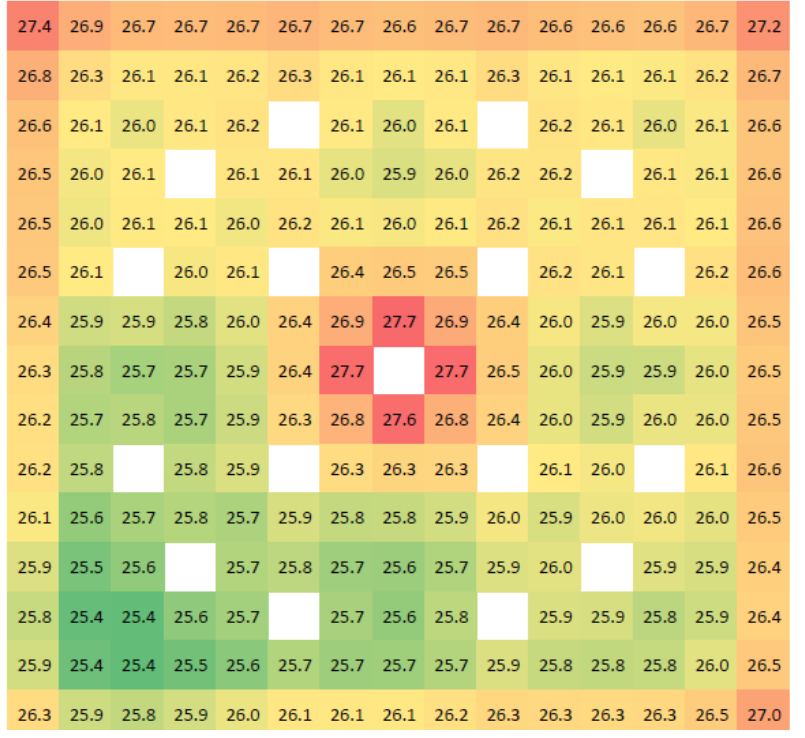

(a)

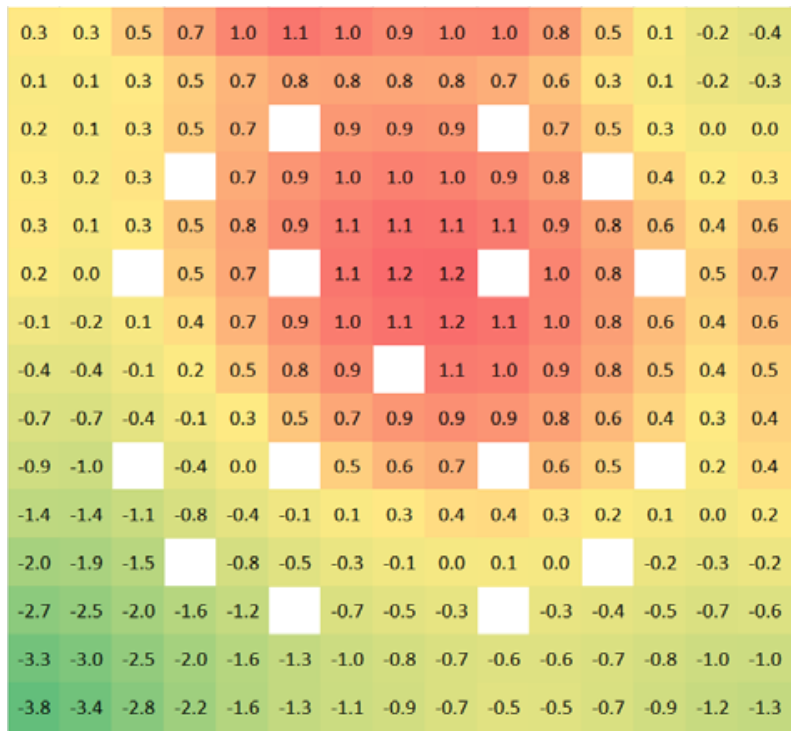

(b)

Fig. 24. (a) Calculated burnup (GWd/tU) in each fuel rod of assembly NJ05YU after the first cycle (Cycle 9) based on the with-neighbor model. (b) Relative difference (\%) in burnup of each fuel rod of assembly NJ05YU after the first cycle between with- and without-neighbor models.

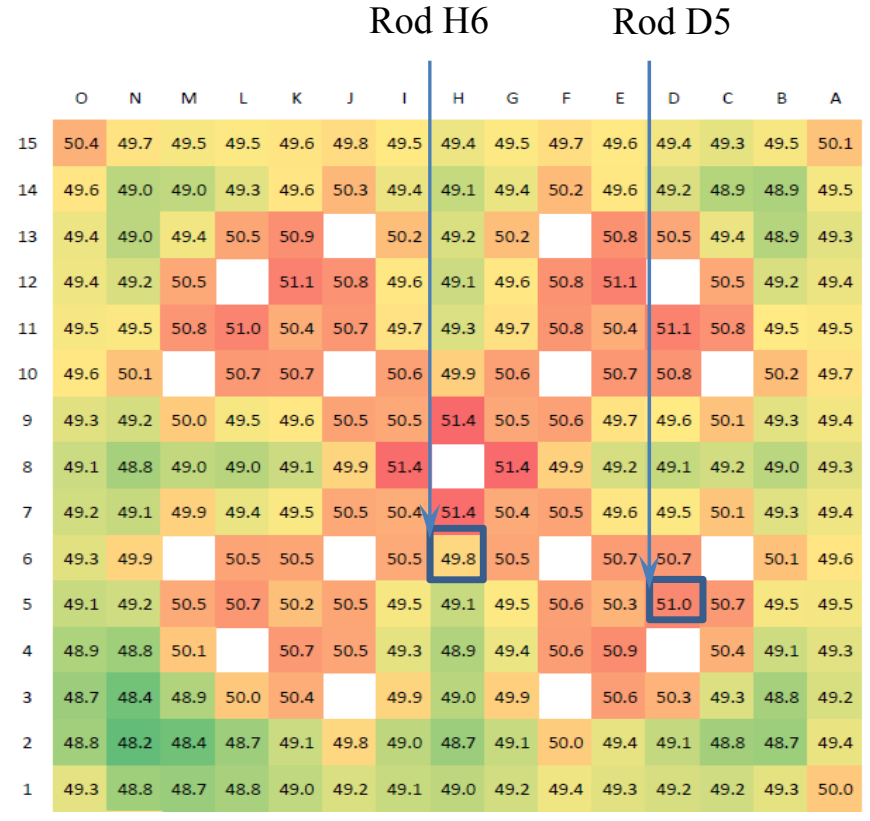

(a)

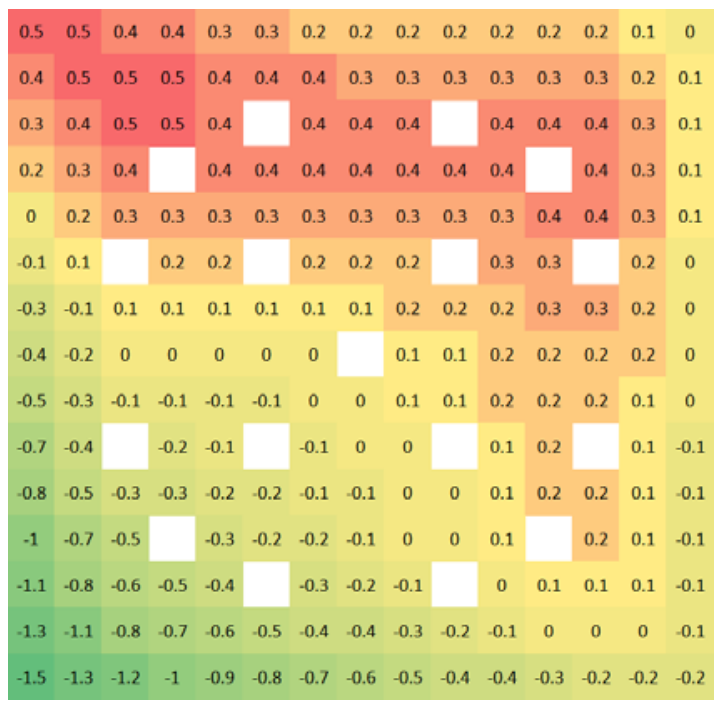

(b)

Fig. 25. (a) Calculated burnup (GWd/tU) in each fuel rod of assembly NJ05YU after the second cycle (Cycle 10) based on the with-neighbor model. (b) Relative difference (\%) of burnup in each fuel rod of assembly NJ05YU after the second cycle between the with- and without-neighbor models. 
The pin-by-pin burnup distribution of TMI-1 fuel was not provided by operator; thus, direct comparisons cannot be made. However, the burnups of the two interior rods (D5 and H6, selected for DA measurement) were estimated by the operator [38], and they are compared to the calculated values. Remember that in the calculation the operator-estimated assembly average burnup was input to the models. The comparisons are summarized in Table 11. The results from both with- and without-neighbor models are in good agreement with the operator data, indicating the models can accurately predict burnups for interior rods well based on the operator-provided assembly average burnup. The differences between the two models are small, indicating neighbor assemblies have small impacts on interior rods.

Table 11. Average burnup of rod D5 and $\mathrm{H6}$ in assembly NJ05YU

\begin{tabular}{|c|c|c|c|c|c|}
\hline & \multicolumn{3}{|c|}{ Average burnup of the fuel rod (GWd/tU) } & \multicolumn{2}{c|}{$\begin{array}{c}\text { Relative difference (\%) compared to } \\
\text { operator estimates }\end{array}$} \\
\hline Rod ID & $\begin{array}{c}\text { Operator } \\
\text { estimates }\end{array}$ & $\begin{array}{c}\text { Calculated }^{a} \\
\text { (with neighbor) }\end{array}$ & $\begin{array}{c}\text { Calculated } \\
\text { (without neighbor) }\end{array}$ & $\begin{array}{c}\text { With-neighbor } \\
\text { model }\end{array}$ & $\begin{array}{c}\text { Without-neighbor } \\
\text { model }\end{array}$ \\
\hline D5 & 49.36 & 50.96 & 50.87 & $3.24 \%$ & $3.06 \%$ \\
\hline H6 & 48.70 & 49.83 & 49.84 & $2.32 \%$ & $2.34 \%$ \\
\hline
\end{tabular}

${ }^{a}$ The operator-estimated assembly average burnup was input to the models.

\subsubsection{Assembly NJ070G}

Figure 26 (a) shows the pin-by-pin burnup ( $\mathrm{GWd} / \mathrm{tU})$ of assembly NJ070G calculated using the withneighbor model. As expected, the radial burnup distribution has a significant gradient from the west side of assembly to the east, because the west neighbor was a fresh assembly while the east neighbor was previously irradiated (as shown in Fig. 26 (b)). The average burnup on the west edge is 16\% higher than that on the east. On the other hand, the burnups are almost symmetric between the north and south half of the assembly because of the symmetric neighbor configuration in this direction. No power peaking was observed for fuel rods around guide tubes as normally seen because BPRs were inserted for this cycle. As shown, the burnups in the four gadolinia rods (highlighted in green) are significantly lower than the assembly average because gadolinium absorbs neutrons and thus reduces the power.

The pin-by-pin burnup distribution was not available from the operator, so only comparisons of the burnups of rod $\mathrm{O} 1$ and $\mathrm{O} 12$ (selected for both DA and NDA measurement) from assembly NJ070G were made here. In addition to the results presented in Table 8, the calculated burnups of these two rods using the TRITON model are added for comparison and presented in Table 12. As shown, the calculated burnups for these two edge rods are significantly higher than the measurements, especially for rod $\mathrm{O} 12$ $(18.63 \%)$. These results demonstrate the inability of TRITON model to predict burnups in exterior (edge) rods with acceptable accuracies. TRITON significantly overpredicted the burnup gradient across assembly NJ070G in the east-west direction, but under-predicted the gradient in the north-west direction. Also shown in this table, smaller relative burnup difference between rods $\mathrm{O} 1$ and $\mathrm{O} 12$ was predicted by TRITON than what was observed in measurements. The discrepancies of this calculation may largely be attributed to the limitation of the model - only the immediate neighbor assemblies were modeled and reflective boundary conditions, instead of realistic boundary conditions, were applied. In general, the assemblies in a reactor core are all coupled with one another, so the relative power distribution across the entire core influences the gradient across the assembly. Normally reactor operators have to model all assemblies in the core using full-core 3D commercial codes to predict power (burnup) share among the 
assemblies, which provides boundary conditions for subsequent models to predict pin-by-pin burnup distribution within a single assembly.

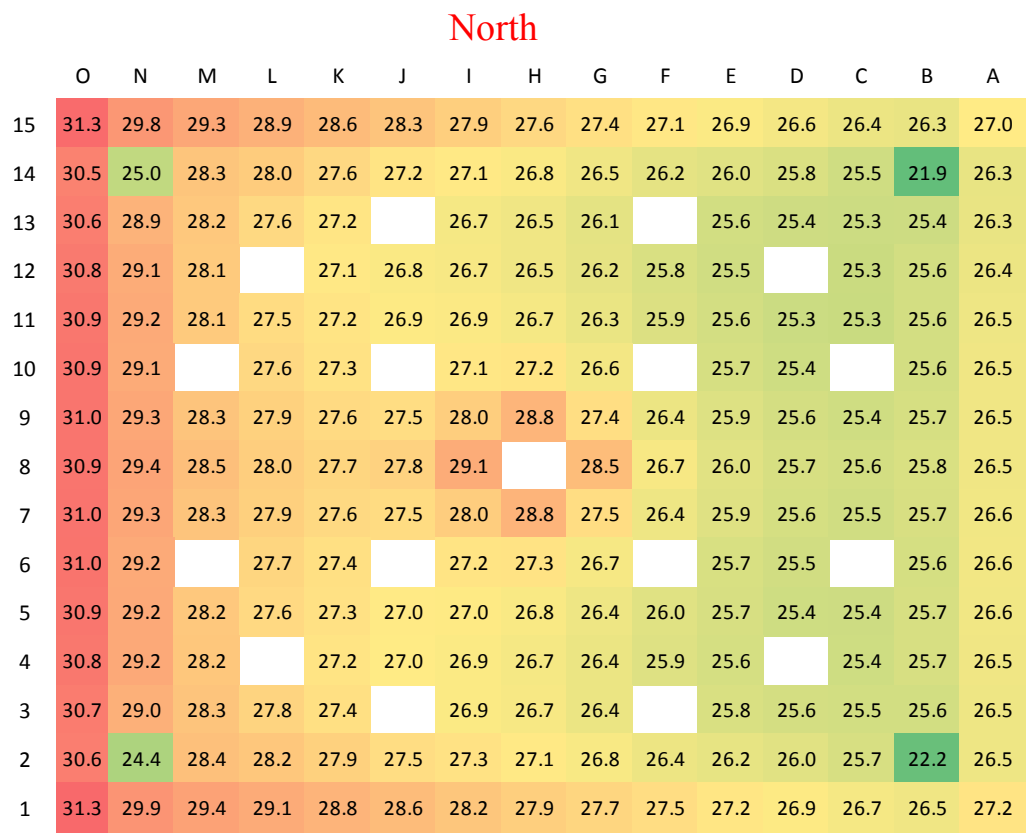

(a)

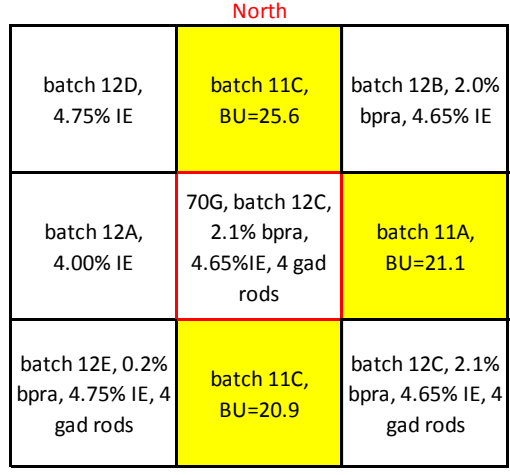

(b)

Fig. 26. (a) Calculated burnup (GWd/tU) in each fuel rod of assembly NJ070G after Cycle 10 (the first cycle) using the with-neighbor model; (b) Assembly NJ070G with its neighbor assemblies in Cycle 10 (duplicate of Fig. 20).

Table 12. Average burnup of rods $\mathrm{O1}$ and $\mathrm{O12}$ in assembly NJ070G determined by different methods

\begin{tabular}{|c|c|c|c|c|c|c|c|}
\hline & \multicolumn{4}{|c|}{ Average burnup of the fuel $\operatorname{rod}(\mathrm{GWd} / \mathrm{tU})$} & \multicolumn{3}{|c|}{$\begin{array}{c}\text { Relative difference (\%) compared to } \\
\text { "scan+Nd148" }\end{array}$} \\
\hline $\begin{array}{l}\text { Rod } \\
\text { ID }\end{array}$ & $\begin{array}{c}\text { scan }+ \\
\text { Nd148 }\end{array}$ & $\begin{array}{c}\text { scan }+ \\
\text { Ref. rod }\end{array}$ & OP.-est. ${ }^{c}$ & Calculation $^{d}$ & $\begin{array}{c}\text { scan }+ \\
\text { Ref. rod }\end{array}$ & OP.-est. & calculation \\
\hline $\mathrm{O} 1$ & 29.50 & 28.48 & 29.1 & 31.32 & -3.47 & -1.39 & 6.16 \\
\hline $\mathrm{O} 12$ & 25.93 & 25.25 & 27.1 & 30.76 & -2.63 & 4.6 & 18.63 \\
\hline
\end{tabular}

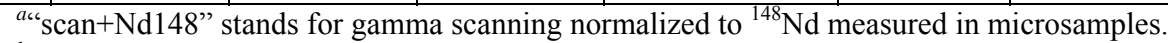

b، scan+Ref. rod" stands for gamma scanning normalized to a reference rod.

${ }^{c}$ Operator estimates

${ }^{d}$ Based on the "with neighbor" TRITON model as shown in Fig. 20, the operator-estimated assembly average burnup was input to the model.

These results demonstrate the impact of neighbor assemblies on radial burnup distributions can be difficult to predict in a lattice model. The TRITON model calculated the local burnups well for interior rods, but not for exterior rods in this study. For accurate estimates of the pin-by-pin burnup for the entire assembly, the use of full-core 3D commercial codes should be investigated. 


\subsubsection{Nuclide Concentrations}

In addition to the radial burnup distributions, the nuclide concentrations in these two assemblies were also calculated and analyzed. Some of the results are presented in this subsection.

\subsubsection{Impact of Neighbor Assemblies}

In addition to the impacts on radial burnup distributions, the neighbor assemblies were also observed to have important impacts on nuclide concentrations. Results for two important nuclides, ${ }^{244} \mathrm{Cm}$ and ${ }^{239} \mathrm{Pu}$, are presented. Curium-244 is a main source nuclide for passive neutrons in spent fuel, and ${ }^{239} \mathrm{Pu}$ is one of the main plutonium isotopes. Figure 27 (a) shows the comparison of ${ }^{244} \mathrm{Cm}$ concentration in each rod after the first cycle between the with- and without-neighbor models. As shown, the neighbor assemblies caused a maximum difference of $22 \%$ in the concentration of ${ }^{244} \mathrm{Cm}$ in the fuel rod at the southwest corner, due to the much lower burnup observed in that corner. The difference in ${ }^{244} \mathrm{Cm}$ is expected to be much smaller after the second cycle because the difference in burnup was smaller between these two models. Figure 27 (b) shows the comparison for ${ }^{239} \mathrm{Pu}$. Because ${ }^{239} \mathrm{Pu}$ is not as nearly sensitive to burnup as ${ }^{244} \mathrm{Cm}$, the differences in ${ }^{239} \mathrm{Pu}$ concentration between these two models are much smaller (with a maximum difference of $2.4 \%$ ).

Table 13 shows the relative difference (\%) in predicted nuclide concentrations between the with- and without-neighbor models. These results are based on the average nuclide concentrations in the exterior rod O1, which was not measured, and the interior rod D5 from assembly NJ05YU after the second cycle. As expected, the neighbor assemblies are shown to have quantifiable impacts on nuclides in the exterior rods, but marginal impacts on the interior rods.

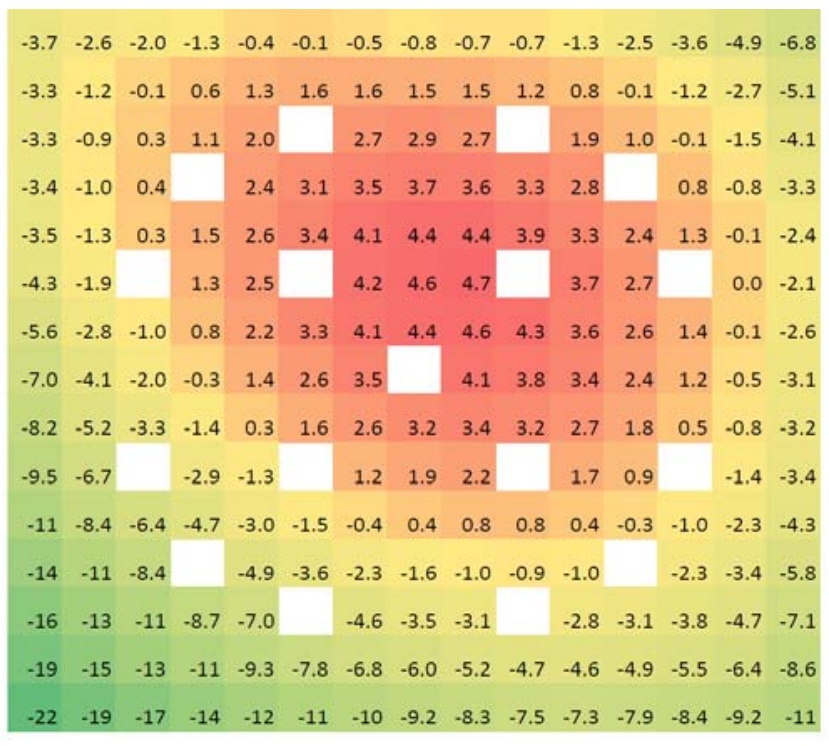

(a) ${ }^{244} \mathrm{Cm}$

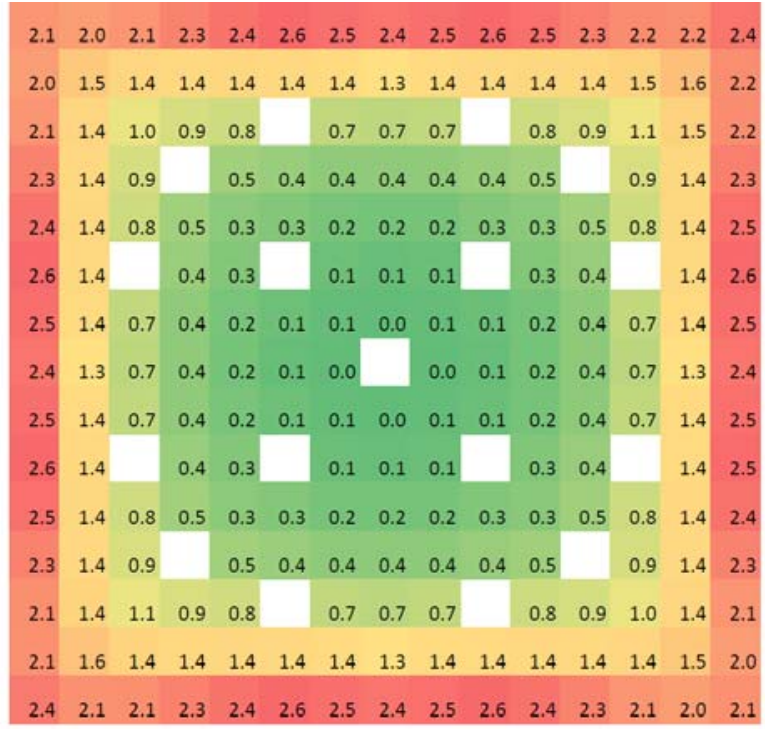

(b) ${ }^{239} \mathrm{Pu}$

Fig. 27. Relative difference (\%) in calculated nuclide concentrations of assembly NJ05YU between with- and without- neighbor models: (a) ${ }^{244} \mathrm{Cm}$ after the first cycle; (b) ${ }^{239} \mathrm{Pu}$ after the second cycle. 
Table 13. Relative difference (\%) in predicted nuclide concentrations between the with- and without-neighbor models in the exterior rod 01 and the interior rod D5 of assembly NJ05YU

\begin{tabular}{|l|c|c|}
\hline Nuclide & \multicolumn{2}{|c|}{$\begin{array}{c}\text { Relative difference (\%) between with- and } \\
\text { without-neighbor models }\end{array}$} \\
\hline & Rod O1 & Rod D5 \\
\hline${ }^{235} \mathrm{U}$ & 3.25 & -0.53 \\
\hline${ }^{239} \mathrm{Pu}$ & 2.36 & 0.51 \\
\hline${ }^{241} \mathrm{Pu}$ & 2.36 & 0.33 \\
\hline total $\mathrm{Pu}$ & 0.45 & 0.27 \\
\hline${ }^{244} \mathrm{Cm}$ & -4.30 & 0.40 \\
\hline
\end{tabular}

\subsubsection{Comparison to Measured Nuclide Concentrations}

In addition to DA measurements, NDA measurements on TMI-1 fuel are also available. The gamma spectra were recently measured at ORNL on fuel samples from rod D5 and H6 of assembly NJ05YU [42]. Table 14 shows a comparison of activity ratios of ${ }^{154} \mathrm{Eu} /{ }^{137} \mathrm{Cs}$ and ${ }^{134} \mathrm{Cs} /{ }^{137} \mathrm{Cs}$ of TMI fuel samples between the gamma measurement (NDA) and calculation. The DA-measured burnups of the fuel samples were used in the calculation. The agreement is good with all relative differences less than $3 \%$. These results demonstrate that if the fuel burnup is known, SCALE/TRITON can calculate the concentration of gamma-emitting nuclides accurately.

Table 14. Comparison of activity ratios of ${ }^{154} \mathrm{Eu} /{ }^{137} \mathrm{Cs}$ and ${ }^{134} \mathrm{Cs} /{ }^{137} \mathrm{Cs}$ of TMI fuel samples, from assembly NJ05YU NDA vs. calculation

\begin{tabular}{|c|c|c|c|c|c|c|c|}
\hline $\begin{array}{c}\text { Rod } \\
\text { ID }\end{array}$ & $\begin{array}{c}\text { Sample } \\
\text { ID }\end{array}$ & \multicolumn{2}{|c|}{$\begin{array}{c}\text { Measured activity ratio by } \\
\text { NDA }\end{array}$} & \multicolumn{2}{c|}{ Calculated activity ratio } & \multicolumn{2}{c|}{$\begin{array}{c}\text { Relative difference (\%), } \\
\text { calculation vs. NDA }\end{array}$} \\
\hline \multirow{4}{*}{ D5 } & & ${ }^{154} \mathrm{Eu} /{ }^{137} \mathrm{Cs}$ & ${ }^{134} \mathrm{Cs} /{ }^{137} \mathrm{Cs}$ & ${ }^{154} \mathrm{Eu} /{ }^{137} \mathrm{Cs}$ & ${ }^{134} \mathrm{Cs} /{ }^{137} \mathrm{Cs}$ & ${ }^{154} \mathrm{Eu} /{ }^{137} \mathrm{Cs}$ & ${ }^{134} \mathrm{Cs} /{ }^{137} \mathrm{Cs}$ \\
\cline { 2 - 8 } & $\mathrm{S} 1$ & 0.0261 & 0.0113 & 0.0263 & 0.0112 & 0.71 & -0.88 \\
\cline { 2 - 8 } & $\mathrm{S} 2$ & 0.0271 & 0.0119 & 0.0271 & 0.0121 & 0.03 & 1.63 \\
\cline { 2 - 8 } & $\mathrm{S} 3$ & 0.0268 & 0.0126 & 0.0276 & 0.0124 & 2.91 & -1.68 \\
\cline { 2 - 8 } & $\mathrm{S} 4$ & 0.0282 & 0.0128 & 0.0276 & 0.0125 & -2.20 & -2.18 \\
\hline
\end{tabular}

The DA measurement of nuclide concentrations on fuel samples from assembly NJ070G, performed by GE-VNC, provides a good opportunity to assess the ability of SCALE/TRITON to predict nuclide compositions in spent fuel and also to validate the TMI-1 models. The sample O12S5, from the exterior fuel rod O12, was chosen for this study because this sample was in the middle of rod (axial elevation: 77.6 in.), and NDA measured the burnup of this rod relatively well (as shown in Table 8).

In order to perform burnup calculations on the fuel sample, the burnup of the fuel sample needs to be known beforehand and entered into the model.

Table 9 presents the differences in the burnup values of this sample based on different methods: DA measurement, NDA measurement, and operator estimate. The DA measured burnup was based on the measured ${ }^{148} \mathrm{Nd}$ in the dissolved fuel solution, and then it was converted into burnup using the ASTM standard [30]. The NDA measured burnup was taken as the average value determined by the "scan+Nd148" and "scan+Ref. rod" methods as described previously. The operator-estimated burnup on this sample was derived from the operator-provided rod-average burnup and the axial profile. In addition, the sample burnup can also be calculated using the TRITON model based on the operator-estimated assembly average burnup. (The assembly average burnup at the axial elevation of the sample was derived 
from the axial burnup profile.) As shown, the difference between the DA- and NDA-measured burnup is $4.5 \%$, whereas the results from operator estimate and calculation deviate from DA measurement significantly ( $10.2 \%$ and $23.4 \%$, respectively).

The different burnup values for the sample were applied to each TRITON model to calculate the nuclide inventory in the sample, and the calculated inventory was then compared to measured results. Table 15 shows the relative difference (\%) in nuclide concentrations calculated by four different models compared to DA measurements. As shown, the TRITON model predicts the nuclide concentrations well if the DA or NDA measured burnups are provided, with most nuclides agreeing to the experiment within $5 \%$, and " $\mathrm{Pu}$ total" was $1.1 \%$ and $4.0 \%$ different from measurement, respectively. Neodymium-148 was used as the burnup indicator in the DA measurement, and ${ }^{137} \mathrm{Cs}$ was used in the NDA measurement. These results demonstrate that both ${ }^{148} \mathrm{Nd}$ and ${ }^{137} \mathrm{Cs}$ are good burnup indicators. With operator-estimated burnup, the calculated results are in large disagreements with experiment; this is not surprising because the TMI operator data on burnup for exterior rods was not accurate as described earlier. If only the assembly average burnup is known and no information about the local burnup is available, even with the neighbor assemblies included, the model significantly miscalculates the burnup (23.4\%) and nuclide concentrations (13.7\% in "Pu total" and even larger errors in some other nuclides). These results reaffirm the limitation of the assembly lattice burnup models in predicting local burnups in exterior fuel rods.

\section{Table 15. Relative differences (\%) in nuclide concentrations calculated by four different models ${ }^{a}$ compared to measurement for the TMI-1 sample O12S5 from assembly NJ070G}

\begin{tabular}{|l|c|c|c|c|}
\hline \multirow{2}{*}{} & \multicolumn{5}{|c|}{$\begin{array}{c}\text { Relative differences (\%) in nuclide concentrations between calculations and } \\
\text { measurements. The calculations used four different burnup values determined } \\
\text { by different methods }\end{array}$} \\
\cline { 2 - 5 } & DA burnup & NDA burnup & OP.-est. burnup & Calculated burnup \\
\hline Burnup & $26.5^{b}$ & $277.7^{b}\left(4.5^{c}{ }^{c}\right)$ & $29.2^{b}\left(10.3 \%^{c}\right)$ & $23.7^{b}\left(23.4 \%{ }^{c}\right)$ \\
\hline U-235 & 3.9 & 0.4 & -4.1 & -11.2 \\
\hline Pu-239 & 3.4 & 4.9 & 6.7 & 9.6 \\
\hline Pu-241 & -5.4 & 0.6 & 8.0 & 20.6 \\
\hline Pu total & 1.1 & 4.0 & 7.6 & 13.7 \\
\hline Cm-244 & -18.3 & 1.2 & 31.0 & 96.9 \\
\hline Nd-148 & 2.2 & 7.0 & 13.0 & 23.4 \\
\hline Cs-137 & -4.4 & 0.0 & 5.6 & 15.2 \\
\hline
\end{tabular}

\footnotetext{
${ }^{a}$ The four models were input four different burnup values for the sample: DA measured burnup, NDA measured burnup, operator estimated burnup, and the calculated burnup based on assembly average burnup.

${ }^{b}$ The burnup values $(\mathrm{GWd} / \mathrm{tU})$ of the sample determined by the four different methods.

${ }^{c}$ Relative difference in burnup values compared to DA measurement.
}

The application of operator and NDA data of the TMI-1 fuel has been examined, and it has been demonstrated that the conventional NDA method of gamma scanning can measure the axial burnup profile well. Asymmetric fuel assembly neighbors have impacts on burnup distribution and nuclide concentrations in the assemblies with low-to-medium burnup, but the gradients tend to be reduced in high-burnup fuel assemblies. Determination of local burnups within an assembly can be challenging, especially for exterior fuel rods. If the fuel burnup is known, the SCALE/TRITON burnup model can calculate the nuclide concentrations with reasonable accuracies. However, lattice physics codes may be inadequate in predicting local burnups in exterior fuel rods; full-core 3D core simulator codes should be investigated for predicting local burnups for the entire assembly. 


\section{IMPACTS OF NUCLEAR DATA UNCERTAINTIES ON CALCULATED NUCLIDE INVENTORIES}

Advanced modeling and simulation codes have been used extensively for instrument design, development, and calibration. Quantifying the uncertainties in these codes is an essential task required for instrument calibration. The uncertainties in the underlying nuclear data used by the computer codes affect the calculated nuclide concentrations in spent fuel and thus the predicted instrument responses; however, such impacts have not been previously studied under the NGSI program. Nuclear data uncertainties represent the limiting (smallest) uncertainties that can be expected from the code predictions, and therefore define the highest attainable accuracy of the instrument.

The impacts of nuclear data uncertainties on calculations of spent nuclear fuel content and associated NDA instrument responses are studied in this section. Recently developed methods [43] within the SCALE code system are applied in this study. The impacts of nuclear data uncertainties on advanced NDA responses are summarized in the next section.

The study addresses only the uncertainties in the calculated nuclide concentrations of the spent fuel assembly; it does not include the impacts of nuclear data uncertainties on radiation transport calculations of the MCNP detector model.

\subsection{UNCERTAINTIES IN NUCLEAR DATA}

There are three main types of nuclear data involved in burnup calculations: 1) neutron cross sections (e.g., fission and absorption cross sections); 2) fission product yields (e.g., fission product generation due to the fission of an actinide); and 3) decay data (e.g., half-lives, branching ratios). Uncertainties exist in all nuclear data; for example, uncertainties exist in the cross-section values, measured half-lives, and branching ratios. In addition, many of the data are correlated, and accurate representations of these data correlations (covariance files) are necessary for rigorous uncertainty analysis.

The majority of research effort in uncertainty analysis has been directed at expanding the covariance data for nuclear cross sections. The most recent release of the Evaluated Nuclear Data Files, ENDF/B-VII.1 [44], provides extensive data on cross-section uncertainties (covariance data evaluations) for 190 isotopes that are particularly important in nuclear technology applications. The previous release, ENDF/B-VII.0 [45], contained neutron cross-section covariances for 26 materials, of which only 14 were considered complete representation of the reaction energy range and major reaction channels. The expansion of neutron cross-section covariance data represents one of the major advances in the latest nuclear data library. The neutron cross-section covariance data used in this work were developed prior to the release of ENDF/B-VII.1 and are distributed with the SCALE code system. Selected covariance evaluations were taken from the pre-release of ENDF.B-VII.1, while most of the data were taken from ENDF/B-VII.0, ENDF/B-VI, and JENDL, and additional low-fidelity data for more than 300 nuclides were developed by U.S. national laboratories under a DOE project for nuclear criticality safety [46]. Cross section covariances for a total of 401 materials were available.

ENDF/B-VII and other international evaluated nuclear data files currently do not include covariance information for fission product yields, which are highly correlated. The evaluations contain uncertainties for the direct and cumulative fission yields, but not the correlations necessary to apply the data for fission product uncertainty analysis. To support uncertainty analysis for fission products, correlation matrices for direct fission yields have recently been developed by ORNL using the nuclear data and uncertainties in the ENDF/B-VII.0 evaluations, developed by England and Rider [47], and these covariance files have been implemented for use in SCALE. The decay data are generally correlated to a lesser degree, and the uncertainties for decay data are available through ENDF/B-VII. The covariance files are utilized by SCALE for the uncertainty analyses. 


\subsection{UNCERTAINTY ANALYSIS METHODS}

A newly developed uncertainty analysis tool within SCALE, named Sampler [43], was applied to the burnup calculations used to support NGSI spent fuel analysis in this work. Sampler generates perturbed nuclear data libraries that have been adjusted by Monte Carlo (stochastic) sampling of the data in a manner that is consistent with the uncertainties and correlations in the data. This stochastic sampling of the correlated nuclear data uncertainties is performed using the XSUSA code developed by GRS in Germany. Sampler can be applied to any SCALE sequence (e.g., burnup and criticality calculations). Sampler repeatedly calls the SCALE sequence to perform the calculation, each time using a different set of perturbed nuclear data libraries, and then post-processes the results to obtain the distribution and statistical parameters on the calculated quantities. Figure 28 shows the flowchart of Sampler.

The TRITON module within SCALE is widely used to perform burnup calculations and is used within the NGSI-SF project to generate the reference spent fuel inventories for the spent fuel assemblies being measured at the Clab facility in Sweden and the assemblies measured in ROK. For each set of the perturbed data libraries, an individual TRITON calculation was executed and the responses (e.g., nuclide concentrations in this case) due to the different data libraries were obtained. The variance in the responses attributed to the nuclear data uncertainties can thus be assessed. Sampler will post-process the response distributions to compute statistical parameters (e.g., standard deviation of the concentration of a particular nuclide). Sampler can also perform perturbations to modeling parameters of a system to assess the impacts of uncertainties in material densities, temperatures, dimensions, etc.

TRITON couples the two-dimensional deterministic neutron transport code NEWT, which was used in this work, or the three-dimensional Monte Carlo KENO code for the neutron transport calculation, with the ORIGEN code for nuclide depletion and decay calculations. Therefore, uncertainties in the neutron cross sections (used in both the neutron transport and depletion calculation), fission product yields, and nuclear decay data are all included in the total uncertainty analysis.

\subsection{IMPACT OF NUCLEAR DATA UNCERTAINTIES ON NUCLIDE CONCENTRATIONS}

A simplified assembly model of a typical $15 \times 15$ PWR design with 16 guide tubes and 1 central instrument tube was developed for this work, and it is shown in Figure 29. All the fuel rods were modeled using a single fuel material mixture (uniform composition). In reality, the fuel content will vary from rod to rod, but for purposes of this study, uniform rod compositions were used (i.e., no burnup gradient) because the focus here is to establish minimum uncertainties due to the nuclear data. The fuel has an initial ${ }^{235} \mathrm{U}$ enrichment of $4.5 \mathrm{wt} \%$ and was irradiated to $45 \mathrm{GWd} / \mathrm{tU}$ and cooled for 5 years.

A total of 120 separate burnup calculations were performed, with each calculation using a different set of perturbed cross section, fission yield, and decay libraries. By examining the distribution of nuclide concentrations from these calculations, the standard deviation for each nuclide was obtained. Figure 30 shows uncertainty in calculated ${ }^{239} \mathrm{Pu}$ content caused by nuclear data uncertainties. As shown, the uncertainty of ${ }^{239} \mathrm{Pu}$ increases with burnup and reaches $1.3 \%$ at $45 \mathrm{GWd} / \mathrm{tU}$ due to the accumulation of nuclear data uncertainties at higher burnups. Figure 31 shows the distribution of ${ }^{239} \mathrm{Pu}$ content after the 5 -year cooling time for all 120 samples, indicating that the predicted ${ }^{239} \mathrm{Pu}$ content is within the range of 27 to $28 \mathrm{~mol}$ per tonne $\mathrm{U}$ (tU) $(\sim 0.6 \%$ in heavy metal concentration). The mean value and relative standard deviation of the distribution is $27.42 \mathrm{~mol} / \mathrm{tU} \pm 1.3 \%$. This value presents the expected uncertainty in the calculated result due to the nuclear data alone. Uncertainties for any other nuclide or calculated quantities can be obtained in a similar manner. This distribution of the results will approach a normal distribution as the number of samples increases. 


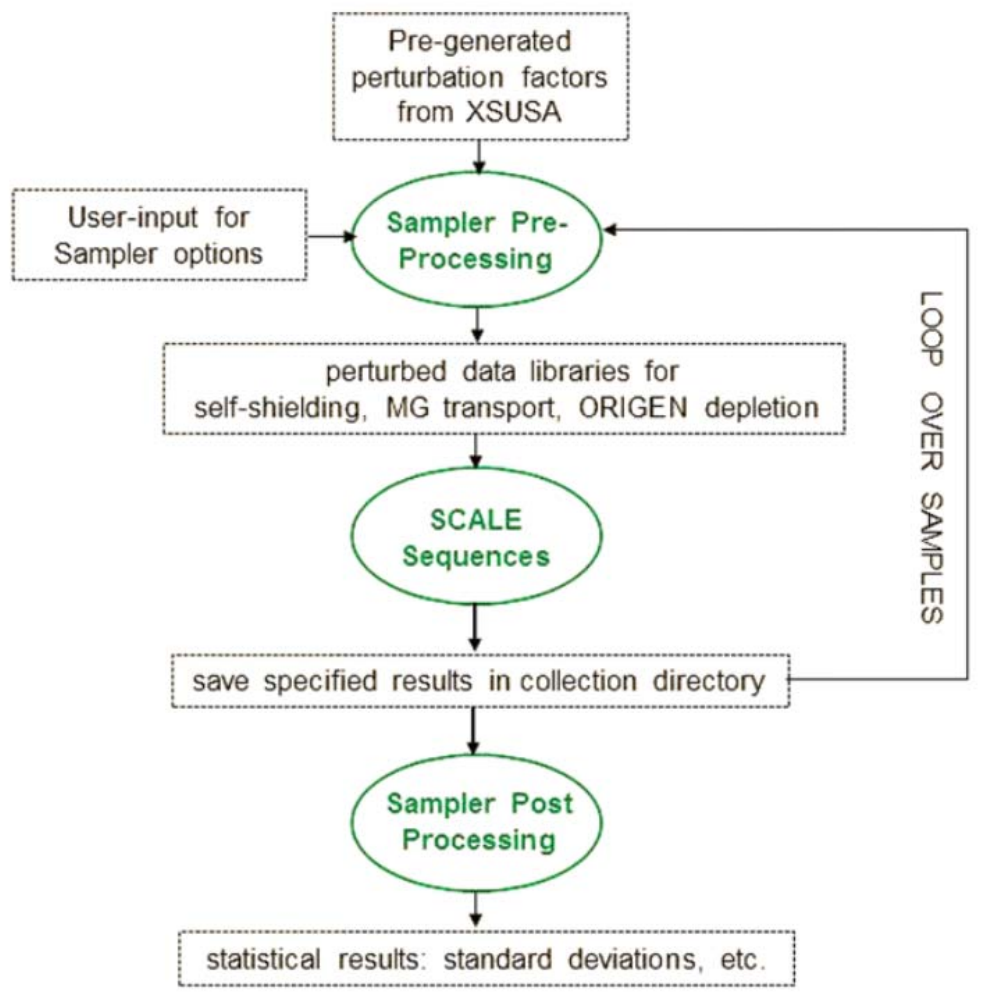

Fig. 28. Sampler flowchart [43].

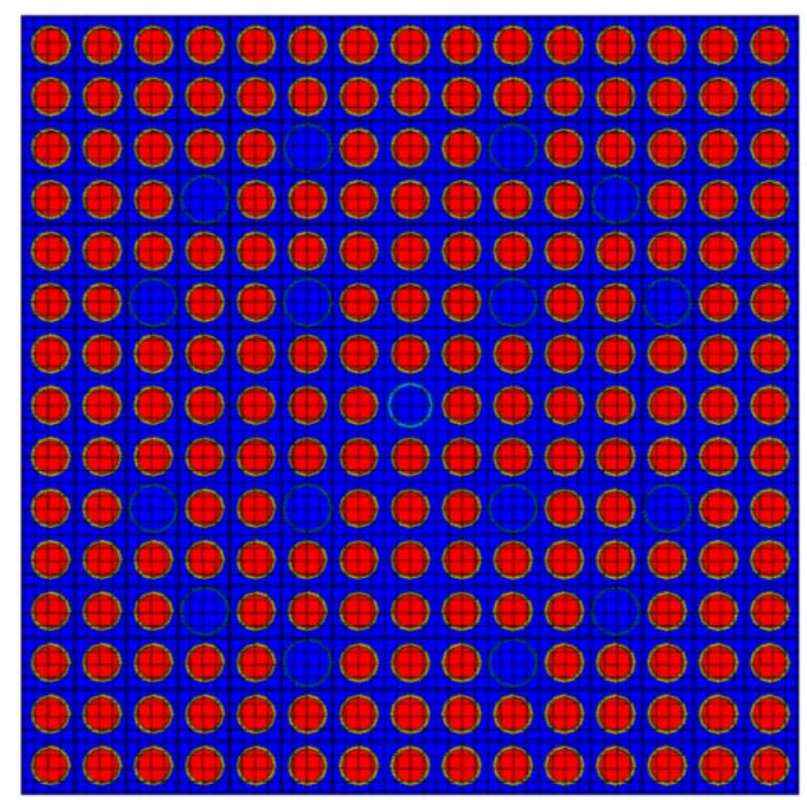

Fig. 29. The simplified $15 \times 15$ PWR spent fuel assembly as modeled in TRITON. 


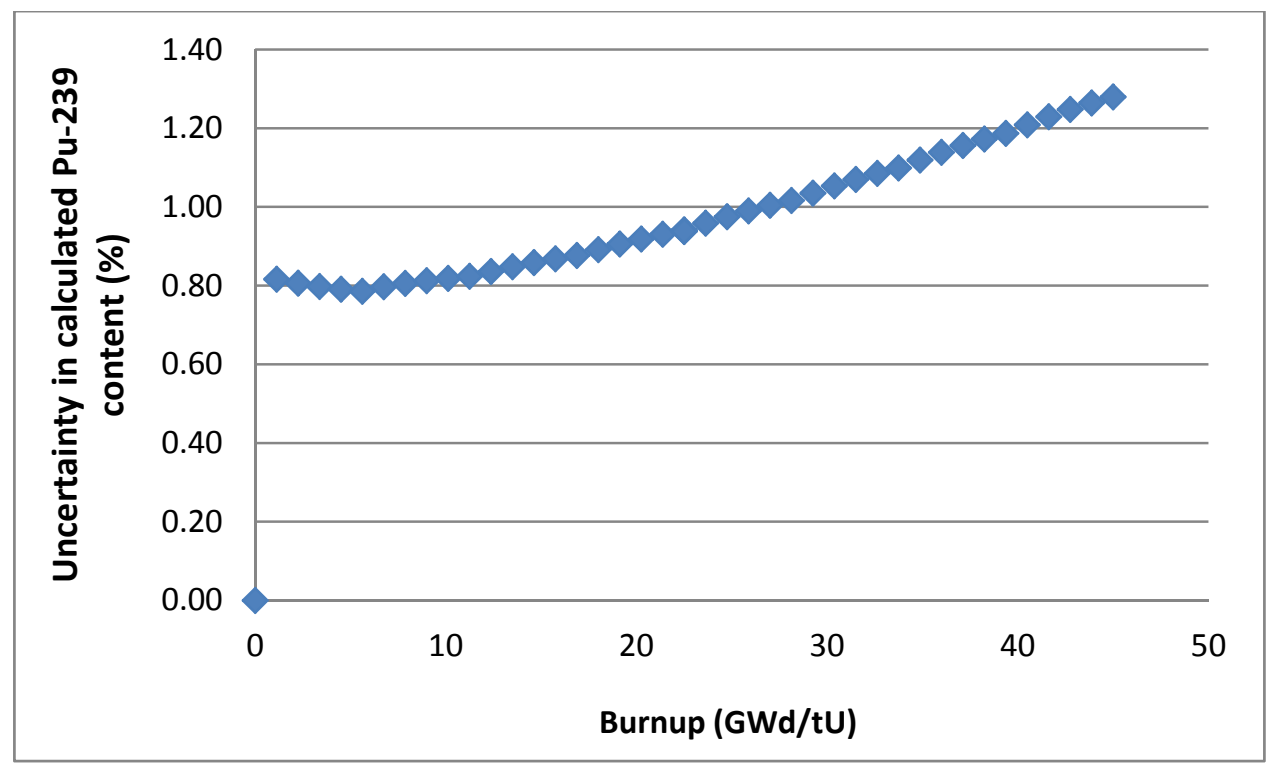

Fig. 30. Uncertainty in calculated ${ }^{239} \mathrm{Pu}$ content as a function of burnup.

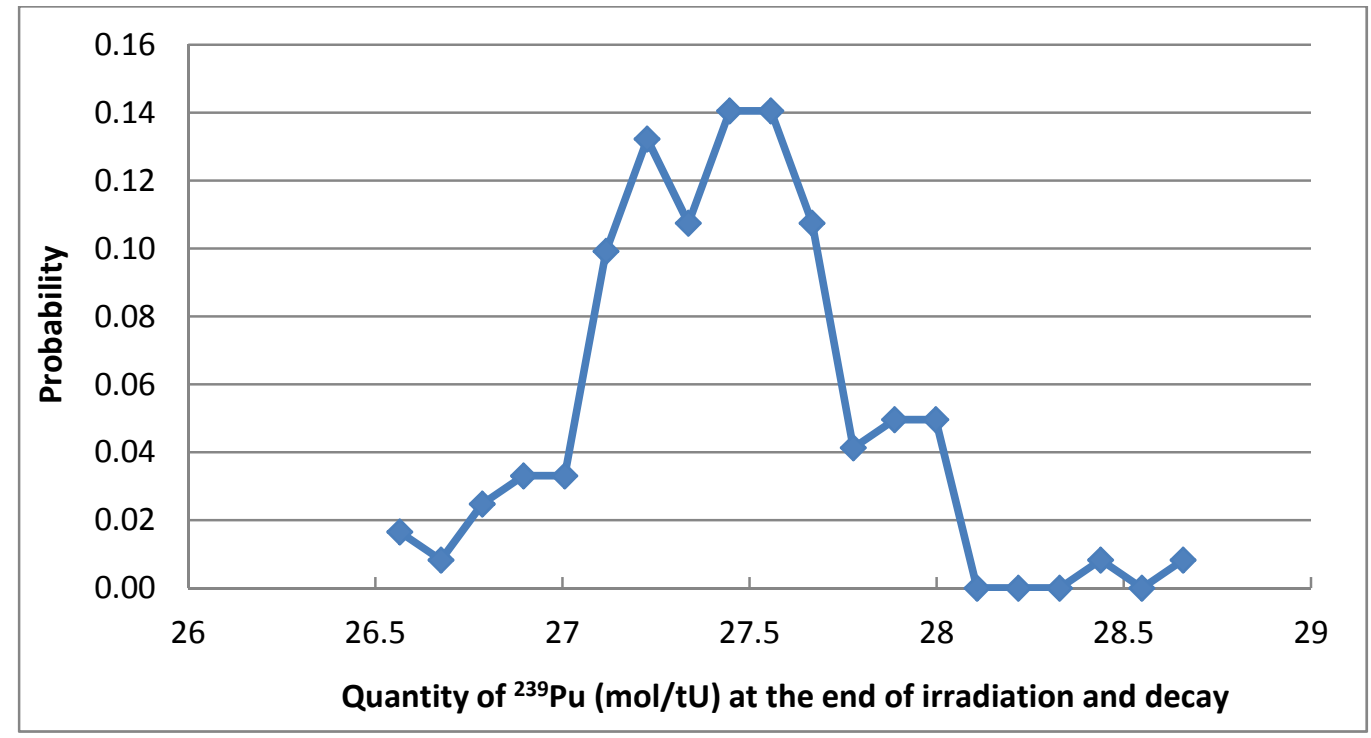

Fig. 31. Distribution of calculated ${ }^{239} \mathrm{Pu}$ mass results for 120 samples. 
Figure 32 shows the relative standard deviation of the major actinides based on the 120 samples. As shown, the relative standard deviations caused by the uncertainties in nuclear data are generally within $2 \%$ for most actinides, and they vary from one nuclide to another because their production paths are different. The standard deviation for ${ }^{239} \mathrm{Pu},{ }^{240} \mathrm{Pu}$, and ${ }^{241} \mathrm{Pu}$, the three major plutonium isomers, are $1.3 \%$, $1.4 \%$, and $1.0 \%$, respectively. Because ${ }^{244} \mathrm{Cm}$ is a dominant passive neutron source in spent fuel, the large relative standard deviation of ${ }^{244} \mathrm{Cm}(6.5 \%)$ may have significant impacts on the responses of the NDA instruments that measure passive neutrons. The isotopes ${ }^{235} \mathrm{U},{ }^{239} \mathrm{Pu}$, and ${ }^{241} \mathrm{Pu}$ are the primary fissile nuclides in spent fuel, and ${ }^{240} \mathrm{Pu}$ and ${ }^{241} \mathrm{Am}$ are the primary neutron absorbers. These nuclides have important impacts on the neutron multiplication factor in spent fuel and thus on NDA neutron signals.

Figure 33 shows the relative standard deviation for several important fission products. Compared to the actinides, the fission products uncertainties are much larger because the uncertainties in fission yield data are generally greater than for neutron cross sections. It is important to note that the fission product yield covariance file used in this study is known to overestimate the fission product uncertainties. Therefore, the results shown here represent conservative estimates of uncertainties in the simulations. As shown, for most fission products, the standard deviation varies from $5 \%$ to $10 \%$. The standard deviation for ${ }^{137} \mathrm{Cs}$ and ${ }^{134} \mathrm{Cs}$ is $2.3 \%$ and $5.1 \%$, respectively $\left({ }^{137} \mathrm{Cs}\right.$ and ${ }^{134} \mathrm{Cs}$ are two of the primary photon source nuclides). Many of these nuclides (e.g., ${ }^{133} \mathrm{Cs},{ }^{143} \mathrm{Nd},{ }^{149} \mathrm{Sm},{ }^{154} \mathrm{Eu}$ ) are major neutron absorbers in spent fuel, and they have important impacts on NDA instrument neutron signals.

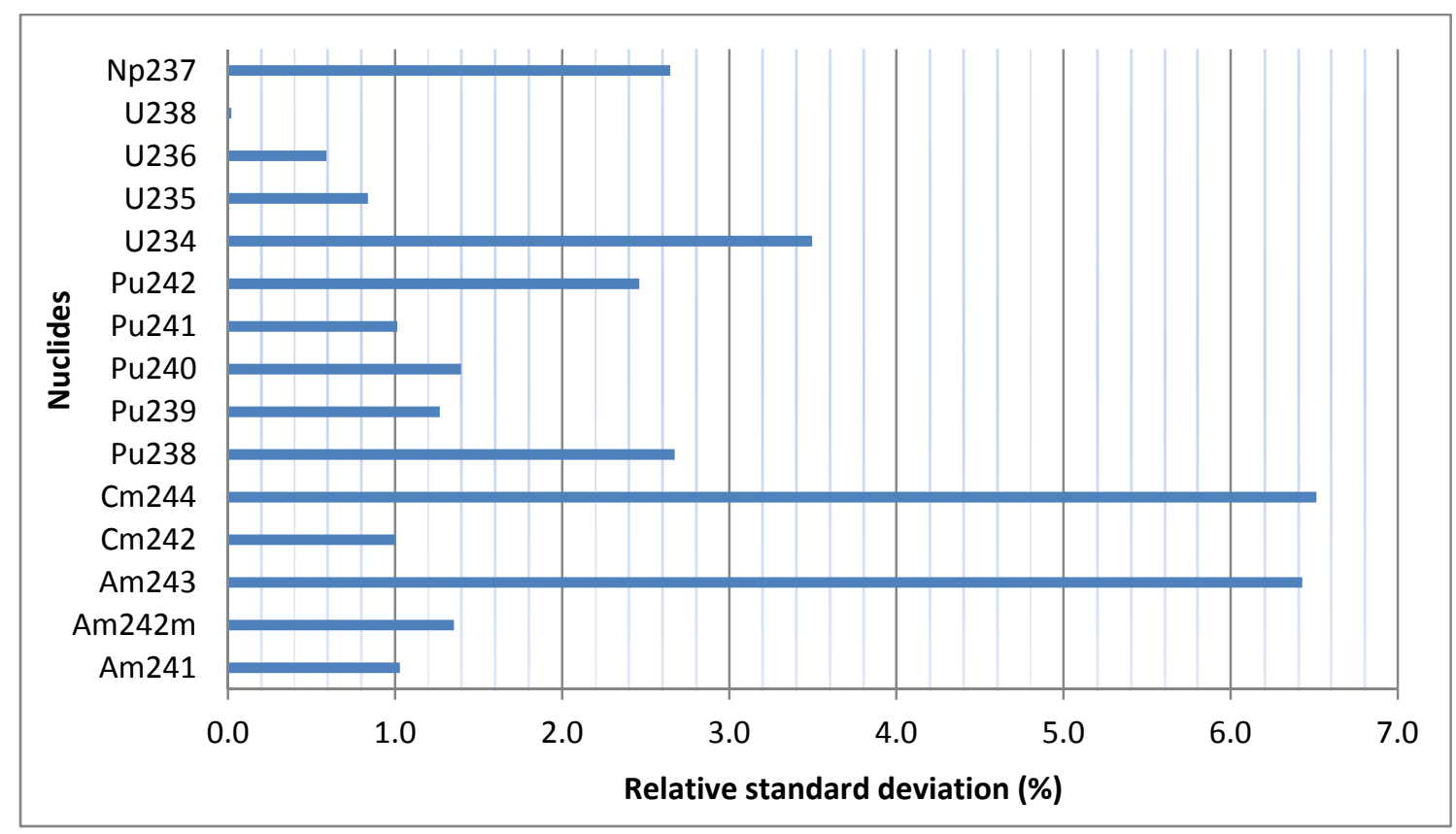

Fig. 32. Relative standard deviation of major actinides. 


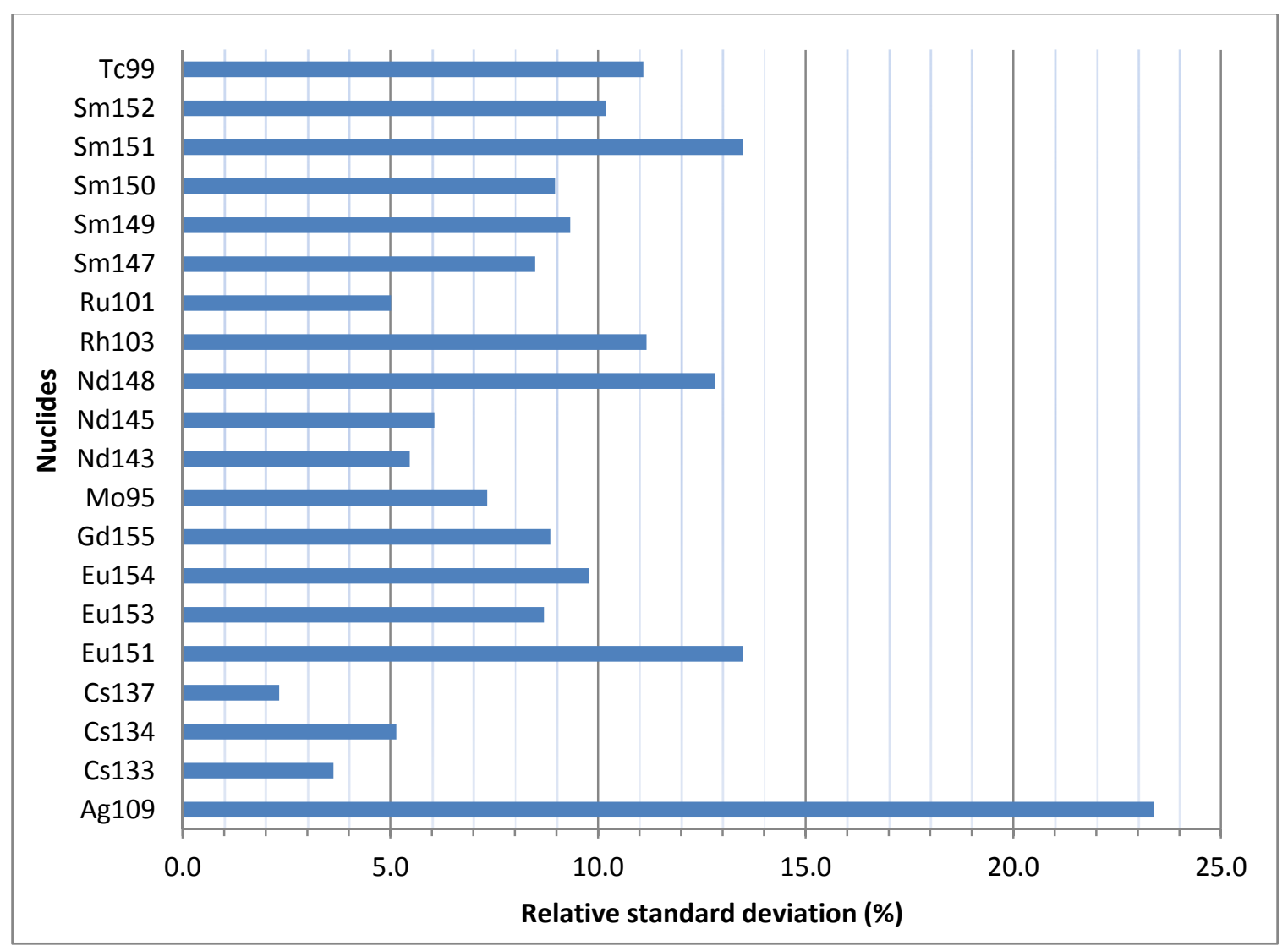

Fig. 33. Relative standard deviation of important fission products.

In summary, this work examined the impact of nuclear data uncertainties on nuclide concentrations in spent fuel. Uncertainties in the nuclide concentrations were estimated based on burnup calculation using 120 sets of perturbed nuclear data libraries generated using stochastic sampling of the uncertainty and covariance data. The resulting nuclide concentrations in each case were compared to that of the reference case, in which the nuclear data were not perturbed. The impact of nuclear data uncertainties on major plutonium isotopes is approximately $1 \%$, and the impact on most other actinides is within $4 \%$. For ${ }^{244} \mathrm{Cm}$, the most important source of passive neutrons in spent fuel, the uncertainty is around $6 \%$. Uncertainties in calculated fission product concentrations are greater than those for actinides due to larger uncertainties in fission yield data. 


\section{UNCERTAINTY PROPAGATION TO ADVANCED NDA SIGNALS}

In the previous sections, we discussed how uncertainties in design and operating history information, NDA data, and nuclear data affect the nuclide compositions in a spent fuel assembly. In this section we will examine how these uncertainties propagate to the detector responses. This examination is critical, because the uncertainties in a working standard calibration assembly can affect the response of different advanced NDA instruments in different ways. For instance, gamma-ray signals may be highly sensitive to uncertainties in the burnup gradient of the assembly, whereas neutron signals may be more sensitive to the uncertainties of assembly average burnups. It is therefore important to not only quantify the uncertainties in the compositions of a calibration assembly but also the net impacts of those uncertainties on the signals measured by advanced NDA instruments. Californium Interrogation Prompt Neutron (CIPN) instrument is one of the advanced NDA instruments [1] that will be used for the field tests [2]. CIPN was therefore selected to evaluate the effect of uncertainties for this study because its detection capability penetrates across the entire assembly [48].

\subsection{DESCRIPTION OF CIPN}

CIPN is a relatively low-cost and lightweight instrument that resembles a Fork detector, except that CIPN has an active interrogation source $\left({ }^{252} \mathrm{Cf}\right)$. CIPN currently does not measure gamma spectrum, but such capability could be added. CIPN shows promising capability for determining fissile content and in detecting diversion of fuel rods in spent nuclear fuel assemblies [48-50].

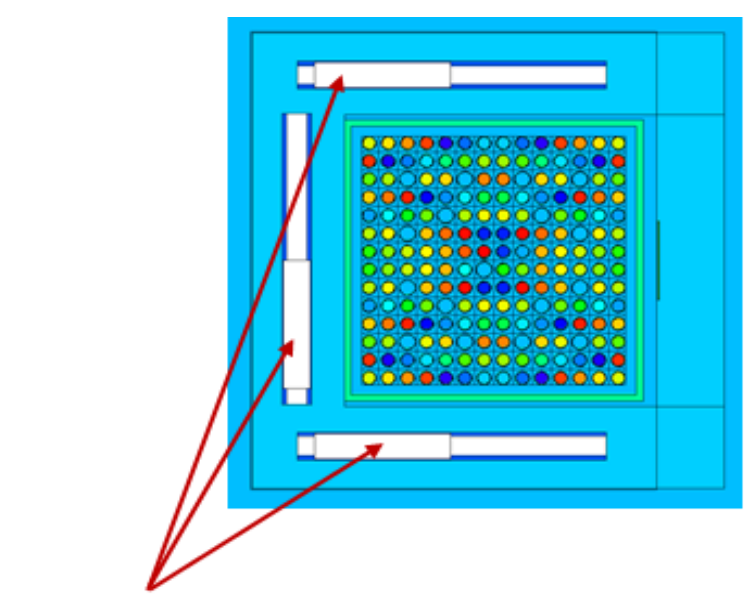

fission chambers

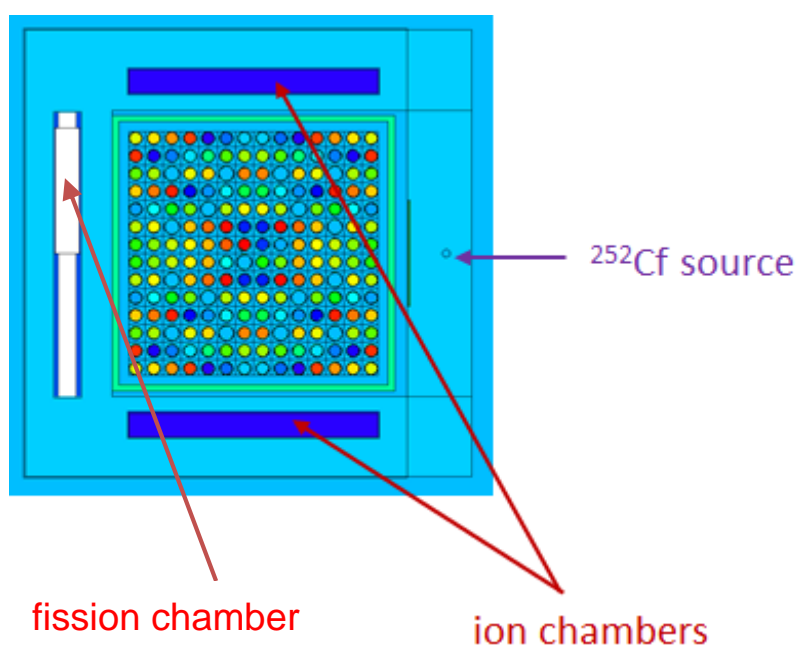

(b)

Fig. 34. Cross-sectional views of the CIPN instrument at two axial levels: (a) $\mathrm{Z}=-3 \mathrm{~cm}$; (b) $\mathrm{Z}=3 \mathrm{~cm}$.

Figure 34 shows the cross-sectional views of the CIPN instrument at two axial levels: $Z=-3 \mathrm{~cm}$ and $Z=$ $3 \mathrm{~cm}$ (the center of the assembly is set as $Z=0$ ). As shown, there are four fission chambers in the instrument to detect total neutrons and two ion chambers to detect total photons. CIPN can operate in both passive and active modes. In the passive mode, the californium source is not present, and the passive neutrons and photons are emitted from the spent fuel assembly itself. In the active mode, a californium source is placed in proximity to the assembly. In addition to the passive neutrons, the neutrons emitted from the californium source will induce fissions in the fuel, and these fission neutrons will add to the neutron signal. The difference of neutron counts between the active and passive mode, or the net neutron 
count, is related to the neutron multiplication factor of the assembly and thus the fissile content [48]. (For photon counts, the active mode is similar to passive mode because addition of the active neutron source does not appreciably impact the photon counts.) The net neutron counts are mainly driven the external neutron source (californium) and the multiplication factor, which is determined by the combined effect of multiple fissile nuclides and neutron absorbing nuclides. Due to the complexity in net neutron count rate, the passive neutron and photon count rate of CIPN is the focus in this study.

\subsection{PROPAGATION OF UNCERTAINTIES TO CIPN}

Several scenarios were studied to assess how uncertainties in the nuclide contents for a reference calibration assembly affect the CIPN signals. The three parameters identified as being of high importance to calculating assembly compositions were investigated: (a) impact of neighbor assemblies on the reference calibration assembly (in case the information about the neighbor assemblies is not available from the operator), (b) impact of uncertainty in the operator-provided assembly burnup, and (c) uncertainty in the burnup distribution in the assembly. In addition, the impacts of nuclear data uncertainties on CIPN count rates were studied. The following cases were analyzed:

1) Case 1, modeling an assembly with or without the neighbor assembly information;

2) Case 2, an assembly average burnup uncertainty of 5\%;

3) Case 3, modeling an assembly using the burnup for each fuel rod and using a burnup distribution estimated using only the burnup of the four corner rods; and

4) Case 4, CIPN count rates of 20 assemblies that are generated using perturbed nuclear data libraries are compared to the count rate of the reference assembly.

In Case 1, depletion models were developed based on the TMI-1 $15 \times 15$ Mark B assembly NJ05YU (as described in Sect. 6); one with the neighbor assemblies and the other without (reflective boundary conditions applied). The study in Sect. 6 demonstrated that the impact of the neighbor assemblies can influence the outer rows of fuel rods in the assembly, and has a diminishing effect for the inner rows. The two sets of assembly nuclide compositions from the two depletion models were imported into the MCNP model of CIPN to simulate both the neutron and photon (gamma) count rates. The purpose of this case is to assess the impact of neighbor assemblies on the detector response, because the information about neighbor assemblies may be difficult to obtain from the operator [10]. As concluded in the previous section, the neighbor assemblies have significant impacts on the nuclide compositions of assembly NJ05YU after the first cycle, but marginal impacts after the second cycle (due to the symmetric neighbor configuration in the second cycle), so most results on detector response presented in this section are based on the first cycle.

In Case 2, assembly NJ05YU was modeled using two different burnups, $48.57 \mathrm{GWd} / \mathrm{tU}$ (the declared burnup) and $51.0 \mathrm{GWd} / \mathrm{tU}$ (5\% higher than the declaration), and the two sets of nuclide compositions were imported into CIPN to calculate the count rates. The purpose of this case is to assess the uncertainty in advanced NDA response introduced by the uncertainties in operator-provided burnup, which have been estimated to be up to $5 \%[7,19,51]$.

In Case 3, the assembly compositions were based on two different pin-by-pin burnup distributions of three $14 \times 14$ ROK assemblies. These assemblies were selected because detailed burnup information was provided for each rod of the assembly, in addition to the assembly average burnup. In one scenario, the detailed burnup distribution provided by the operator was used to develop the assembly model, whereas in the other scenario was based a burnup distribution derived from the burnup of the four corner rods. The latter scenario assumed that burnup (or relative burnup) of the four corner rods could be measured using conventional NDA techniques. The assembly average burnup, as estimated by the operator, was the same in both scenarios. Therefore the main difference between the two scenarios was the spatial distribution of nuclides in the assembly caused by the burnup variations. The resulting nuclide compositions from these scenarios were imported to the CIPN model, and the count rates were compared. The purpose of this case 
is to assess the impact of uncertainties in the pin-by-pin burnup distribution derived from operator data or from NDA measurements.

In Case 4, 20 sets of assembly nuclide concentrations were generated with perturbed nuclear data libraries using Sampler, and then these concentrations were imported into the CIPN MCNPX model to simulate the CIPN count rates. These count rates were then compared to the ones of the reference assembly.

\subsubsection{Case 1}

Figure 35 shows the relative percent difference in CIPN neutron count rate due to the two different sets of nuclide compositions generated by two different depletion models for assembly NJ05YU; one modeled the actual neighbor assemblies during irradiation and the other did not. Also shown is the relative difference in ${ }^{244} \mathrm{Cm}$ in each fuel rod between the two depletion models. As discussed in the previous section, the neighbor assemblies can have a significant impact on nuclide compositions in the first cycle due to asymmetries in the neighbor configuration. As shown in this figure, the neutron count rates of the CIPN passive mode from the two lower-left detectors are $4.69 \%$ and $3.14 \%$ lower, respectively, compared to the corresponding model developed without considering the neighbor assemblies. (Curium-244 is the primary source of neutrons in the passive mode because the fuel is cooled for more than 15 years.) The magnitude of the changes in neutron count rate is not as dramatic as the change in ${ }^{244} \mathrm{Cm}$ concentration (with the maximum of 22\%) because the CIPN instrument has good penetration into the assembly, meaning CIPN responds to changes across the entire assembly due to neutron multiplication in the assembly, not just the outer rods [50]. Although not depicted specifically here, other nuclides also play an aggregated role that affects the CIPN signals.

Similarly, Figure 36 shows the relative difference in CIPN photon count rate due to the same two sets of nuclide compositions. Also shown is the relative difference in ${ }^{137} \mathrm{Cs}$ in each fuel rod between the two depletion models after the first cycle. (Because the fuel is cooled for over 15 years, ${ }^{137} \mathrm{Cs}$ is the primary gamma source.) The photons usually cannot travel far because of the high attenuation within a fuel assembly; thus, the gamma signals are primarily correlated to outer fuel rods that are closest to the detectors. For example, the relative difference in the response of the upper ion chamber (with and without neighbor cases) is $3.1 \%$, which is consistent with the difference of the ${ }^{137} \mathrm{Cs}$ concentration in the top row of fuel rods (varying between 2 to $3 \%$ ).

The differences in nuclide compositions of assembly NJ05YU after the second cycle are much smaller than the first cycle, and thus the differences in CIPN responses are small as well (less than $1 \%$ in neutron signals and about $1.7 \%$ in gamma signals). 


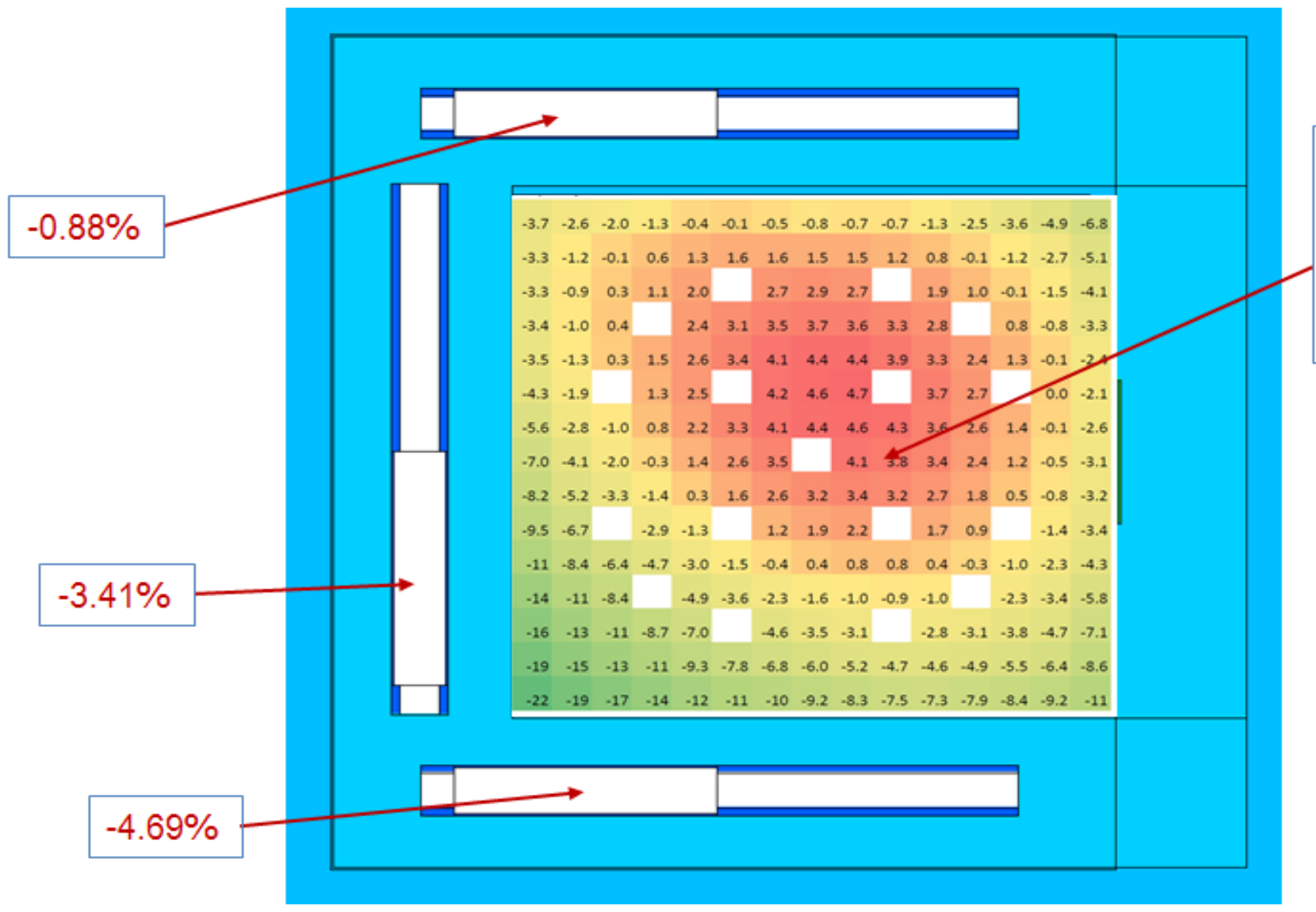

Difference (\%) in

Cm244 distribution

between "with

neighbors" and

"without neighbors"

Fig. 35. The relative difference (\%) in CIPN passive neutron count rate due to different nuclide compositions generated by with- and without-neighbor models. Also shown is the relative difference $(\%)$ in ${ }^{244} \mathrm{Cm}$ in each fuel rod between the two models. 


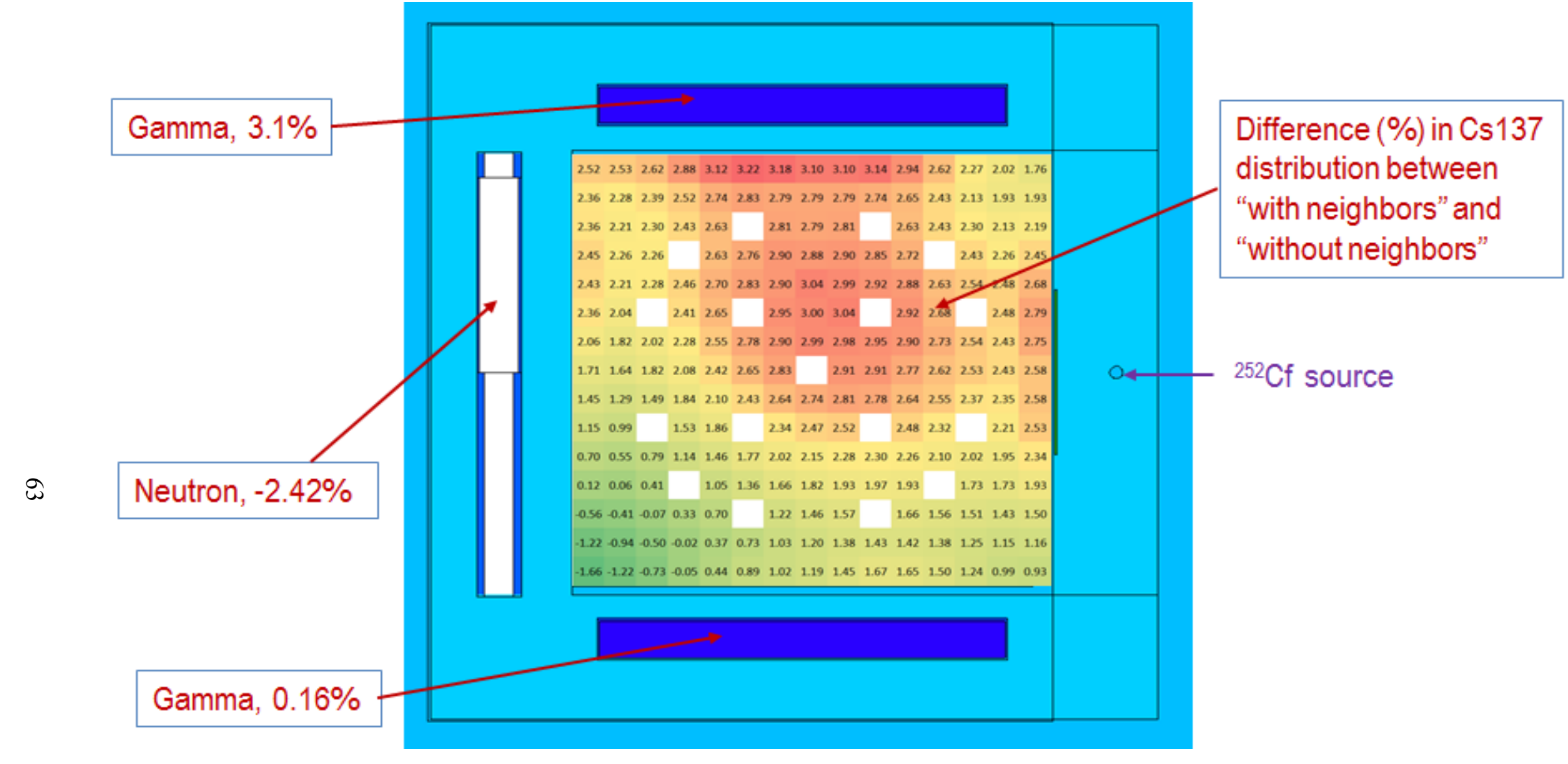

Fig. 36. The relative difference (\%) in CIPN photon count rate due to different nuclide compositions generated by with- and without-neighbor models. Also shown is the relative difference $(\%)$ in ${ }^{137} \mathrm{Cs}$ in each fuel rod between the two models. 


\subsubsection{Case 2}

The nuclide compositions are sensitive to assembly average burnup, as previously shown in Table 4 (Section 3.5). This case evaluates the impacts due to uncertainties in assembly average burnup using two cases that have a 5\% difference in average burnup based on assembly NJ05YU. The differences in total ${ }^{244} \mathrm{Cm}$ are found to be about $20 \%$, while ${ }^{137} \mathrm{Cs}$ is about $5 \%$ different. This is due to the fact that the generation of ${ }^{244} \mathrm{Cm}$ is highly sensitive to burnup (to the fourth power). Consequently, the average difference in the CIPN passive neutron signals is around $17 \%$, and around $5 \%$ for the average gamma signals. The multiplication in the assembly with 5\% higher burnup is smaller because there is less fissile material remaining. Thus, the neutron signal is only $17 \%$ higher, although there is $20 \%$ more ${ }^{244} \mathrm{Cm}$ in that assembly.

\subsubsection{Case 3}

The impacts of different burnup distributions within an assembly on CIPN gamma and neutron count rates were also studied using three ROK fuel assemblies. Assembly 1 (FA1) is a low-burnup assembly $(\sim 17 \mathrm{GWd})$ that was not subjected to significant cross assembly power gradients. The lowest burnup occurred for fuel on the four corners. Assembly 2 (FA2) is a higher-burnup assembly ( $\sim 45 \mathrm{GWd} / \mathrm{tU})$ that exhibited a limited power gradient, while Assembly 3 (FA3) is a medium-burnup assembly $(\sim 35 \mathrm{GWd} / \mathrm{tU})$ with a significant burnup gradient.

Conventional NDA measurements of spent fuel assemblies to estimate burnup are typically performed using measurements performed at the side, corners, or side plus corners of the assembly. Utilizing such detectors (excluding PDET) to obtain information about the internal assembly fuel rods is limited; that is, gamma detectors are dominated by the outer rows of fuel rods. In order to quantify the impact of potential uncertainties in the fuel burnup distribution in an assembly, a comparison was done using these three assemblies that had operator-estimated burnup distributions. The reference burnup distribution was the operator-provided pin-by-pin burnup. A second burnup distribution was derived using the corner pin burnup values (from operator estimates) and a linear interpolation scheme for the remaining fuel rods. In this second NDA-based approach, the burnup in each rod was normalized such that the assembly average burnup values are consistent with the operator data.

Table 16 shows the relative difference (\%) in neutron count rates of CIPN due to different burnup distributions within the assembly (both passive and net counts). As shown, the impact on CIPN signal due to the burnup distribution was small because the neutron signal of CIPN provides an almost uniform measure of all fuel rods. Table 17 shows the relative difference (\%) in photon count rate. The photon results are more sensitive to the distribution than that of photon because photon measurements are dominated by outer fuel rods and photons are less penetrating than neutrons. 
Table 16. Relative difference (\%) in neutron count rate of CIPN due to different burnup distributions within the assembly

\begin{tabular}{|c|c|c|c|c|c|c|}
\hline Assembly & Fission Chamber & $\begin{array}{l}\text { West } \\
\text { FC1 }\end{array}$ & $\begin{array}{l}\text { West } \\
\text { FC2 }\end{array}$ & $\begin{array}{c}\text { South } \\
\text { FC }\end{array}$ & $\begin{array}{c}\text { North } \\
\text { FC }\end{array}$ & Total \\
\hline & & \multicolumn{5}{|c|}{ Diff. (\%) compared to the reference case } \\
\hline \multirow{2}{*}{ FA1 } & Passive Count & $-1.78 \%$ & $-1.57 \%$ & $-1.63 \%$ & $-0.55 \%$ & $1.38 \%$ \\
\hline & Net Count & $0.49 \%$ & $0.62 \%$ & $-0.31 \%$ & $-0.02 \%$ & $0.15 \%$ \\
\hline \multirow[t]{2}{*}{ FA2 } & Passive Count & $-1.77 \%$ & $-0.77 \%$ & $-0.60 \%$ & $1.14 \%$ & $0.53 \%$ \\
\hline & Net Count & $0.09 \%$ & $0.17 \%$ & $0.40 \%$ & $-0.28 \%$ & $0.09 \%$ \\
\hline \multirow{2}{*}{ FA3 } & Passive Count & $6.69 \%$ & $-0.55 \%$ & $8.02 \%$ & $-6.21 \%$ & $2.75 \%$ \\
\hline & Net Count & $0.62 \%$ & $0.83 \%$ & $-0.20 \%$ & $1.76 \%$ & $0.78 \%$ \\
\hline
\end{tabular}

Table 17. Relative difference (\%) in gamma count rate of CIPN due to different burnup distributions within the assembly

\begin{tabular}{|c|c|c|c|c|}
\hline \multirow[t]{2}{*}{ Ion Chamber } & \multirow[t]{2}{*}{ Assembly } & North IC & South IC & Total \\
\hline & & \multicolumn{3}{|c|}{ Diff. (\%) compared to the ref. case } \\
\hline \multirow{3}{*}{$\begin{array}{l}\text { Passive Gamma } \\
\text { Count }\end{array}$} & FA1 & $3.13 \%$ & $4.47 \%$ & $3.81 \%$ \\
\hline & FA2 & $0.92 \%$ & $2.64 \%$ & $1.79 \%$ \\
\hline & FA3 & $3.98 \%$ & $0.19 \%$ & $2.37 \%$ \\
\hline
\end{tabular}

\subsubsection{Case 4}

As described in Sect. 7, different assembly nuclide concentrations can be generated with different sets of nuclear data libraries, with each set reflecting the uncertainties in the underlying nuclear data, using Sampler. The impacts of nuclear data uncertainties on CIPN count rates can be accessed by comparing the count rates of perturbed cases to the reference case (in which the nuclear data were not perturbed). Given the high computational demand of MCNPX simulation, only 20 detector simulation calculations were performed instead of 120 samples used for the burnup analysis for this study. The 20 sets of assembly nuclide concentrations based on the perturbed nuclear data libraries were applied in the MCNPX model used to simulate uncertainties in the CIPN count rates. These 20 sets of assembly nuclide concentrations can also be applied to test any other NDA instruments using different MCNPX models. Figure 37 shows the relative percent difference between the passive gamma count rates for each of the 20 perturbed cases from that of the reference case (in which the nuclear data were not perturbed). For the relatively long cooling time (5 years) used, cesium isotopes, especially ${ }^{137} \mathrm{Cs}$, are the main gamma sources. As shown, the uncertainties in nuclear data introduce an uncertainty in the CIPN passive gamma count rates of $2.1 \%$ (relative standard deviation), a value that is similar to the uncertainty in ${ }^{137} \mathrm{Cs}$, as shown in Figure 33 . Figure 38 shows the uncertainty in the passive neutron count rate, dominated by ${ }^{244} \mathrm{Cm}$. The uncertainty in the CIPN passive neutron count rates is $6.4 \%$, which is similar to that of ${ }^{244} \mathrm{Cm}$, as shown in Figure 32 . The nuclear data uncertainties have a larger impact on passive neutron count rates than gamma count rates because ${ }^{244} \mathrm{Cm}$ is more sensitive to nuclear data uncertainties than ${ }^{137} \mathrm{Cs}$. 
The net neutron count rate can be obtained by subtracting the passive count rate from the active count rate. Figure 39 shows the relative percent difference of the net neutron count rate of the samples from that of the reference case. As shown, the nuclear data affect the CIPN net neutron count rates with a standard deviation of about $1 \%$. The CIPN net neutron count rate is mainly driven by the multiplication of the assembly, which is defined by the geometry and the concentrations of the major actinides and fission products in the fuel. The relatively low impact on net neutron count rate is consistent with the small standard deviations found in the major fissile nuclides (e.g., ${ }^{235} \mathrm{U}$ and ${ }^{239} \mathrm{Pu}$ ) and major actinide neutron absorber (e.g., ${ }^{240} \mathrm{Pu}$ ), as shown in Figure 32.

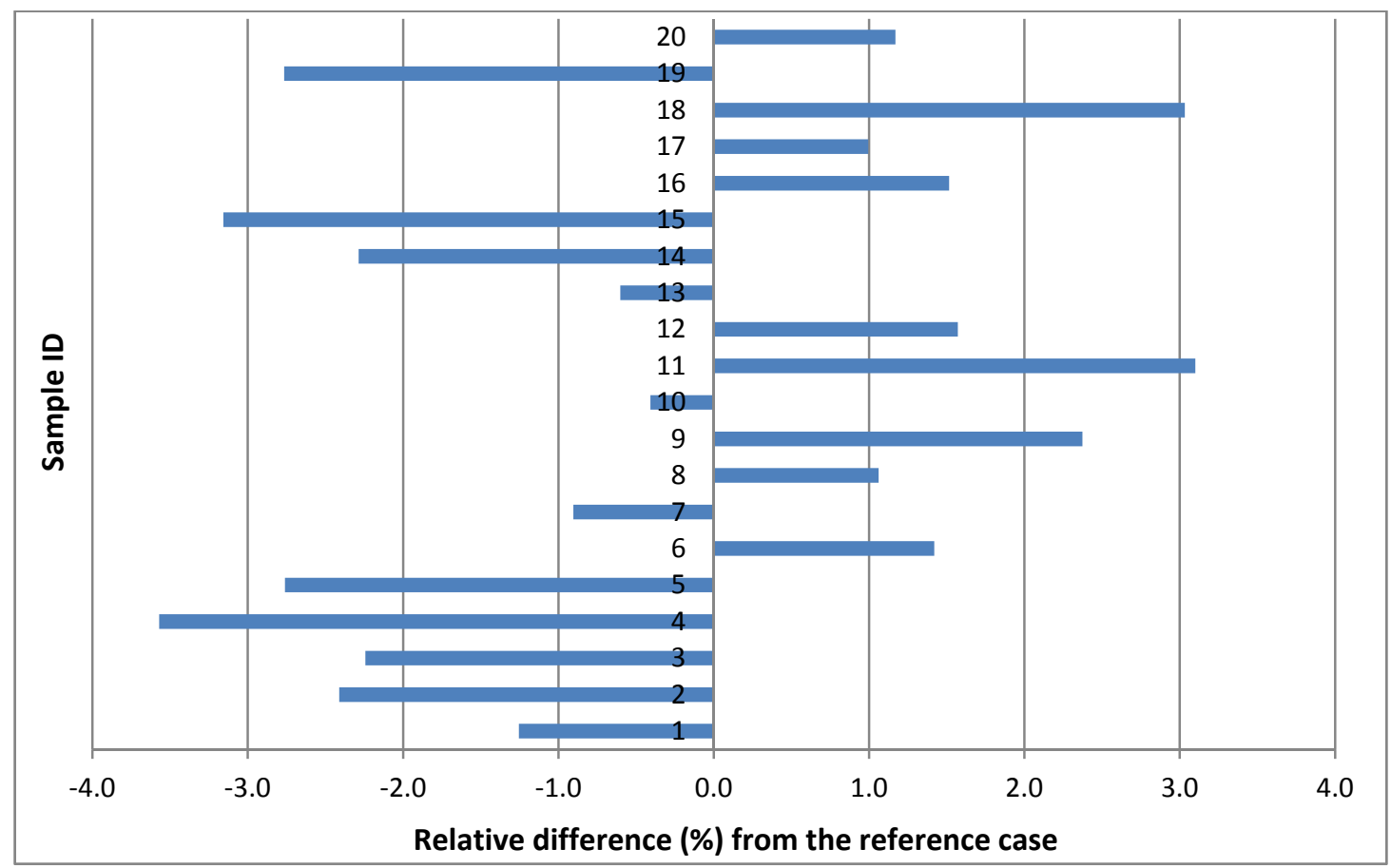

Fig. 37. Relative difference of the passive gamma count rate of the samples from that of the reference case. 


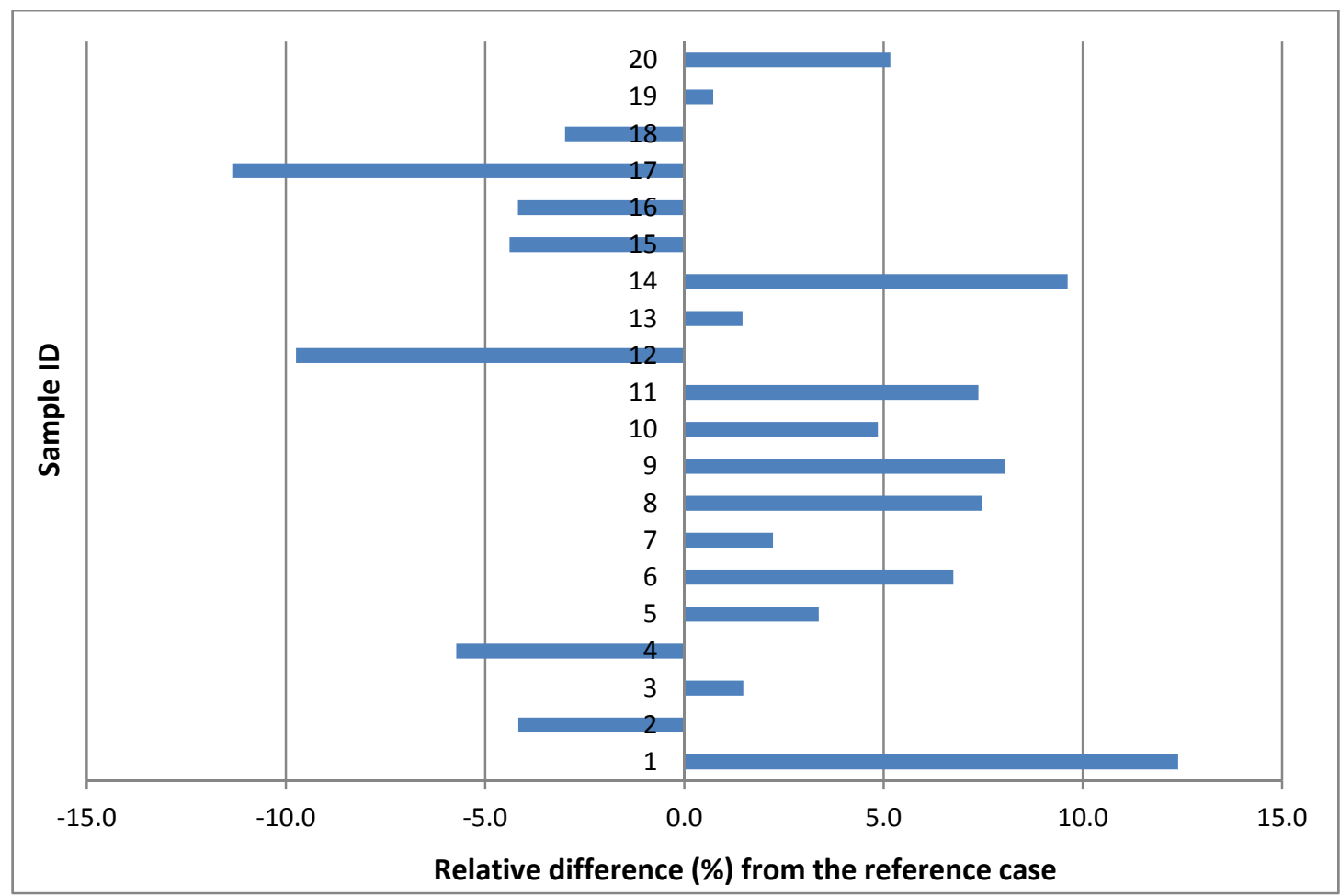

Fig. 38. Relative difference of the passive neutron count rate of the samples from that of the reference case.

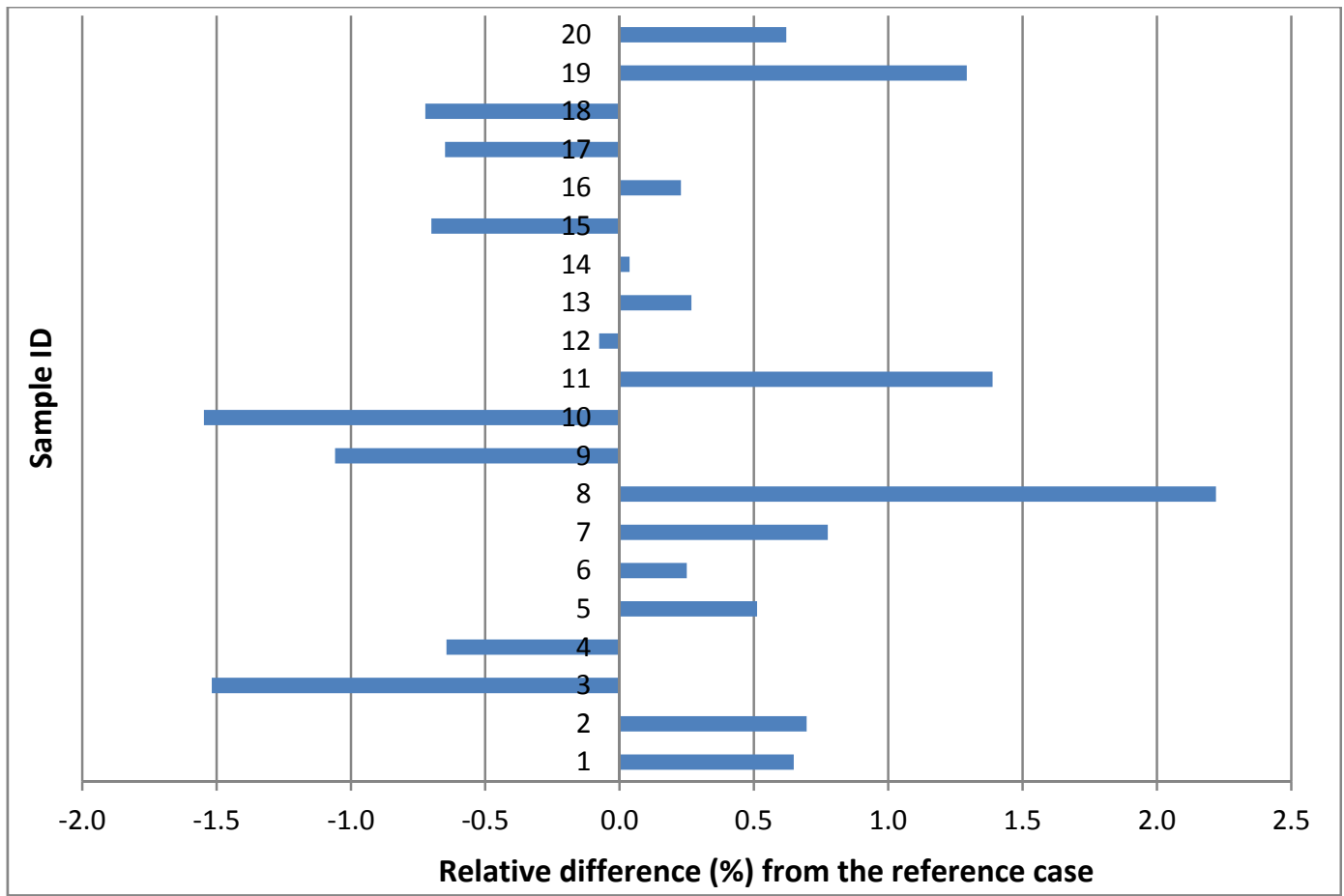

Fig. 39. Relative difference (\%) of the net neutron count rate of the samples from that of the reference case. 



\section{SUMMARY, CONCLUSIONS, AND FUTURE WORK}

Reference spent fuel assemblies, or "working standards," are needed to test, benchmark, and calibrate the advanced NDA instruments under the NGSI-SF project. The nuclide compositions of a calibration assembly need to be well characterized, as any uncertainties in the compositions will contribute to the overall accuracy of the NDA instrument calibration. The main focus of this work was to develop and demonstrate procedures to generate the nuclide compositions for spent fuel assemblies utilizing burnup code and information on the fuel design and operation of the reactor supported by conventional NDA data; quantify the uncertainties in the calculated nuclide compositions; and evaluate the impact of the uncertainties on the ability to accurately calibrate advanced NDA instruments such as CIPN.

\section{In this work, we achieved the following.}

- Reviewed the existing DA data that have been used to validate SCALE and the performance of the depletion capability of SCALE.

- Reviewed the data required for a burnup modeling to calculate nuclide compositions in spent fuel.

- Examined the typical uncertainties in fuel design and operating data, and quantified the impacts of these uncertainties on nuclide compositions.

- Reviewed the ability of conventional NDA instruments to characterize spent nuclear fuels, especially on burnup measurements and the associated uncertainties.

- Described a newly developed 3D depletion capability (ORIGAMI) within SCALE that can take radial and axial burnup profiles and generate detailed nuclide compositions for the entire assembly.

- Reviewed the detailed fuel and operator data of two TMI-1 assemblies, and examined the quality of operator data and NDA measurements.

- Assessed the ability of burnup codes to calculate radial burnup profiles and nuclide compositions based on detailed operating information including neighbor assemblies.

- Assessed the impacts of neighbor assemblies on nuclide and burnup distributions across the assembly.

- Evaluated the impacts of nuclear data uncertainties in calculated spent fuel nuclide compositions.

- Simulated the uncertainty propagation into signals of an advanced NDA instrument - CIPN.

- Evaluated the impact of neighbor assemblies on CIPN response, the impact of uncertainties in assembly average burnup, and uncertainties in radial burnup profiles on CIPN signals.

\section{The key findings of this work include the following.}

- Modeling and simulation will play an essential role in generating spent fuel assembly calibration standards, because DA measurement on an entire assembly is not practical and NDA has limitations in terms of characterizing spent fuel assemblies.

- Full cooperation from reactor and spent fuel facility operators will be a prerequisite for generation of spent fuel working standards, in order to obtain detailed fuel and operator data.

- Fuel burnup and exposure to reactivity control measures (e.g., BPRs) are found to be the two most important factors that affect nuclide compositions. The uncertainties in fuel assembly burnup, as provided by the reactor operator, were found to be $2-5 \%$, and the uncertainties in burnup of local fuel rod segments are found to be significantly higher (up to 20\%).

- The newly developed 3D parallel depletion capabilities in the ORIGAMI code (in SCALE) have been used to calculate detailed isotopic concentrations for spent fuel assembly standards for the NGSI project.

○ With local assembly burnup provided by either measurements or high-quality operator data, SCALE has been demonstrated to be able to predict the nuclide compositions accurately using a benchmark suite of DA measurements for more than 100 spent fuel samples. 
- Neighbor assemblies have significant impacts on radial burnup distributions, especially at low and intermediate burnups. However, assembly models developed in this work were found to be insufficient to predict pin-by-pin burnup for an entire assembly using information on the neighbor assemblies, especially for exterior fuel rods. The pin-by-pin burnup of the SKB assemblies, on which the advanced NGSI NDAs will be tested, will be provided by the operator.

- NDA techniques can measure the axial burnup profile accurately and supplement information to operator data. Operator data should be carefully reviewed before use.

- Uncertainties in assembly average burnup have significant impacts on CIPN signals.

Uncertainties in radial burnup distribution (when the assembly average burnup value is known)

have small impacts on CIPN signals due to the good penetration capabilities of CIPN.

- Uncertainties in calculated nuclide concentrations due to nuclear data uncertainties alone are about $1 \%$ for the main fissile nuclides, $6 \%$ for ${ }^{244} \mathrm{Cm}$ (a primary passive neutron source), and $2 \%$ for ${ }^{137} \mathrm{Cs}$ (a primary passive gamma source).

- The pin-by-pin burnup (or radial burnup distribution) has significant impacts on the distribution of nuclide compositions. The pin-by-pin burnup values obtained from operator data were determined to be of higher quality than data extrapolated from preliminary PDET measurements. However, the accuracies of PDET data need to be further reviewed (as planned at the SKB facility). PDET data may be useful to cross-check operator data, or provide measured burnup distributions when other sources of this information are unavailable.

- The combined axial assembly burnup distribution measured by gamma scan and radial burnup distributions obtained from the operator (or measured using PDET) can be used directly to calculate 3D assembly nuclide compositions using the ORIGAMI code.

The uncertainties in fuel burnup and nuclide concentrations are summarized in Table 18 and Table 19, respectively.

Table 18. Summary of uncertainties in burnup of spent fuel determined using different methods

\begin{tabular}{|c|c|c|c|c|}
\hline \multirow{2}{*}{ Item } & \multicolumn{4}{|c|}{ Uncertainties in burnup } \\
\cline { 2 - 5 } & DA & NDA & Operator-est. & Calculation \\
\hline Assembly average & $\mathrm{N}^{a} \mathrm{~A}^{a}$ & $\mathrm{~N} / \mathrm{A}^{b}$ & $2-5 \%^{c}$ & $\mathrm{~N}^{\mathrm{f}} \mathrm{A}^{d}$ \\
\hline Rod average & $\mathrm{N}^{e} \mathrm{~A}^{e}$ & $\sim 2-4 \%^{f}$ & $\sim 2-5 \%^{f}$ & $3-19 \%^{g}$ \\
\hline $\begin{array}{c}\text { Local } \\
\text { (sample/nodal) }\end{array}$ & $2 \%^{h}$ & $\sim 5 \%^{i}$ & $2-19 \%^{j}$ & $3-24 \%^{k}$ \\
\hline
\end{tabular}

${ }^{a}$ To measure the assembly average burnup, dissolving the entire assembly is required and it is not practical in a laboratory. At a reprocessing plant, multiple assemblies are typically dissolved at the same time.

${ }^{b}$ NDA measurement on assembly average burnup is not reliable due to high gamma attenuation and neutron multiplication in the assembly. NDA measurement on each fuel rod after dismantling the entire assembly can provide accurate results, but generally are not practical.

${ }^{c}$ Both EPRI and AREVA estimated the uncertainty to be around $2 \%$, before considering the additional uncertainties due to conversion of reaction rate (in instruments) to fuel burnup.

${ }^{d}$ Burnup models normally need input of assembly average burnup.

${ }^{e}$ Requires dissolving an entire fuel rod, generally not practical.

$f_{\text {Refer to Table } 8 .}$.

${ }^{g}$ Varies widely based on studies on TMI-1 fuel, depending if it is exterior (Table 12) or interior (Table 11) fuel rod.

${ }^{h}$ Uncertainty in measurement of ${ }^{148} \mathrm{Nd}$ is about $1 \%$; an additional $1 \%$ is assumed due to the uncertainty in conversion of ${ }^{148} \mathrm{Nd}$ to burnup.

${ }^{\mathrm{i}}$ Refer to Fig. 8; larger uncertainties were observed in TMI-1 fuel.

${ }^{j}$ Varies widely based on studies on TMI-1 fuel, depending if it is exterior (Table 9) or interior (Table 10) fuel rod. Lower uncertainties are observed in newer data (Fig. 3).

${ }^{k}$ Varies widely based on studies on TMI-1 fuel, depending if it is exterior (Table 15) or interior (Table 11) fuel rod. 
Table 19. Summary of uncertainties in nuclide concentrations in spent fuel samples ${ }^{a}$ using different methods

\begin{tabular}{|c|c|c|}
\hline \multirow{2}{*}{ Nuclides } & \multicolumn{2}{|c|}{ Uncertainties in nuclide concentrations } \\
\cline { 2 - 3 } & (\%) $^{*}$ DA $^{b}$ & $\begin{array}{c}\text { Calculation } \\
\text { (using DA- } \\
\text { measured burnup }\end{array}$ \\
\hline${ }^{235} \mathrm{U}$ & 1 & $1.2 \pm 3.5 \%$ \\
\hline${ }^{238} \mathrm{Pu}$ & 5 & $11.7 \pm 5.9 \%$ \\
\hline${ }^{239} \mathrm{Pu}$ & 1.2 & $4.1 \pm 3.5 \%$ \\
\hline${ }^{240} \mathrm{Pu}$ & 1.2 & $2.2 \pm 3.4 \%$ \\
\hline${ }^{241} \mathrm{Pu}$ & 1.2 & $1.4 \pm 4.5 \%$ \\
\hline${ }^{242} \mathrm{Pu}$ & 1.2 & $5.9 \pm 6.1 \%$ \\
\hline${ }^{244} \mathrm{Cm}$ & 5.5 & $4.4 \pm 11.1 \%$ \\
\hline${ }^{137} \mathrm{Cs}$ & 3.5 & $0.7 \pm 3.1 \%$ \\
\hline${ }^{148} \mathrm{Nd}$ & 1.5 & $0.6 \pm 1.4 \%$ \\
\hline
\end{tabular}

${ }^{a}$ DA measurements on whole fuel rod or assembly are not available. (A sample is typically the size of a pellet.)

${ }^{b}$ See Ref. 3 .

${ }^{c}$ Average difference from DA measurement \pm standard deviation. See Table 2.

${ }^{d}$ Calculated results based on burnups determined by other methods vary widely, depending on the accuracy of the burnup values (see Table 15).

\section{Future work in support of the NGSI NDA measurements includes the following.}

- Generating reference nuclide compositions for the PWR assemblies being measured at the SKB Clab facility. Such reference assemblies will be used to calibrate several advanced NDA instruments.

- Process the PDET measurement data to be collected from the SKB PWR assemblies and further evaluate the capability of PDET to measure assembly radial burnup profile.

- Perform sensitivity studies on BWR assemblies and establish a methodology to generate reference calibration assemblies for BWR fuel. 



\section{REFERENCES}

1. M. A. Humphrey, S. J. Tobin and K. D. Veal, "The Next Generation Safeguards Initiative's Spent Fuel Nondestructive Assay Project," Journal of Nuclear Materials Management, vol. 40, no. 3, p. 6, 2012.

2. S. Tobin, H. Menlove, M. Swinhoe, H. Trellue and M. Humphrey, "Prototype Development and Field Trails under the Next Generation Safeguards Initiative Spent Fuel Non-Destructive Assay Project," in Proc. of ESARDA 35 ${ }^{\text {th }}$ Annual Meeting, Bruges, Belgium, 2013.

3. R. D. Reager, R. B. Adamson and K. W. Edsinger, TRW Yucca Mountain Project Test Report, Test Report, Phase 2. TRW Purchase Order No. A09112CC8A, GE Nuclear Energy, 1999.

4. TMI-1 Cycle 10 Fuel Rod Failures, Volume 1: Root Cause Failure Evaluations, EPRI Report TR108784-V1, EPRI, Palo Alto, CA, 1998.

5. G. Radulescu, I. C. Gauld, and G. Ilas, SCALE 5.1 Predictions of PWR Spent Nuclear Fuel Isotopic Compositions, Oak Ridge National Laboratory, ORNL/TM-2010/44, 2010.

6. SCALE: A Comprehensive Modeling and Simulation Suite for Nuclear Safety Analysis and Design, Oak Ridge National Laboratory, Oak Ridge, TN, ORNL/TM-2005/39, June 2011.

7. EPRI, "Determination of the Accuracy of Utility Spent-Fuel Burnup Records," Electric Power Research Institute, TR-112054, 1999.

8. Y. Ham and S. Sitaraman, "Partial Defect Verification of the Pressurized Water Reactor Spent Fuel Assemblies," Tokai-mura, Japan, 2010.

9. G. Ilas, I. Gauld, and G. Radulescu, "Validation of new depletion capabilities and ENDF/B-VII data libraries in SCALE," Annals of Nuclear Energy, vol. 46, pp. 43-55, 2012.

10. Working Party on Nuclear Criticality Safety (WPNCS), "Spent Nuclear Fuel Assay Data for Isotopic Validation," Nuclear Science Committee, Nuclear Energy Agency, 2011.

11. G. Ilas, I. Gauld, and B. Murphy, "Analysis of Experimental Data for High Burnup PWR Spent Fuel Isotopic Validation-ARIANE and REBUS Programs ( $\mathrm{UO}_{2}$ Fuel)," Oak Ridge, TN, 2010.

12. M. DeHart and S. Bowman, "Reactor Physics methods and analysis capabilities in SCALE," Nuclear Technology, vol. 174, no. 2, p. 196, 2011.

13. M. Dehart, M. Brady and C. Parks, OECD/NEA burnup Credit Calculational, Oak Ridge National Laboratory, Oak Ridge, TN, ORNL/TM-6901, 1996.

14. U. Mertyurek, M. Francis and I. Gauld, SCALE 5 analysis of BWR spent nuclear fuel isotopic compositions for safety studies, Oak Ridge National Laboratory, Oak Ridge, TN, ORNL/TM2010/286, 2010.

15. H. J. Smith, I. C. Gauld, and U. Mertyurek, Analysis of Experimental Data for High Burnup BWR Spent Fuel Isotopic Validation- SVEA-96 and GE14 Assembly Designs, Nuclear Regulatory Commission, NUREG/CR-7162, 2013.

16. Private communication with Magnus Kruners from Studsvik, 2013.

17. B. Broadhead, I. Gauld, and H. Trellue, "Utilizing NGSI Spent Fuel Sensitivity Libraries to Estimate Model Uncertainties," in INMM Annual Meeting, Orlando, FL, 2012.

18. H. L. Massie, "Reactor Record Uncertainty Determination," Areva, 2004.

19. B. Bevard, J. Wagner, C. Parks, and M. Aissa, "Review of Information for Spent Nuclear Fuel Burnup Confirmation," U.S. NRC Office of Nuclear Regulatory Research, NUREG 6998, 2009. 
20. Studsvik, "SIMULATE5," Studsvik, [Online]. Available: http://www.studsvik.com/en/BusinessAreas/Operating-Efficiency/Nuclear-Fuel-Analysis-Software/In-Core-Fuel-

Management/SIMULATE5/. [Accessed 2110 1013].

21. A. Worrall, and C. Ott, "Physics Analysis of BNFL's First Commercial MOX Fuel Using CMS," in Advances in Nuclear Fuel Management III (ANFM 2003), Hilton Head Island, South Carolina, USA, 2003.

22. A. Tiitta, J. Hautamaki and A. Turunen, "Spent BWR Fuel Characterisation Combining a Fork Detector with Gamma Spectrometry," Finnish Support Programme to IAEA Safeguards, Stuk, Sateilyturvakeskus, Stralsakerhetscentralen, February 2001.

23. K. van de Meer and M. Coeck, "Is the FORK detector a partial defect tester," Vienna, Austria, 2006.

24. S. Vaccaro, J. Hu, J. Svedkauskaite, A. Smejkal, P. Schwalbach, P. D. Baere, and I. Gauld, "New approach to Fork measurements data analysis by RADAR-CRISP and ORIGEN integration," in Advancements in Nuclear Instrumentation Measurement Methods and their Applications, Paris, France, 2013.

25. M. Zendel, "IAEA safeguards equipment," International Journal of Nuclear Energy Science and Technology, Vol. 4, 2008.

26. Y. H. S. Sitaraman, "Sensitivity Studies for an In-Situ Partial Defect Detector (PDET) in Spent Fuel using Monte Carlo Technieques," in INMM Annual Meeting, Nashville, TN, July 2008.

27. Y. Nakahara, K. Suyama and T. Suzaki, "Translation of Technical Development on Burn-up Credit for Spent LWR Fuels," 2000.

28. M. Dennis and S. Usman, "Analysis, Feasibility of 106Ru peak measurement for MOX fuel burnup," Nuclear Engineering and Design, vol. 240, no. 10, JAEA-Tech 2000-071 (ORNL/TR-2001/01), 2010.

29. K.-J. Park, J.-S. Ju, and J.-S. Kim, "Determination of Burnup and PU/U Ratio of PWR Spent Fuels by Gamma-Ray Spectrometry," Nuclear Engineering and Technology, vol. 41, no. 10, pp. 13071314, August 8, 2009.

30. "Standard Test Method for Atom Percent Fission in Uranium and Plutonium Fuel," ASTM E321-96, 2012.

31. Y. Ham and S. Sitaraman, "Shipper/receiver difference verification of spent fuel by use of PDET," in Advancements in Nuclear Instrumentation Measurement Methods and their Applications, Ghent, Belgium, 2011.

32. D. Pelowitz (editor), "MCNPX user's manual," Los Alamos National Laboratory, LA-CP-11-00438, 2011.

33. I. Gauld, G. Radulescu, G. Ilas, B. Murphy, M. Williams, and D. Wiarda, "Isotopic Depletion and Decay Methods and Analysis Capabilities in SCALE," Nuclear Technology, vol. 174, 2011.

34. M. Fensin, J. Hendricks and S. Anghaie, "The Enhancements and Testing For the MCNPX 2.6.0 Depletion Capability," Nuclear Technology, vol. 70, 2010.

35. W. Wilson, S. Cowell, T. England, A. Hayes and P. Moller, A Manual for CINDER'90 Version 07.4 Codes and Data, Los Alamos National Laboratory, LA-UR-07-8412, 2007.

36. D. Poston and H. Trellue, User's Manual, Version 2.0 for MONTEBURNS Version 1.0, LA-UR-994999, 1999. 
37. I. Gauld, "Validation of ORIGEN-S Decay Heat Predictions for LOCA Analysis," in Proc. of PHYSOR-2006, American Nuclear Society Topical Meeting on Reactor Physics: Advances in Nuclear Analysis and Simulation, Vancouver, British Columbia, Canada, September 10-14, 2006.

38. L. B. Wimmer, Summary Report of Commercial Reactor Criticality Data for Three Mile Island Unit 1, Bechtel SAIC Company, Prepared for the US Department of Energy, Las Vegas, Nevada, August 2001.

39. J. Scaglione, Three Mile Island Unit I Radiochemical Assay Comparisons to SAS2H Calculations, Yucca Mountain Project Report, CAL-UDC-NU-000011, Rev. A, 2002.

40. S. F. Wolf, D. L. Bowers, and J. C. Cunnane, Analysis of Spent Nuclear Fuel Samples from Three Mile Island and Quad Cities Reactors: Final Report, Argonne National Laboratory, 2000.

41. U.S. Department of Energy, "Nuclear Fuel Data Survey Form RW-859," Energy Information Administration, 2001.

42. 42.S. Richards and C. Romano, "Determination of Plutonium Content in Spent Fuel from Passive Gamma Measurements," in The 9th International Conference on Facility Operations - Safeguards Interface, Savannah, Georgia, 2012.

43. M.L. Williams, F. Havluj, D. Wiarda, M. Pigni, and I.C. Gauld, "SCALE Uncertainty Quantification Methodology for Criticality Safety Analysis of Used Nuclear Fuel," in ANS NCSD 2013 Criticality Safety in the Modern Era: Raising the Bar, Wilmington, NC, September 2013.

44. M. B. Chadwick et al., "ENDF/B-VII.1 Nuclear Data for Science and Technology: Cross Sections, Covariances, Fission Product Yields and Decay Data," Nuclear Data Sheets 112 (12), 2887, 2011.

45. M. B. Chadwick et al., "ENDF/B-VII.0: Next Generation Evaluated Nuclear Data Library for Nuclear Science and Technology,” Nuclear Data Sheets 107 (12), 2931, 2006.

46. R. C. Little, T. Kawano, and G. D. Hale et al., "Low-Fidelity Project," Nuclear Data Sheets 109 (12), 2928, 2008.

47. T. R. England and B. F. Rider, "ENDF-349 Evaluation and Compilation of Fission Product Yields," Technical Report LA-UR-94-3106, Los Alamos National Laboratory, 1994.

48. J. Hu, S. Tobin, H. Menlove, D. Henzlova, J. Gerhart, M. Swinhoe and S. Croft, "Developing the Californium Interrogation Prompt Neutron Technique to Measure Fissile Content and to Detect Diversion in Spent Nuclear Fuel Assemblies," Journal of Nuclear Materials Management , vol. 40, no. 3, pp. 49-57, Spring 2012.

49. J. Hu, D. Henzlova and S. Tobin, "Customized Design and Simulated Performance of the Californium Interrogation Prompt Neutron Detector for Spent Fuel Measurement at the Post Irradiation Examination Facility in the Republic of Korea," in INMM Annual Meeting, Orlando, FL, 2012.

50. J. Hu, S. Tobin and H. Menlove, "Quantifying Fissile Content in Spent Nuclear Fuel Assemblies Using ${ }^{252}$ Cf Interrogation," in Global 2011, Tokyo, Japan, 2011.

51. H. J. Smith, "Modeling Depletion Simulations for a High-Burnup, Highly Heterogeneous BWR Fuel Assembly with SCALE," in PHYSOR 2012 - Advances in Reactor Physics - Linking Research, Industry, and Education, Knoxville, TN, April 15-20, 2012. 